\title{
Extensive fluid-rock interaction and pressure solution in a UHP fluid pathway recorded by garnetite, Lago di Cignana, Western Alps
}

\begin{tabular}{|r|l|}
\hline Journal: & Journal of Metamorphic Geology \\
\hline Manuscript ID & JMG-20-0072.R3 \\
\hline Manuscript Type: & Original Article \\
\hline Author: & $\mathrm{n} / \mathrm{a}$ \\
\hline Complete List of Authors: & $\begin{array}{l}\text { van Schrojenstein Lantman, Hugo; University of Pavia, Department of } \\
\text { Earth and Environmental Sciences } \\
\text { Scambelluri, Marco; Universtà di Genova, DIPTERIS } \\
\text { Gilio, Mattia; University of Pavia, Department of Earth and } \\
\text { Environmental Sciences } \\
\text { Wallis, David; University of Cambridge, Department of Earth Sciences } \\
\text { Alvaro, Matteo; University of Pavia, Department of Earth and } \\
\text { Environmental Sciences }\end{array}$ \\
\hline Keywords: & $\begin{array}{l}\text { subduction fluids, garnet dissolution, hydrostatic stress, garnetite, } \\
\text { ultrahigh pressure }\end{array}$ \\
\hline &
\end{tabular}




\section{Title}

2 Extensive fluid-rock interaction and pressure solution in a UHP fluid pathway recorded by

3 garnetite, Lago di Cignana, Western Alps

4

\section{Running Title}

6 Garnetite fluid-rock interaction

7

\section{Authors}

9 Hugo W. van Schrojenstein Lantman ${ }^{1 *}$, Marco Scambelluri $^{2}$, Mattia Gilio ${ }^{1}$, David Wallis ${ }^{3 * *}$, Matteo $10 \quad$ Alvaro $^{1}$

1. Department of Earth and Environmental Sciences, University of Pavia, Via A. Ferrata, 1 I27100 Pavia, Italy

2. Department of Earth, Environment and Life Sciences, University of Genoa, Corso Europa 26, 16132 Genoa, Italy

3. Department of Earth Sciences, Utrecht University, Budapestlaan 4, 3584CD Utrecht, The Netherlands

17

*Corresponding author (hugo.vanschrojenste01@universitadipavia.it) U. K. 


\section{Abstract}

This study combines the microstructural and petrological analysis of garnet and its inclusions in quartzite-hosted garnetite from the ultrahigh-pressure Lago di Cignana metaophiolite (Western Alps). We present a comprehensive record of metamorphism, compaction, and the state of stress during interaction between oceanic metasediments and infiltrating fluids along a major opensystem fluid pathway.

The arrangement of garnet into garnetite layers is attributed to concomitant compaction and dissolution that resulted in the formation of a garnet stylolite. The fluid pulses that were accommodated by this pathway subsequently resulted in several stages of garnet deformation, dissolution, local reprecipitation, and recrystallization. Abundant evidence for pressure solution in garnet, alongside near-hydrostatic to hydrostatic conditions indicated by elastic strains of quartz inclusions in garnet obtained through Raman spectroscopy, support low differential stresses during fluid-rock interaction.

The high degree of dissolution recorded by the garnetite showcases the strong potential for compaction by fluid-assisted volume loss and mass transfer. Dehydration of subducting rocks with subsequent migration of resulting fluids through the slab provides a mechanism of mass transfer and has the potential to drive compaction and exert control on differential stress along fluid pathways.

\section{Keywords}

Subduction fluids, garnet dissolution, hydrostatic stress, garnetite, ultrahigh pressure

\section{INTRODUCTION}

The importance of fluids in subduction systems is well established, as they control rheology, metamorphism, metasomatism, and volcanism (Peacock, 1990; Scambelluri \& Philippot, 2001; Bürgmann \& Dresen, 2008; Gerya \& Meilick, 2011; Spandler \& Pirard, 2013). In subduction zones, the volumes of fluids released from the slab (Van Keken et al., 2011) and the difference in fluid composition from dehydration at the source rock to solute-rich fluid in the mantle wedge, require that fluid-rock interaction takes place along the intervening pathways (Hermann et al., 2006; 
Bebout, 2007; Herms et al., 2012; Dragovic et al., 2015; Taetz et al., 2018; Brovarone et al., 2020). Despite the relevance of fluid-rock interaction for interpreting geological processes, several factors, such as complex solubilities and speciation, retrograde overprinting, limited exhumation and exposure, and other gaps in the rock record challenge our progress in this field.

A viable process of fluid interaction with high-pressure rocks is dissolution-precipitation (e.g., Ague \& Nicolescu, 2014; Angiboust et al., 2017; Ferrando et al., 2017; Giuntoli et al., 2018). As this mechanism can take place at low differential stresses, it is widespread in subduction zones (Wassmann et al., 2011; Wassman \& Stöckhert, 2013b). However, as precipitation does not necessarily occur at or near the site of dissolution, this fluid-driven process can facilitate mass loss at the reaction sites and mass transfer in subducting slabs while leaving barely perceptible traces. Tracing dissolution can be further complicated by retrograde overprinting, which is common in high-pressure terranes. Considering the long distances of up to several kilometres over which mass transport is hypothesized in subduction settings, finding an intact fluid pathway on this scale within dismembered high-pressure terranes is unlikely. Therefore, field-based studies will only probe small portions of fluid pathways, which should be treated as open systems (Plümper et al., 2017). Consequently, to understand the process of mass transfer through the slab, the single components of such large-scale systems must be studied individually.

The ultrahigh-pressure metamorphic (UHPM) Lago di Cignana unit (LCU) is a famous coesite- and diamond-bearing Alpine meta-ophiolite (Reinecke, 1991; Frezzotti et al., 2011) and a rare example of oceanic crust that reached 90-110 km depths (Reinecke, 1998; Groppo et al., 2009). Garnetite is common to various LCU lithologies, and although garnetites are typically sedimentary, metasomatic, melt- or fluid-related in origin (e.g., Spry et al., 2000; Vrijmoed et al., 2006; Angiboust et al., 2017; Hadjzobir et al., 2017), no origin mechanism has been established for the LCU garnetites. Infiltration of external fluids and extensive fluid-rock interaction within this unit have been revealed by detailed fluid-inclusion and geochemical studies, suggesting influx of locally solute-rich serpentinite-derived fluids (Hawkins et al., 2009; Frezzotti et al., 2011; 
Halama et al., 2020). Therefore, the LCU potentially includes remnants of a large-scale fluid pathway, which has not yet been identified and described in detail.

In this study, we examine the relation between the LCU Mn-rich quartzites and the garnetite lenses that they host using a combination of petrological, mineralogical and microstructural data. The observations elucidate how fluid pathways shaped the metasediments, how garnetite formed by a newly-described mechanism involving pressure solution, how fluidrock interaction evolved over time during metamorphism, and the stress regime during this process.

\section{GEOLOGICAL BACKGROUND}

The Alpine high-pressure ophiolites of the Piemonte zone (Figure 1) are the dismembered remnants of the Mesozoic Tethyan Ocean that was subducted during Alpine plate convergence and orogeny (Dal Piaz et al., 1999 and references therein). The Lago di Cignana Unit is a coesiteand diamond-bearing UHPM ophiolitic sliver cropping out between two major metaophiolitic units: the underlying Zermatt-Saas Zone (ZSZ) recording eclogite-facies metamorphic conditions of $520 \pm 20^{\circ} \mathrm{C}, 2.3 \mathrm{GPa}$ (Angiboust et al., 2009), and the overlying Combin Zone (CZ) recording blueschist-facies conditions of $300-345^{\circ} \mathrm{C}, \sim 0.9 \mathrm{GPa}$ (Reddy et al., 1999).

The relation between the LCU and the ZSZ is still debated. One possibility is that the LCU is one of several minor bodies of diverse origin that crop out along the contact between the ZSZ and CZ (Dal Piaz et al., 2001; Gilio et al., 2019), which differ in their peak-metamorphic age, $P$-T evolution, and provenance (Theodul Glacier Unit, Etirol-Levaz Slice, Allalin Gabbro; Weber et al., 2015; Bucher \& Grapes, 2009; Beltrando et al., 2010). The alternative is that the LCU is located within the upper levels of the ZSZ, and only deviates in terms of peak metamorphic pressure, while metamorphic ages and temperatures match (Groppo et al., 2009; Skora et al., 2015).

The LCU consists of coesite-bearing eclogite, serpentinite (Gilio et al., 2019) and metasediments varying from calcschist and marble to several types of manganiferous quartzites (Reinecke, 1998; Forster et al., 2004). The quartzite varies from schistose garnet-amphibolephengite quartzites, to purple, hydrothermally Mn-enriched quartzite similar to other Mn-rich 
metasediments from the ZSZ (Tumiati et al., 2010). Garnetite is present in several metasediments

109 and eclogites as lenses and boudins. Certain LCU garnetites contain fluid inclusions with solutes

110 that originated from the dissolution of carbonate and quartz (Frezzotti et al., 2011). Furthermore,

111 Hawkins et al. (2009) observed an assemblage of daughter minerals in fluid inclusions in

112 garnetite, consisting of jadeite, paragonite, phengite, chlorite, amphibole, titanite and K-feldspar

113 alongside Ca-sulfates, phosphates and oxides. This evidence suggests the dissolution of a

114 polymineralic component of the system during garnet growth, beyond quartz and carbonates

115 (Frezzotti et al., 2011; Hawkins et al., 2009). Boron concentrations and isotopic ratios in white

116 mica within several lithologies in the LCU area indicate that a fluid derived from partially

117 dehydrated serpentinites was the driver behind fluid-rock interaction in quartzite, but not in

118 eclogite (Halama et al., 2020).

1193 METHODS

$120 \quad 3.1$ Sample preparation

121 Samples were processed into sections $100 \mu \mathrm{m}$ thick for petrographic analysis and electron

122 microscopy. For the purpose of strain analysis on inclusions in garnet, sections $250 \mu \mathrm{m}$ thick were

123 prepared to maximize the number of inclusions without strain dissipation due to proximity to the

124 surface of the section. Sections were polished with a $0.05-\mu \mathrm{m}$ colloidal-silica suspension in 125 preparation for high-quality electron microscopy.

\section{$126 \quad 3.2$ Electron microscopy}

127 Electron probe micro-analysis (EPMA) measurements of major elements were performed using 128 a JEOL JXA 8200 Superprobe at the Department of Earth Sciences, University of Milan. An 129 accelerating potential of $15 \mathrm{kV}$ and a beam current of $15 \mathrm{nA}$ were used for spot analyses with a 13030 second counting time. Measurements for element-distribution maps were performed with a combination of WDS and EDS, at $15 \mathrm{nA}$ and $100 \mathrm{nA}$ for high-detail maps. Element distribution maps were plotted using an inversion of the "roma" scientific colour map (Crameri, 2018).

\section{$133 \quad 3.3$ Electron Backscatter Diffraction}


Electron backscatter diffraction (EBSD) data were acquired on a Phillips XL-30 field-emission gun scanning electron microscope equipped with an Oxford Instruments' Nordlys-Nano EBSD detector and AZtec 3.3 acquisition software. An EBSD map of $1638 \times 1228$ pixels was acquired at a step size of $0.9 \mu \mathrm{m}$ and an accelerating voltage of $30 \mathrm{kV}$. Data were processed using the MTEX v5.1.1 toolbox (Bachmann et al., 2010) for MATLAB®. Grain reconstruction was performed with a minimum misorientation value for grain boundaries of $2^{\circ}$. Although this value is low, no subgrain boundaries were misidentified as grain boundaries as subgrains are absent in the analysed garnet crystals. All grains below 5 pixels in size were considered to result from misindexing and were removed. Unindexed areas 1 pixel in size were filled in by interpolation. Grains in contact with the outer boundary of the map were removed from grain-size analysis. The EBSD map was colour coded by grain size using an inversion of the "roma" scientific colour map

145 (Crameri, 2018).

\subsection{Raman spectroscopy}

Raman spectra of quartz inclusions in garnet were collected with a Horiba LabRam HR Evolution spectrometer (holographic gratings of 1800 grooves/mm) equipped with an Olympus BX41 confocal microscope at the controlled temperature of $20(1){ }^{\circ} \mathrm{C}$. Raman spectra were excited using the $514.532 \mathrm{~nm}$ line of a solid state (YAG) laser. The laser power on the sample surface was approximately 1-2 $\mathrm{mW}$. The spectrometer was calibrated to the silicon Raman peak at $520.5 \mathrm{~cm}^{-1}$. The spectra were baseline corrected for the continuum luminescence background when necessary, temperature reduced to account for the Bose-Einstein occupation factor (Kuzmany, 2009) and normalized to the acquisition time. Peak positions, full-widths at half maximum (FWHMs), and integrated intensities were determined from fits with pseudo-Voigt functions ( pseudoVoigt $=(1-q) *$ Lorentz $+q *$ Gauss, where $\mathrm{q}$ is the mixing coefficient $)$.

\subsection{Elastic-strain analysis}

Elastic strains in quartz were determined for 17 quartz inclusions in garnet by using the relationship between strain and shifts in the position of selected Raman peaks (Angel et al., 2019;

160 Murri et al., 2019). The shift, $\Delta \omega$, of each Raman peak is the difference between the peak positions 
161 in the inclusion, $\omega_{i}$, and an unstrained reference crystal, $\omega_{0}$. To reduce shifts in peak position due

162 to instrumental drift and/or minor changes to room temperature, the unstrained standard was

163 measured multiple times per session. The $\omega_{0}$ values were averaged and then subtracted from the

$164 \omega_{i}$ of the strained inclusions analysed in between two consecutive standards. Sets of $\Delta \omega$ (modes

$165128,206,464$ and, when available, 265) for each inclusion were converted to strain using the

166 software stRAinMAN (Angel et al., 2019), applying the Grüneisen tensors for quartz (Murri et al.,

167 2018) and relaxation of the strains (Angel et al., 2014a). Strain interference can occur due to

168 complex inclusion geometries or inclusion proximity to the sample surface, outer edge of the

169 garnet, or other inclusions. Therefore, we only analysed non-faceted, rounded and sub-rounded

170 inclusions, isolated by at least three times their radius (Campomenosi et al., 2018; Mazzucchelli

171 et al., 2018; Zhang, 1998).

172 For comparison with the strain state in inclusions measured with Raman, numerically

173 predicted strains were calculated based on expected entrapment conditions using the software

174 EosFit7c (Angel et al., 2014b). The prograde P-T path for the LCU (Reinecke, 1998; Groppo et al.,

1752009 ) was divided into four segments of $0.5 \mathrm{GPa}$ by $100{ }^{\circ} \mathrm{C}$ (varying with pressure along the $P-T$

176 path), from 1.0 GPa to 3.0 GPa. Pressure was extended into the coesite field to accommodate any

177 potential overstepping of the quartz-coesite transformation. Precise $P$ - $T$ values and resulting

178 calculated strain states are available in the supplementary material. The host garnet mainly

179 consists of an almandine + spessartine mixture, however a complete set of elastic and

180 thermodynamic properties for these two garnet endmembers is unavailable in literature. Thus,

181 we calculated expected strains for given entrapment $P$ - $T$ conditions using data for grossular.

182 Differences between elastic properties of garnet endmembers are small, and as a result, only

183 minor variations ( $<5 \%$ at near-identical ratio of $\varepsilon_{1}+\varepsilon_{2}$ vs $\left.\varepsilon_{3}\right)$ in expected strains should occur when

184 using properties of a different endmember (Zaffiro, 2020).

\section{4 SAMPLE DESCRIPTION}

186 Garnetite layers and lenses are present in several of the LCU lithologies, including the Mn-rich

187 schistose quartzite investigated here (Figure 3a-c) and eclogite (Figure 3d). However, this 
quartzite best preserves the relationship between the host rock and the garnetite. In contrast, the eclogite contains only sparse garnetite, and the structural relationship between eclogite and garnetite is unclear.

The Mn-rich schistose quartzite forms a $5 \mathrm{~m}$-thick layer, at the centre of which is a $30 \mathrm{~cm}$ thick zone where the majority of the garnetite is located. Here, the garnetite occurs as lenses, discontinuous layers, dismembered fold hinges and limbs transposed along a phengite foliation (Figure 3a-c). This garnet quartzite can thus be subdivided into (i) garnet- and phengite-bearing schistose host rock and (ii) garnetite (Figure 3a). Boudinage of the garnetite indicates a competence contrast between the garnetite and the quartzite host rock (Figure 3b,c). The garnetite lenses, particularly the thicker parts, are structurally complex and appear heterogeneous in terms of garnet content based on colour variations. Some quartz-rich veins and patches cross cut the lens and its outer margins.

\subsection{Host rock}

The matrix of the host-rock quartzite exhibits a foliation defined by phengite, and contains garnets as euhedral grains $<1 \mathrm{~mm}$ in size (Figure $4 \mathrm{~b}$ ). Smaller anhedral garnet crystals are concentrated into lenses and layers $<1 \mathrm{~cm}$ across. The host rock also contains strongly zoned epidotes and aggregates of amphibole of a composition between magnesio-hornblende, actinolite, and winchite, alongside phengite, biotite, and quartz.

Two distinct mineral assemblages are present as inclusions in garnet (Table 1). In the cores of this garnet, inclusions of quartz, apatite, magnesite, dolomite, rutile, and zircon are present. Rutile is often $<1 \mu \mathrm{m}$ in size, giving the garnet core an orange hue. In the garnet mantle, an assemblage of coesite, kyanite, clinozoisite, phengite, rutile, and zircon is present. The euhedral garnet rims contain occasional quartz inclusions.

\subsection{Garnetite}

The garnetite is microstructurally diverse (Figure 4a), and can be subdivided into an inner and outer garnetite. This subdivision is based on garnet size and on quartz content, with the outer garnetite having more interstitial quartz and larger garnets (Figure 4c). Besides being smaller 
and having less to no interstitial quartz, garnets in the inner garnetite have a "welded" appearance

216 (Figure 4d). Large euhedral garnets are locally present on the outer margin of the inner garnetite

217 (Figure $4 \mathrm{e}$ ). The outer garnetite contains up to $\sim 50 \%$ interstitial quartz by volume and occasional

218 quartz veins cross cut the entire garnetite (Figure 4a). Rare accessory minerals, including

219 phengite, apatite, biotite, and sulphides, are present in the garnetite. A variety of structures are

220 present within the garnetite. The garnets in the outer garnetite are mostly euhedral and are often distributed in chains separated by quartz (Figure 4c). Garnets within this zone also exhibit a weak

222 shape preferred orientation, as their long axis is subparallel to the host-rock foliation and perpendicular to the garnet chains.

In both garnetite zones the main inclusion assemblage is similar to that of host rock garnet cores and consists of quartz, apatite, magnesite, dolomite, rutile, and zircon (Table 1). As in the host-rock garnets, rutile is usually sub-micron sized and occurs in clusters, which give the garnet an orange hue (Figure 4d). In the outer garnetite an inclusion-free rim is present around the inclusion-rich garnet core. The euhedral garnet overgrowth on the outer margin of the inner garnetite contains quartz inclusions (Figure 4f). No coesite has been observed in the garnetite.

\section{GARNET STRUCTURES AND COMPOSITION}

\subsection{Host rock}

The backscattered electron (BSE) image of a representative host-rock garnet displays strong compositional zonation that is locally complicated by irregularities (Figure 5a). Radial veinlets that appear with the same brightness in BSE as the euhedral rims cross cut the darker garnet. The garnet cores do not exhibit any irregularity in zonation besides radial veinlets. In contrast, the growth zones surrounding the core (garnet mantle) are separated by irregular boundaries between compositional zones.

EPMA analyses and element distrution mapping of representative host rock garnets reveal a strong compositional zonation (Figure 7a,d,g, Figure 8a). Garnet compositions corresponding to coesite inclusions in host-rock garnet are marked as representing UHPM garnet growth (Figure 7a,d; Figure 8). From these analyses, two trends can be distinguished. The first 
compositional trend (labelled 1 in Figure 8a) forms the common prograde metamorphic zoning trend. Mn-rich garnet cores progress to compositions richer in Fe, whereas Mg initially increases in the intermediate mantle before decreasing so that $\mathrm{Mg}$ concentrations are similar between earliest and latest compositions. This metamorphic zonation is interrupted by irregular compositional boundaries located within the Mg-richer UHPM zone. the Mg-richer excursion, essentially forming a series of intermediate compositions between the earliest prograde growth stage and the latest growth stage (Figure 8). Compositions related to this trend occur along the radial veinlets, in the cores of garnets, and as the outer rim (very similar BSE intensity in Figure 5a; Figure 7a,d). The veinlets appear to radiate from the core of the garnet, where a $\sim 50-100 \mu \mathrm{m}$ zone of elevated Ti signal can be found, linked to the presence of sub-micron rutile inclusions (Figure $7 \mathrm{~g}$ ).

\subsection{Garnetite}

Garnets in the outer garnetite exhibit several similarities with garnets in the host rock (Figure 5 b-e). One irregular boundary between compositional zones is typically present (Figure 5c) and, in addition, these garnet crystals display truncation of the metamorphic zones at garnet-garnet contacts (Figure $5 b, c$ ). The truncation involves portions of the garnet core and mantle, and is locally overgrown by another zone of garnet (Figure 5c). Radial veinlets are common to garnets in the outer garnetite (Figure 5b-e). Occasionally, garnets exhibit interlocking lobate structures between two cores (Figure 5d,e). The outer zone of the garnets is euhedral and free of veinlets. Particularly in the garnet-richer zones of the outer garnetite, garnet-garnet contacts are often sealed with a late growth of garnet (Figure $5 b, e$ ).

Garnets in the inner garnetite do not resemble the other garnet types, as they do not exhibit a distinct metamorphic zonation and lack radial veinlets (Figure 5f). In addition, these garnets exhibit irregular grain shapes, illustrated by interlocking lobes of dark grey garnet

267 (Figure 5f). Interlocking features are more common in garnetite with lower quartz content. Most garnet-garnet grain boundaries are sealed with a late growth of garnet (e.g., Figure 5e), which 
269 also gives the inner garnetite a single-crystal appearance in thin section and hand specimen. The 270 euhedral garnets at the outer margin of the inner garnetite locally contain inclusions of garnet 271 from the inner garnetite (see supplementary Figure S1f). Grain boundaries in the inner garnetite can be difficult to distinguish based on compositional zones alone. However, individual grains can be clearly separated based on crystal orientations measured by EBSD. Figure 6a presents an EBSD map of a portion of inner garnetite. Whereas the majority of the garnetite has a relatively consistent distribution of grain size, some bands of a consistently finer grain size, a few hundred micrometres thick (blue domain in Figure $6 a)$, are present within the inner garnetite. In BSE images, these zones exhibit an increase in complexity of grain shape and zonation relative to the adjacent garnetite (Figure $6 a, b$ ), and abundant rutile and zircon grains, with strong BSE signal and often $<1 \mu \mathrm{m}$ in size. Figure $6 \mathrm{c}$ presents an extreme case of rutile and zircon enrichment along these fine-grained zones. 2: recrystallization) as are present in the compositions of host-rock garnet, are recognizable in the garnetite garnets (Figure 8). The compositions along this trend are somewhat enriched in Mn in the outer and inner garnetite relative to those corresponding to UHPM and late growth in the host rock. In the outer garnetite, the garnet zone with compositions matching the UHPM garnet is significantly thinner than in host-rock garnets, despite a similar size of garnet cores (Figure 7ab, d-e, g-h). Garnet growth over the truncated zones (Figure 7 b,e; see line labelled "Truncation boundary" in Figure 8b) corresponds to compositions of coesite domains in host-rock garnets. Garnet cores in the garnetite, often displaying erratic zonation (Figure 7b,c,e,f), adhere to the recrystallization trend also found in the host rock (Figure 8). In the inner garnetite, garnet of the same composition as the coesite zone in host-rock garnet is barely present, only occurring as minor component in interlocking lobes and in the euhedral overgrowth at the outer margin. This overgrowth does not correspond to the euhedral late-stage growth that is observed in the outer garnetite and host rock, based on their different compositions. 
Compositions matching the second trend in the outer garnetite occur mainly in recrystallized garnet cores, alongside Ti enrichment attributed to rutile inclusions (Figure 7g-i).

297 The interlocking lobes lack these rutile inclusions, similar to garnet of corresponding 298 compositions in the outer garnetite and host rock. Garnet-garnet grain boundaries are also sealed with garnet of a Fe-rich composition along either trend. This trend of garnet compositions is also observed along radial veinlets and as an outer garnet rim. That the recrystallization of garnet cores resulted in a similar composition as garnet within veinlets is most visible in Figure $7 \mathrm{~b}$, where veinlets and the recrystallized core appear strongly related. Recrystallization processes partially overprinted and obscured original zonation of garnet cores in the garnetite.

\section{STRAIN STATE OF QUARTZ INCLUSIONS IN GARNET}

Elastic strain analysis via Raman spectroscopy allowed for the determination of the strain state and associated $2 \sigma$ variance-covariance ellipsoid for quartz inclusions located in the euhedral garnet overgrowth at the outside margin of the inner garnetite (Figure 9a, corresponding to Figure 4e,f; upside-down triangles in Figure 8c). These inclusions were measured to study the relationship between stress and fluid-driven mechanisms. Only the quartz inclusions in this specific garnet population was used, to avoid potential interference from radial veinlets or recrystallization as is observed in other garnet populations.

The method of elastic geothermobarometry was developed for the primary aim of obtaining entrapment $P$ - $T$ conditions. However, we can also numerically predict what values of $\varepsilon_{1}+\varepsilon_{2}$ and $\varepsilon_{3}$ are expected for hydrostatic entrapment conditions and envisage deviations from these calculated strains as factors external to the host-inclusion, either during formation or afterwards (Figure 9b; Alvaro et al., 2020; Bonazzi et al., 2019; see supplementary Tables S8-S11 for full data). The expected strain states based on LCU $P$ - $T$ data from literature (Figure $2 \mathrm{~b}$; Reinecke 1998; Groppo et al., 2009) have been provided for comparison. for $\varepsilon_{1}+\varepsilon_{2}$, and between -0.0054 and 0.0014 for $\varepsilon_{3}$. Within error, most inclusions cluster along or near both the hydrostatic stress line and the expected strains for the LCU. Two inclusions (i14 
and i20) have no apparent strain, probably having been affected by fractures in the host garnet. The strain states of the majority of measured quartz inclusions cluster around the line corresponding to $0.75 \mathrm{GPa}$ inclusion pressure (Figure 9a,b), in accordance with entrapment conditions between 1.5 and $2.0 \mathrm{GPa}$ for the prograde temperatures of the LCU.

\section{DISCUSSION}

The garnet microstructures and compositions and the mineral inclusions in garnet described here provide key information on the subduction-zone evolution of the Lago di Cignana UHP garnetquartzite and garnetite. Importantly, our data demonstrate that garnetite formed through a process of mineral compaction and pressure solution. Moreover, the inclusion populations in garnet provide information on the possible evolution of matrix minerals through time and during garnet growth, and Raman spectroscopy of quartz inclusions in garnetite helps understanding the stress regime operating during garnet fluid-mediated deformation and dissolution in garnetite.

\subsection{Evidence for fluid-rock interaction}

\subsubsection{Host rock}

In the UHPM garnet quartzite presented here, host-rock garnets display zonation patterns that are interrupted by irregular boundaries of contrasting composition (Figures 5a,c; 7a,d). These boundaries are spatially related to resorption of Mn (Figure 7a), suggesting that periods of garnet growth were halted by stages of garnet dissolution driven by disequilibrium between garnet and an infiltrating fluid (Figures 5a-c; 7a,d). The cyclicality of dissolution and growth suggests that fluids pulsed over an extended period during metamorphism.

In host-rock garnets, ubiquitous radial veinlets of a late-stage garnet composition cross cut the majority of the zonation. These veinlets, indicate a mechanism of selective garnet replacement along fractures formed during retrograde metamorphism (Whitney, 1996; Angiboust et al., 2012; Giuntoli et al., 2018; Broadwell et al., 2019; Rubatto et al., 2020). Currently known mechanisms for garnet fracturing during metamorphism, either seismic fracturing (Angiboust et al., 2012; Giuntoli et al., 2018), or hydrofracturing due to increased pore fluid 
pressure (Rimša et al., 2007), normally do not generate radial fractures. The radial nature of the observed fractures could derive from stressed mineral inclusions in the garnet cores (Van der Molen \& Van Roermund, 1986).

In the host-rock garnet, the mineral inclusion assemblages are: (i) quartz, rutile, dolomite, magnesite, apatite, zircon in the core, (ii) coesite, kyanite, clinozoisite, phengite, zircon in the mantle, (iii) quartz in the rim (Table 1). The distribution of quartz and coesite in this garnet (Figure 7a,d) indicates a primary origin of such inclusions, despite the fractures in the host garnets which could have re-equilibrated the inclusions (Whitney, 1996; Griffiths et al., 2014). The inclusions thus correspond to preserved remnants of the evolving rock matrix at different stages of garnet growth. Absence in the matrix of key inclusion minerals present in the host-rock garnet (e.g. carbonates) suggests that such minerals might have been involved in the same mineral dissolution process recorded by the garnet. Overall, the quartzite hosting the garnetite layers retains evidence of dissolution that affected the garnet and some matrix minerals.

\subsubsection{Garnetite}

The majority of garnet-garnet contacts in the outer garnetite exhibit discontinuous zonation (Figure 5b-e) interrupted by an irregular pattern of garnet grain boundaries where garnets indent and flatten each other. These microstructures are the result of pressure solution, a fluidmediated deformation mechanism that operates through the increased solubility at stressed grain contacts, resulting in localized dissolution and potential reprecipitation at lower-stress areas. This mechanism has previously been recognized for garnet (Smit et al., 2011; Wassmann \& Stöckhert, 2013a), and can be distinguished from undeformed polycrystalline garnet aggregates as only deformation by pressure solution will lead to discontinuous zonation across grain boundaries (Smit et al., 2011). Figures 5c and 7b,e display garnet that has overgrown truncated garnet-garnet contacts, indicating that pressure solution was not a retrograde feature as described by Wassmann and Stöckhert (2013a) but instead took place during prograde to peak metamorphism. 

garnetite (Figure 4c) and coincide with garnet flattening and truncation of compositional zones by pressure solution. The garnet-chain microstructure resembles stacked garnet as described and interpreted by Massey et al. (2011) as the result of flattening in a direction parallel to the chains coupled with lateral stretching, accommodated by pressure solution and reprecipitation of interstitial quartz. In the case of the LCU outer garnetite, the host-rock foliation is near perpendicular to the garnet chains, supporting the notion that the shortening direction is parallel to the chains. Moreover, the origin and preservation of this microstructure relies on little to no simple shear. Truncated zonation from pressure solution is also observed in parts of garnetite that are not rich in quartz (Figure 5e), suggesting that flattening strain in garnetite did not rely on the local remobilization of quartz alone, as was suggested for this microstructure by Massey et al. (2011). The garnet stacking provides no constraints on strain perpendicular to the stacking and instead can also indicate uniaxial strain with no related stretching, which relies on the reduction of volume by local dissolution coupled with removal of mass from the system.

Most garnet-garnet contacts in the inner garnetite and a few in the outer garnetite have developed highly interlocking lobate structures by recrystallization through grain boundary migration (GBM) (Figure $5 \mathrm{~d}-\mathrm{f}$ ). This recrystallization mechanism is a process where grain boundaries sweep over part of an old grain, recrystallizing it as part of the neighbouring grain. As a result, the grain morphology is altered, yielding a higher degree of interlocking than is known from pressure solution (see microstructures of chemically-induced GBM in calcite; Hay \& Evans, 1987; Smit et al., 2011). The GBM-recrystallized garnet differs from the precursor garnet as the result of a change in garnet composition during recrystallization (Figure 5f, 7c,f,i). For the composition to change, an input and output of solutes is required, particularly as this mechanism should destroy and regrow equal amounts of garnet. GBM took place along all grain boundaries where garnet cores were in contact, and therefore a saturated wetting fluid was present throughout the garnetite. GBM in the outer garnetite relied on pressure solution to expose two garnet core and bring them into contact; core-mantle contact yielded no GBM (Figure 5b). 
The bands with finer grain size that cross cut the inner garnetite (Figure 6) differ from surrounding garnetite in grain size and in enrichment of rutile and zircon. Both differences can be explained by a higher degree of garnet dissolution within the fine-grained bands, leading to a grain-size reduction and the liberation of less soluble inclusions (zircon, rutile). Alternatively, release of $\mathrm{Zr}$ from the garnet could drive zircon precipitation. An alternative mechanism for the accumulation of rutile is an influx of a Ti-bearing fluid (Scambelluri \& Philippot, 2001) leading to rutile precipitation. Either way, rearrangement of pre-existing rutile grains into an evolving garnet microstructure, or rutile precipitation in trails within this garnet, are both fluid-mediated processes.

In quartz-poor areas of the garnetite, garnet-garnet contacts are sealed by a final stage of garnet growth. This garnet is of similar composition to garnet in the radial veinlets and outermost garnet rim in the outer garnetite and host rock (Figure 5b), corresponding to the Fe-rich part of the composition range (Figure 8; note lower Mg and Mn of this garnet in Figure 7). Since no interstitial minerals were present to drive a garnet-forming reaction, either within fractures or along grain boundaries, the garnet must have precipitated from a fluid. An alternative mechanism relies on the selective replacement of garnet similar to the formation of radial veinlets by a fluid along fractures. The textures presented here thus indicate that the garnetite garnet was wetted by fluids during GBM and during late-stage garnet growth and/or replacement in fractures, grain boundaries, and as tiny rims.

In the inner and outer garnetite, carbonates only occur as inclusions in the garnet core and are absent as intergranular phases, pointing to dissolution of intergranular carbonate. A lack of interstitial quartz in the inner garnetite, where quartz inclusions are common, suggests that intergranular quartz was also removed. This mineral dissolution supports the finding of (i) bicarbonate and carbonate ions and silica monomers in fluid inclusions and of (ii) associated microdiamonds in other, nearby, garnetite lenses in the LCU (Frezzotti et al., 2011).

\subsubsection{Reconstruction}


428 Garnet microstructures can be linked to the well-established $P$ - $T$ path of the LCU (Figure $2 \mathrm{~b}$ ) by 429 comparing garnet composition linked to those microstructures to the presence of primary quartz 430 and coesite inclusions in host-rock garnet of the same composition. Although garnet morphology 431 varies between garnetite and host rock, the studied garnets exhibit a near-identical compositional 432 evolution (Figure 8), the only difference being a slight Mn enrichment in the garnetite. This 433 similarity, together with the similar size (Figure $7 \mathrm{~g}-\mathrm{i}$ ) and reactivity of inner garnet cores in all 434 garnet types, suggests a common initial garnet-forming reaction at a similar rate of nucleation versus growth. Based on this linked garnet growth, the composition and inclusions of quartz versus coesite in the host rock garnets are used as a tool for relative timing and an estimate for UHPM conditions of garnet growth throughout the system.

The temporal link between the rock domains established through garnet composition is used to reconstruct their evolution in terms of garnet growth, dissolution, deformation, and recrystallization, and related fluid flow patterns (Figure 10). After the initial growth of garnet cores at approximately $1.0 \mathrm{GPa}$ and $400{ }^{\circ} \mathrm{C}$ (Reinecke, 1998), the first stage of compaction by fluidrock interaction took place by dissolving and transporting interstitial material (stage 1, Figure 10b). The above processes concentrated garnet in what is now the inner garnetite, essentially forming a garnet stylolite. The euhedral garnet growing at the outer margins of the inner garnetite formed after this compaction, and the lower range of $P$ - $T$ conditions obtained from quartz inclusions in this garnet $(\sim 1.5-2.0 \mathrm{GPa})$ indicate that compaction took place at conditions of 1.0$1.5 \mathrm{GPa}$ and $400-450^{\circ} \mathrm{C}$. No fluid-rock interaction during this phase is recorded in the host rock. The second stage (stage 2, Figure 10b) was marked by the dissolution of matrix minerals adjacent to the inner garnetite and related arrangement of garnets in the garnet chain microstructure, while host-rock garnets continued regular metamorphic growth. While the outer garnetite was compacting and partially dissolving into an infiltrated fluid, the inner garnetite underwent GBM and growth of euhedral crystals at the outer margin. This phase took place at conditions between stage 1 and UHPM conditions, thus $1.5-2.6 \mathrm{GPa}$ and $450-550{ }^{\circ} \mathrm{C}$. 

outer garnetite were affected by fluid pulses that induced cycles of dissolution and growth in garnet. Only local fluid pathways still allowed fluid flow in the inner garnetite. By examining the youngest preserved garnet before pressure solution and the garnet that grew over truncated zonation (Figures $5 \mathrm{c}$ and $7 \mathrm{~b}, \mathrm{e}$ ), a window for pressure solution in the outer garnetite is constrained as prograde to the first part of UHPM (Figure 8b,d), coincident with formation of the mantle of host-rock garnet.

In the final stage (stage 4, Figure 10b) during exhumation, garnets in the outer garnetite event was coeval with a final phase of garnet growth, sealing all garnet-garnet grain boundaries and forming a euhedral outer rim on garnets throughout the system.

The above evidence suggests that fluid flow and mineral dissolution during prograde metamorphism was focused in and directly adjacent to the inner garnetite, whereas most of the fluid pulses during UHPM were focused in the host rock, with lesser impact on the outer garnetite. This progression suggests a shift over time of the fluid pathway, not only migrating from the inner garnetite towards the host rock but also widening in the process.

\subsection{Evaluation of stress conditions from quartz inclusions}

472 The studied quartz inclusions are inside euhedral garnet crystals located at the outer margin of the inner garnetite. This euhedral garnet grew from circulating fluids, after formation of the inner garnetite and coeval with GBM, and are considered representative of the stress conditions during garnet growth at approximate $P$ - $T$ conditions of $1.5-2.0 \mathrm{GPa}$ and $450-490^{\circ} \mathrm{C}$.

Factors external to the host-inclusion system, such as differential stress during entrapment, can change the strain components from the expected strain state. As a result, inclusions that are entrapped under hydrostatic conditions should correspond to calculated strains for the $P-T$ conditions of entrapment, while a significant differential stress during entrapment will lead to a deviation from the predicted strains, along a line of constant inclusion 
pressure (Figure 9b; Bonazzi et al., 2019). This method is not calibrated as quantitative, so currently no magnitude of differential stress during entrapment can be obtained.

With the exception of two outliers, the calculated strain states of all measured quartz inclusions fall within uncertainty of the line that indicates the strain ratio expected for entrapment under hydrostatic stress, and the expected strain states for hydrostatic entrapment along the prograde $P$ - $T$ path for the LCU. Depending on the peak metamorphic temperature of the LCU (590-605 ${ }^{\circ} \mathrm{C}$, Groppo et al., 2009; $630{ }^{\circ} \mathrm{C}$, Reikecke, 1998), little to no plastic deformation occurred in garnet, and therefore the state of strain and inclusion pressure of the quartz is reliable (Voegelé et al., 1998; Zhong et al., 2020).

The inferred hydrostatic entrapment conditions for quartz in garnet fit the fluid-driven deformation process envisaged, with a fluid wetting the garnet crystals. Load-bearing and consequently stressed grain contacts resulted in local pressure solution, while other parts of the garnet were coated by a fluid, where quartz subsequently recorded (near-) hydrostatic stress during entrapment.

\subsection{Implications}

Reconstructing the evolution of the garnetite-host-rock system in the LCU quartzite has yielded several gaps in the rock record, most notably when comparing the inclusion mineral assemblages to the current matrix mineral assemblages. The extensive evidence for garnet dissolution presented here is not coupled with concomitant reprecipitation, which implies that the whole process took place under open system conditions, with overall loss of material. The fluids responsible for mineral dissolution were externally derived and likely made available by dehydration of nearby serpentinite (Halama et al., 2020). Because garnets are concentrated into garnetite by dissolution of more soluble interstitial minerals along a fluid pathway, the garnetite can be considered a stylolite. The genesis of garnetite is generally linked to precipitation from a fluid or melt, or sedimentary processes (e.g., Spry et al., 2000; Vrijmoed et al., 2006; Angiboust et al., 2017; Hadjzobir et al., 2017); therefore, the process described here provides a new mechanism for garnetite formation. 
The fluid pathway described in this study involves mass removal via dissolution and

509 transport of quartz, garnet, and carbonates, due to circulation of large amounts of fluids (Vernon

510 et al., 1987). When considered as a whole, the host rock-garnetite system acted as a fluid pathway

511 throughout metamorphism. The observed fluid-mediated deformation in combination with near-

512 hydrostatic to hydrostatic stresses inferred for garnet growth based on the elastic strain of quartz

513 inclusions in garnet, showcases the capacity of fluids to result in significant compaction at low

514 differential stress.

515 The mechanisms that operated in the LCU quartzite and garnetite provide new insights

516 into the possible evolution of aqueous-carbonic fluids released by dehydration of oceanic slabs.

517 By dissolving minerals located in specific rock domains through the pressure-solution process

518 documented here, fluids may become enriched in rock-forming components, driving enrichment

519 of silicates in water- and carbon-rich solutions when moving across different lithologies within

520 the subducting plates.

\section{CONCLUSIONS}

522 The combination of microstructures, mineral inclusions, and garnet compositions provide a

523 record of metamorphism and fluid-rock interaction for the UHPM garnetite-bearing quartzite of

524 Lago di Cignana. This fluid-rock interaction record showcases the longevity of this system as a

525 major fluid pathway throughout subduction. The externally derived fluids locally led to a

526 significant compaction and mass removal by pressure solution of minerals such as quartz,

527 carbonates, and garnet. Due to its relatively low solubility, garnet was concentrated into garnetite

528 stylolites, constituting a new potential mechanism for the formation of garnetite. Quartz

529 inclusions entrapped in euhedral garnet overgrowths on garnetite yield strains that indicate

530 near-hydrostatic stress conditions during garnet growth. Considering pressure solution as the

531 main mechanism of mass removal, this fluid-rock interaction also operated as a means of exerting

532 control on deformation during metamorphism.

\section{ACKNOWLEDGEMENTS}


534 This project has received funding from the European Research Council under the European

535 Union's Horizon 2020 research and innovation program grant agreement 714936 to M. Alvaro.

536 M. Scambelluri acknowledges funding by the Italian MIUR to the PRIN program n. 2017ZE49E7.

537 The authors have no conflicts of interest to declare. Andrea Risplendente is thanked for

538 performing the EPMA analyses. B. Dragovic and two anonymous reviewers are gratefully

539 acknowledged for their helpful comments. Many thanks to B. Cesare for editorial handling.

\section{REFERENCES}

541 Ague, J.J., Nicolescu, S. (2014). Carbon dioxide released from subduction zones by fluid-mediated reactions. Nature Geoscience, 7, 355-360. DOI: 10.1038/NGE02143

543

544

Amato, J.M., Johnson, C.M., Baumgartner, L.P., Beard, B.L. (1999). Rapid exhumation of the Zermatt-Saas ophiolite deduced from high-precision Sm-Nd and Rb-Sr geochronology. Earth and Planetary Science Letters, 171, 425-438.

547

Alvaro, M., Mazzucchelli, M.L., Angel, R.J., Murri, M., Campomenosi, N., Scambelluri, M., Nestola, F., Korsakov, A., Tomilenko, A.A., Marone, F., Morana, A. (2020). Fossil subduction recorded by quartz from the coesite stability field. Geology, 48(1), 24-28.

551

Angel, R.J., Mazzucchelli, M.L., Alvaro, M., Nimis, P., Nestola, F. (2014a). Geothermobarometry from host-inclusion systems: The role of elastic relaxation. American Mineralogist, 99, 21462149.

Angel, R.J., Gonzalez-Platas, J., Alvaro, M. (2014b). EosFit-7c and a Fortran module (library) for equation of state calculations. Zeitschrift für Kristallographie, 2009, 405-419. 
559

560

561

562

563

564

565

566

567

568

569

570

571

572

573

574

575

576

577

578

579

580

581

582

583

584

585

Angel, R.J., Nimis, P., Mazzucchelli, M.L., Alvaro, M., Nestola, F. (2015). How large are departures from lithostatic pressure? Constraints from host-inclusion elasticity. Journal of Metamorphic Geology, 33(8), 801-813.

Angel, R.J., Mazzucchelli, M.L., Alvaro, M., Nestola, F. (2017). EosFit-Pinc: A simple GUI for hostinclusion elastic thermobarometry. American Mineralogist, 102(9), 1957-1960.

Angel, R.J., Murri, M., Mihailova, B., Alvaro, M. (2019). Stress, strain and Raman shifts. Zeitschrift für Kristallographie - Crystalline materials, 234(2), 129-140. DOI: https://doi.org/10.1515/zkri-2018-2112

Angiboust, S., Agard, P., Jolivet, L., Beyssac, O. (2009). The Zermatt-Saas ophiolite: the largest (60km wide) and deepest (c. 70-80 km) continuous slice of oceanic lithosphere detached from a subduction zone? Terra Nova, 21, 171-180. DOI: 10.1111/j.1365-3121.2009.00870.x

Angiboust, S., Agard, P., Yamato, P., Raimbourg, H. (2012). Eclogite breccias in a subducted ophiolite: A record of intermediate depth earthquakes? Geology, 40, 707-710.

Angiboust, S., Yamato, P., Hertgen, S., Hyppolito, T., Bebout, G.E., Morales, L. (2017). Fluid pathways and high-P metasomatism in a subducted continental slice (Mt. Emilius Klippe, W. Alps). Journal of metamorphic geology, 35, 471-492.

Bachmann, F., Hielscher, R., Schaeben, H. (2010). Texture Analysis with MTEX - Free and Open Source Software Toolbox. Solid State Phenomena, 160, 63-68.

Bebout, G.E. (2007). Metamorphic chemical geodynamics of subduction zones. Earth and Planetary Science Letters, 260, 373-393. 
587 Beltrando, M., Rubatto, D., Manatschal, G. (2010). From passive margins to orogens: The link 588 between ocean-continent transition zones and (ultra)high-pressure metamorphism. Geology, 38, 559-562.

590

591

592

593

594

595

596

597

598

599

600

601

602

603

604

605

606

607

608

609

610

611

612

Bonazzi, M., Tumiati, S., Thomas, J.B., Angel, R.J., Alvaro, M. (2019). Assessment of the reliability of elastic geobarometry with quartz inclusions. Lithos, 350-351, 105201. DOI: 10.1016/j.lithos.2019.105201

Broadwell, K.S., Locatelli, M., Verlaguet, A., Agard, P., Caddick, M.J. (2019). Transient and periodic brittle deformation of eclogites during intermediate-depth subduction. Earth and Planetary Science Letters, 521, 91-102.

Brovarone, A.V., Tumiati, S., Piccoli, F., Ague, J.J., Connolly, J.A.D., Beyssac, O. (2020). Fluidmediated selective dissolution of subducting carbonaceous material: Implications for carbon recycling and fluid fluxes at forearc depths. Chemical Geology, 549, 119682.

Bucher, K., Grapes, R. (2009). The Eclogite-facies Allalin Gabbro of the Zermatt-Saas Ophiolite, Western Alps: a Record of Subduction Zone Hydration. Journal of Petrology, 50-8, 14051442.

Bürgmann, R., Dresen, G. (2008). Rheology of the Lower Crust and Upper Mantle: Evidence from Rock Mechanics, Geodesy, and Field Observations. Annual Review of Earth and Planetary Sciences, 36, 531-567.

Campomenosi, N., Mazzucchelli, M.L., Mihailova, B., Scambelluri, M., Angel, R.J., Nestola, F., Reali, A., Alvaro, M. (2018). How geometry and anisotropy affect residual strain in host-inclusion 
613

614

615

616

617

618

619

620

621

622

623

624

625

626

627

628

629

630

631

632

633

634

635

636

637

638

systems: Coupling experimental and numerical approaches. American Mineralogist, 103(12), 2032-2035. DOI: 10.2138/am-2018-6700CCBY

Cartwright, I., and Barnicoat, A.C. (2002). Petrology, geochronology, and tectonics of shear zones in the Zermatt-Saas and Combin zones of the Western Alps. Journal of Metamorphic Geology, $20,263-281$.

Crameri, F. (2018). Scientific colour-maps. Zenodo. DOI: http://doi.org/10.5281/zenodo.1243862

Dal Piaz, G. (1999). The Austroalpine-Piedmont nappe stack and the puzzle of Alpine Tethys. Memorie di Scienze Geologiche, 51, 155-176.

Dal Piaz, G.V., Cortiana, G., Del Moro, A., Martin, S., Pennacchioni, G., Tartarotti, P. (2001). Tertiary age and paleostructural inferences of the eclogitic imprint in the Austroalpine outliers and Zermatt-Saas ophiolite, western Alps. International Journal of Earth Sciences, 90, 668-684. DOI: $10.1007 / \mathrm{s} 005310000177$

Dragovic, B., Baxter, E.F., Caddick, M.J. (2015). Pulsed dehydration and garnet growth during subduction revealed by zoned garnet geochronology and thermodynamic modeling, Sifnos, Greece. Earth and Planetary Science Letters, 413, 111-122.

Ferrando, S., Groppo, C., Frezzotti, M.L., Castelli, D., Proyer, A. (2017). Dissolving dolomite in a stable UHP mineral assemblage: Evidence from Cal-Dol marbles of the Dora Maira Massif (Italian Western Alps). American Mineralogist, 102, 42-60. 
639 Forster, M., Lister, G., Compagnoni, R., Giles, D., Hills, Q., Betts, P., Beltrando, M. \& Tamagno, E. 640 (2004). Mapping of oceanic crust with" HP" to" UHP" metamorphism: The Lago di Cignana 641 Unit (Western Alps). Mapping geology in Italy: Geological Society of London.

642

Frezzotti, M.L., Selverstone, J., Sharp, Z.D., Compagnoni, R. (2011). Carbonate dissolution during subduction revealed by diamond-bearing rocks from the Alps. Nature Geoscience, 4, 703-706.

646

647

Gerya, T.V., Meilick, F.I. (2011). Geodynamic regimes of subduction under an active margin: effects 648 of rheological weakening by fluids and melts. Journal of Metamorphic Geology, 29, 7-31.

649

650

Gilio, M., Scambelluri, M., Agostini, S., Godard, M., Peters, D., Pettke, T. (2019). Petrology and Geochemistry of Serpentinites Associated with the Ultra-High Pressure Lago di Cignana Unit (Italian Western Alps). Journal of Petrology, 60, 6. DOI: 10.1093/petrology/egz030

653

Giuntoli, F., Lanari, P., Engi, M. (2018). Deeply subducted continental fragments - Part 1: Fracturing, dissolution-precipitation, and diffusion processes recorded by garnet textures of

Griffiths, T.A., Habler, G., Rhede, D., Wirth, R., Ram, F., Abart, R. (2014). Localization of submicron 659 the central Sesia Zone (western Italian Alps). Solid Earth, 9, 167-189. inclusion re-equilibration at healed fractures in host garnet. Contributions to Mineralogy and

661

Groppo, C., Beltrando, M., Compagnoni, R. (2009). The P-T path of the ultra-high pressure Lago di Cignana and adjoining high-pressure meta-ophiolitic units: insights into the evolution of the subducting Tethyan slab. Journal of Metamorphic Geology, 27, 207-231. 
666 Hadjzobir, S., Altenberger, U., Günter, C. (2017). The Edough Massif garnetites: evidence for a 667 metamorphised paleo-garnet beach-sand placer (Cap de Garde, Annaba, Northeast Algeria). $668 \quad$ Journal of Mediterranean Earth Sciences, 9, 1-13.

669

670 Halama, R., Konrad-Schmolke, M., De Hoog, J.C.M. (2020). Boron isotope record of peak 671 metamorphic ultrahigh-pressure and retrograde fluid-rock interaction in white mica (Lago 672 di Cignana, Western Alps). Contributions to Mineralogy and Petrology, 175, 20. DOI: 673 $10.1007 / \mathrm{s} 00410-020-1661-8$

674

675

Hawkins, A.T., Selverstone, J., King, P.L., Frezzotti, M.L. (2009). HP/UHP fluids preserved in Mn676

677 rich garnets from Lago di Cignana, Italy. Geological Society of America Abstracts with Programs. 41(7), 238.

678

Hay, R.S., Evans, B. (1987). Chemically induced grain boundary migration in calcite: temperature dependence, phenomenology, and possible applications to geologic systems. Contributions

682

Hermann, J., Spandler, C., Hack, A., Korsakov, A.V. (2006). Aqueous fluids and hydrous melts in 684

685 high-pressure and ultra-high pressure rocks: Implications for element transfer in subduction

686

687 to Mineralogy and Petrology, 97, 127-141.

688

Herms, P., John, T., Bakker, R.J., Schenk, V. (2012). Evidence for channelized external fluid flow 689 and element transfer in subducting slabs (Raspas Complex, Ecuador). Chemical Geology, 310-311, 79-96.

690 
691 Karato, S., Wang, z., Lio, B., Fujino, K. (1995). Plastic deformation of garnets: systematics and 692 implications for the rheology of the mantle transition zone. Earth and Planetary Science $693 \quad$ Letters, 130, 13-30.

694

695 Kirst, F., Leiss, B. (2017). Kinematics of syn- and post-exhumational shear zones at Lago di 696 Cignana (Western Alps, Italy): constraints on the exhumation of Zermatt-Saas (ultra)high697 pressure rocks and deformation along the Combin Fault and Dent Blanche Basal Thrust. 698 International Journal of Earth Sciences, 106, 215-236. DOI: 10.1007/s00531-016-1316-1

699

Kuzmany, H. (2009). Light Scattering Spectroscopy. In: Solid-State Spectroscopy. Springer, Berlin, 701 Heidelberg

702

Massey, M.A., Prior, D.J., Moecher, D.P. (2011). Microstructure and crystallographic preferred 704 orientation of polycrystalline microgarnet aggregates developed during progressive creep,

Mazzucchelli, M.L., Burnley, P., Angel, R.J., Morganti, S., Domeneghetti, M.C., Nestola, F., Alvaro, M. (2018). Elastic geothermobarometry: Corrections for the geometry of the host-inclusion system. Geology, 46(3), 231-234.

710

Murri, M., Mazzucchelli, M.L., Campomenosi, N., Korsakov, A.V., Prencipe, M., Mihailova, B.D., Scambelluri, M., Angel, R.J., Alvaro, M. (2018). Raman elastic geobarometry for anisotropic mineral inclusions. American Mineralogist, 103(11), 1869-1872.

Murri, M., Alvaro, M., Angel, R.J., Prencipe, M., Mihailova, B.D. (2019). The effects of nonhydrostatic stress on the structure and properties of alpha-quartz. Physics and Chemistry of Minerals, 46, 487-499. DOI: 10.1007/s00269-018-01018-6 
719 Peacock, S.M. (1990). Fluid Processes in Subduction Zones. Science, 248, 329-337.

720

721

722

723

724

725

726

727

728

729

730

731

732

733

734

735

736

737

738

739

740

741

742

743

744

Plümper, O., John, T., Podladchikov, Y.Y., Vrijmoed, J.C., Scambelluri, M. (2017). Fluid escape from subduction zones controlled by channel-forming reactive porosity. Nature geoscience, 10 , 150-158. DOI: 10.1038/NGEO2865

Reddy, S.M., Wheeler, J., Cliff, R.A. (1999). The geometry and timing of orogenic extension: an example from the Western Italian Alps. Journal of Metamorphic Geology, 17, 573-589.

Reinecke, T. (1991). Very-high-pressure metamorphism and uplift of coesite-bearing metasediments from the Zermatt-Saas zone, Western Alps. European Journal of Mineralogy, 3, 7-17.

Reinecke, T. (1998). Prograde high- to ultahigh-pressure metamorphism and exhumation of oceanic sediments at Lago di Cignana, Zermatt-Saas Zone, western Alps. Lithos. 42, 147-189.

Rimša, A., Whitehouse, M.J., Johansson, L., Piazolo, S. (2007). Brittle fracturing and fracture healing of zircon: An integrated cathodoluminescence, EBSD, U-Th-Pb, and REE study. American Mineralogist, 92, 1213-1224.

Rubatto, D., Burger, M., Lanari, P., Hattendorrf, B., Schwarz, G., Neff, C., Schmidt, P.K., Hermann, J., Vho, A., Günther, D. (2020). Identification of growth mechanisms in metamorphic garnet by high-resolution trace element mapping with LA-ICP-TOFMS. Contributions to Mineralogy and Petrology, 175:61. DOI: 10.1007/s00410-020-01700-5

Scambelluri, M., Philippot, P. (2001). Deep fluids in subduction zones. Lithos. 55, 213-227. 
746 Skora, S., Mahlen, N.J., Johnson, C.M., Baumgartner, L.P., Lapen, T.J., Beard, B.L., Szilvagyi, E.T. 747 (2015). Evidence for protracted prograde metamorphism followed by rapid exhumation of the Zermatt-Saas Fee ophiolite. Journal of Metamorphic Geology, 33, 711-734.

749

Smit, M.A., Scherer, E.E., John, T., Janssen, A. (2011). Creep of garnet in eclogite: Mechanisms and implications. Earth and Planetary Science Letters, 311, 411-419.

752

753

Spandler, C., Pirard, C. (2013). Element recycling from subducting slabs to arc crust: A review. Lithos, 170-171, 208-223.

755

756

757

Spry, P.G., Peter, J.M., Slack, J.F. (2000). Meta-Exhalites as Exploration Guides to Ore. Geological Survey of Canada, Contribution no. 1997162, 163-201.

758

Taetz, S., John, T., Bröcker, M., Spandler, C., Stracke, A. (2018). Fast intraslab fluid-flow events 762

Tumiati, S., Martin, S., Godard, G. (2010). Hydrothermal origin of manganese in the high-pressure ophiolite metasediments of Praborna ore deposit (Aosta Valley, Western Alps). European

Van der Molen, I., Van Roermund, H.L.M. (1986). The pressure path of solid inclusions in minerals: the retention of coesite inclusions during uplift. Lithos, 19, 317-324. 
Van Keken, P.E., Hacker, B.R., Syracuse, E.M., Abers, G.A. (2011). Subduction factory: 4. Depthdependent flux of H2O from subducting slabs worldwide. Journal of Geophysical Research, 116. DOI: $10.1029 / 2010 J B 007922$

Vernon, R.H., Flood, R.H., D’Arcy, W.F. (1987). Sillimanite and andalusite produced by base-cation leaching and contact metamorphism of felsic igneous rocks. Journal of Metamorphic Geology, $5,439-450$.

Voegelé, V., Cordier, P., Sautter, V., Sharp, T.G., Lardeaux, J.M., Marques, F.O. (1998). Plastic deformation of silicate garnets II. Deformation microstructures in natural samples. Physics of the Earth and Planetary Interiors, 108, 319-338.

Vrijmoed, J.C., Van Roermund, H.L.M., Davies, G.R. (2006). Evidence for diamond-grade ultra-high pressure metamorphism and fluid interaction in the Svartberget Fe-Ti garnet peridotitewebsterite body, Western Gneiss Region, Norway. Mineralogy and Petrology, 88, 381-405.

Wassmann, S., Stöckhert, B., Trepmann, C.A. (2011). Dissolution precipitation creep versus crystalline plasticity in high-pressure metamorphic serpentinites. Geological Society, London, Special Publications, 360, 129-149.

Wassmann, S., Stöckhert, B. (2013a). Low stress deformation of garnet by incongruent dissolution precipitation creep. Journal of Structural Geology, 46, 200-219.

Wassmann, S., Stöckhert, B. (2013b). Rheology of the plate interface - Dissolution precipitation creep in high pressure metamorphic rocks. Tectonophysics, 608, 1-29. 
796

797

798

799

800

801

802

803

804

805

806

807

808

809

810

811

812

813

814

815

816

817

818

Weber, S., Sandmann, S., Miladinova, I., Fonseca, R.O.C., Froitzheim, N., Münker, C., Bucher, K. (2015). Dating the initiation of Piemonte-Liguria Ocean subduction: Lu-Hf garnet chronometry of eclogites from the Theodul Glacier Unit (Zermatt-Saas zone, Switzerland). Swiss Journal of Geosciences, 108, 183-199. DOI: 10.1007/s00015-015-0180-5

Whitney, D.L. (1996). Garnets as open systems during regional metamorphism. Geology, 24(2), $147-150$.

Whitney, D.L., Evans, B.W. (2010). Abbreviations for names of rock-forming minerals. American Mineralogist, 95, 185-187.

Zaffiro, G. (2020). Constraints on the Equations of State of rutile and zircon: implications for elastic geothermobarometry. PhD Thesis, Cycle XXXII, University of Pavia.

Zhang, Y. (1998). Mechanical and phase equilibria in inclusion-host systems. Earth and Planetary Science Letters, 157, 209-222.

Zhong, X., Moulas, E., Tajčmanová, L. (2020). Post-entrapment modification of residual inclusion pressure and its implications for Raman elastic thermobarometry. Solid Earth, 11, 223-240.

\section{SUPPORTING INFORMATION}

Additional Supporting Information may be found online in the supporting information tab for this article. 


\section{Table Captions}

Table 1: Overview of inclusion assemblages in garnet. An " $\mathrm{x}$ " indicates that the corresponding garnet zone is not present or indistinguishable from the core.

\section{Figure Captions}

Figure 1: Geological map of the large-scale context of the Zermatt-Saas zone in the vicinity of the Lago di Cignana unit, modified after Kirst and Leiss (2017) and references therein. The red square in the main map indicates the location of Lago di Cignana and Figure 2a.

Figure 2: (a) Geological map of the Lago di Cignana area with sample location, modified after Kirst and Leiss (2017) and references therein. (b) P-T paths determined for Lago di Cignana based on metasediments (Reinecke, 1998) and eclogite (Groppo et al., 2009). Mineral abbreviations are from Whitney and Evans (2010).

Figure 3: Outcrop photographs of the garnetite pods in quartzite. (a) Fresh cross section through quartzite with garnetite lens, displaying the complex interior of the garnetite. (b) Deformed garnetite lens exhibiting the sheared nature of these rocks. Garnetite continues as a layer of thin boudins through the exposure. (c) Stack of several garnetite bodies, indicated by white dashed lines. Solid blue lines indicate the highly folded foliation in the host rock. (d) Garnetite as occurring in eclogite from LCU. A garnet-poor, omphacite-rich rim surrounds the garnetite layers and lenses. Dashed black line indicates the inferred boundary between host rock and garnetite with rim.

Figure 4: Micrographs of $100 \mu \mathrm{m}$-thick sections of host rock and garnetite, taken with planepolarized transmitted light. (a) Overview of the section, including host rock in the top left corner. Locations for (b-d) are marked. (b) A garnet typical of those in the host rock. (c) Outer garnetite, occasionally consisting of chains of garnet separated by quartz, (d) Inner garnetite, consisting of 
"welded" garnet with numerous inclusions. (e) Euhedral garnet crystals grown over inner garnetite. (f) Quartz inclusions located inside euhedral garnet overgrowth in (e).

Figure 5: Backscattered electron (BSE) images with contrast adjusted so all minerals besides garnet are black or white and zones within garnet are highlighted. (a) Host-rock garnet exhibiting irregular boundaries between compositional zones, four of which are marked with white arrows. Brighter thin features often perpendicular to the zoning are radial veinlets. (b) Garnets in the outer garnetite garnets exhibit truncated of zones at the grain contacts, as indicated by white arrows. Garnet-garnet contacts are sealed with late-stage garnet. Note the similar BSE contrast for the outermost garnet rim, the garnet inside garnet-garnet contacts and within the radial veinlets. The large, white inclusion is rutile. (c) Garnets in the outer garnetite in part of a garnet chain, with white markers indicating truncated zones with late stage zones grown over the truncation. Black marker indicates an irregular boundary between garnet zones of different compositions. (d) Small aggregate of garnets in the outer garnetite exhibiting truncated zones, indicated by markers, alongside interlocking garnet structures. Selected grain boundaries have been marked by dashed white lines to emphasise the interlocking structure. (e) Outer garnetite with a low amount of interstitial quartz. Markers indicate a late growth of garnet along grain boundaries with a bright shade in BSE, similar in composition to radial veinlets throughout the garnets and related alteration focused in the cores. Black dashed box highlights an interlocking structure between two neighbouring garnets. (f) Mass of garnets in the inner garnetite. Several recrystallized zones by grain-boundary migration have been marked.

Figure 6: Zones of reduced grain size within the garnetite. (a) EBSD grain-boundary map with grains coloured based on surface area, overlain on the band-contrast image. Grains on the edge of the map were removed. (b) BSE image of a similar zone of reduced grain size. (c) Zoom-in of area marked in (b), in which areas of high Ti content as measured with EPMA element mapping are highlighted in red. 
Figure 7: EPMA element distribution maps for Mn (a-c), Mg (d-f) and Ti (g-i) of garnet from three different zones. The host-rock garnet maps (a, d, g) correspond to Figure 5a. Quartz and coesite inclusions as identified by Raman spectroscopy, and the transect along which garnet composition was measured (Figure 8a), are marked in (a) and (d). Based on the inclusions, the garnet has been subdivided into prograde, UHPM (peak) and retrograde zones. Irregular boundaries marking a contrast in composition are indicated with arrows. The outer garnetite zone displayed here (b, e, h) corresponds to Figure 5c. In (b) and (e), markers indicate truncated zones with late stage zones grown over the truncation. The area of inner garnetite (c, f, i) corresponds to Figure 5f. Grain boundaries as obtained by EBSD, alongside areas that were not indexed, are indicated in black. Ti map (i) appears more enriched than (g) and (h), as a result of a beam current of $100 \mathrm{nA}$ instead of the $15 \mathrm{nA}$ used for the other maps. Scale bars represent $100 \mu \mathrm{m}$.

Figure 8: Overview of garnet compositions from the host rock, outer garnetite, and inner garnetite. All EPMA measurements are given with locations in supplementary Tables S1-S7 and Figure S1. $(\mathrm{a}-\mathrm{c})$ Ternary diagrams of major-element compositional zonation by garnet type. Density of measurements is no indicator for relative volume of the corresponding composition. Zoning trends are indicated with grey arrows and are labelled in (a). The approximate composition of new growth over the truncated zones at garnet-garnet contacts in the outer garnetite is marked in (b). The area of compositions that contain coesite inclusions in the hostrock garnet has been indicated in diagrams $(b-c)$ for comparison. As calcium concentrations vary only slightly, Ca was not included in these diagrams.

Figure 9: (a) Strain diagram of quartz inclusions in garnet, comparing $\varepsilon_{1}+\varepsilon_{2}$ with $\varepsilon_{3}$. Strain states are plotted per inclusion including the $2 \sigma$ variance-covariance ellipsoid. Strain states predicted based on four segments of the LCU prograde $P$ - $T$ path have been plotted for comparison. The dashed red line indicates the strain ratio for quartz under hydrostatic stress and the green line 
represents isotropic strain. Black dashed lines indicate states of strain corresponding to the same inclusion pressure. Calculated and predicted strain values are available in the supporting information Tables S10-S11. (b) Simplified $\varepsilon_{1}+\varepsilon_{2}$ vs. $\varepsilon_{3}$ diagram indicating how the strain measured in exhumed quartz inclusions in garnet is affected by entrapment conditions.

Figure 10: (a) Schematic diagram providing a representative overview of garnet zones for the host rock, outer garnetite and inner garnetite. Garnet has been colour-coded to match the colours used in Figure $8 \mathrm{a}-\mathrm{c}$, numbers correspond to (b). The recrystallization trend has been grouped with the rt-inclusion-rich core as they generally coincide. Two situations are displayed for garnets in the outer garnetite. The top case is representative for free growth whereas the lower indicates garnet zonation at garnet-garnet contacts. Garnets in the inner garnetite are also represented by two scenarios. The top case is for garnets that are in contact and were recrystallized by GBM at grain contacts, the bottom is for garnet at the outer margin of the inner garnetite with an overgrowth of prograde garnet composition. (b) Schematic diagram of garnet growth and microstructural evolution and their relation to fluid flow. Garnet growth, microstructures, and fluid flow are indicated per developing zone of the host rock-garnetite system. Blue arrows indicate fluid flow. White can be assumed to be primarily quartz, but could have included other matrix minerals that have since dissolved. An estimated range of $P-T$ conditions is given per phase.

\section{Supporting Information Table Captions}

Table S1: EPMA measurements in wt $\%$ of transect $1 \mathrm{~L} 1$, and corresponding calculated garnet composition in atoms per formula unit. Relative molar percentages of Fe vs Mg vs Mn as plotted in Figure 8 are also given. These values are plotted in Figure 8a. See Figure S1a for the location of the measurements. 
Table S2: EPMA measurements in wt $\%$ of transect $2 \mathrm{~L} 1$, and corresponding calculated garnet composition in atoms per formula unit. Relative molar percentages of $\mathrm{Fe}$ vs $\mathrm{Mg}$ vs $\mathrm{Mn}$ as plotted in Figure 8 are also given. These values are plotted in Figure 8a. See Figure S1b for location of the measurements.

Table S3: EPMA measurements in wt $\%$ of transect $3 \mathrm{~L} 1$, and corresponding calculated garnet composition in atoms per formula unit. Relative molar percentages of Fe vs Mg vs Mn as plotted in Figure 8 are also given. These values are plotted in Figure 8b. See Figure S1c for location of the measurements.

Table S4: EPMA measurements in wt\% of transect 3L2 and point measurement 3-3, and corresponding calculated garnet composition in atoms per formula unit. Relative molar percentages of Fe vs Mg vs Mn as plotted in Figure 8 are also given. These values are plotted in Figure 8b. See Figure S1c for location of the measurements.

Table S5: EPMA measurements in wt $\%$ of transect $4 \mathrm{~L} 1$, and corresponding calculated garnet composition in atoms per formula unit. Relative molar percentages of Fe vs Mg vs Mn as plotted in Figure 8 are also given. These values are plotted in Figure 8c. See Figure S1d for location of the measurements.

Table S6: EPMA measurements in wt $\%$ of transect 5L1, and corresponding calculated garnet composition in atoms per formula unit. Relative molar percentages of Fe vs Mg vs Mn as plotted in Figure 8 are also given. These values are plotted in Figure 8c. See Figure S1e for location of the measurements.

Table S7: EPMA measurements in wt $\%$ of transect $6 \mathrm{~L} 1$, and corresponding calculated garnet composition in atoms per formula unit. Relative molar percentages of Fe vs $\mathrm{Mg}$ vs $\mathrm{Mn}$ as plotted 
in Figure 8 are also given. These values are plotted in Figure 8c. See Figure S1f for location of the measurements.

Table S8: Fitted peak positions and uncertainties for Raman spectra of inclusions and standards, given in in $\mathrm{cm}^{-1}$.

Table S9: Shifts in peak positions in Raman spectra of quartz inclusions in comparison to an unstrained standard crystal. The shift of inclusions i001 to i006 where obtained by subtracting the value of the standard "Qz_std_23_11_1433", while shifts for inclusions i007 to i021 were obtained by subtracting the average of standards "Qz_std_19_12_1007" and "Qz_std_19_12_1237". The shifts are reported together with the instrumental uncertainty $\left[0.5 \mathrm{~cm}^{-}\right.$ ${ }^{1}$ ), or the fitting uncertainties if $>0.5 \mathrm{~cm}^{-1}$.

Table S10: Calculated strains, estimated standard deviations (esd) and errors for quartz inclusions.

Table S11: $P-T$ conditions representing prograde metamorphism of Lago di Cignana, and corresponding strain estimations for quartz inclusions.

\section{Supporting Information Figure Captions}

Figure S1: BSE images including the locations of all EPMA measurements, of $(a, b)$ representative host-rock garnets, $(c)$ outer garnetite, $(\mathrm{d}, \mathrm{e})$ inner garnetite where $(\mathrm{e})$ is a close-up of the marked area in (d), and (f) euhedral overgrowth on the outer margin of the inner garnetite. 
Table 1: Overview of inclusion assemblages in garnet. An " $x$ " indicates that the corresponding garnet zone is not present or indistinguishable from the core.

$\begin{array}{lcccc}\text { Rock type } & \text { Garnet type } & \text { core } & \text { mantle } & \text { rim } \\ \text { Host rock } & \text { Rock forming } & \mathrm{Q} z, \mathrm{Rt}^{*}, \mathrm{Dol}, \mathrm{Mgs}, \mathrm{Ap}, \mathrm{Zrn} & \mathrm{Coe}, \mathrm{Ky}, \mathrm{Czo}, \mathrm{Ph}, \mathrm{Zrn} & \mathrm{Q} z \\ \text { Outer garnetite } & \text { Rock forming } & \mathrm{Q} z, \mathrm{Rt}^{*}, \mathrm{Dol}, \mathrm{Mgs}, \mathrm{Ap}, \mathrm{Zrn} & \text { none } & \text { none } \\ \text { Inner garnetite } & \text { Rock forming } & \mathrm{Qz}, \mathrm{Rt} \text {, , Dol, Mgs, Ap, Zrn } & \mathrm{x} & \mathrm{x} \\ \text { Inner garnetite } & \text { Overgrowth } & \mathrm{Qz}, \mathrm{Ap} & \mathrm{x} & \mathrm{x}\end{array}$




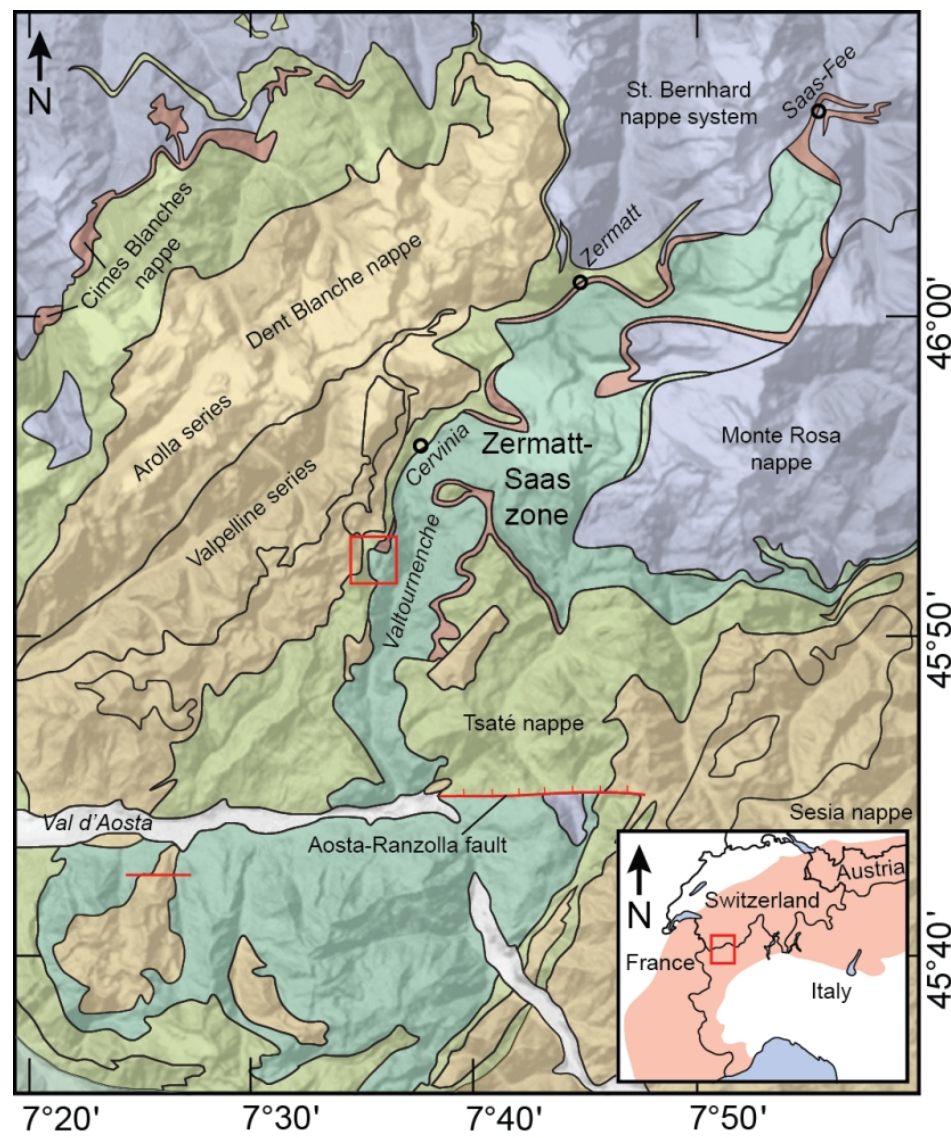
$\square$ Sesia/Dent Blanche
$\square$ Tsaté nappe
Zermatt-Saas zone
D Antrona \& Balma ophiolites
$\square$ Cimes Blanches
St. Bernard \& Monte Rosa

Figure 1: Geological map of the large-scale context of the Zermatt-Saas zone in the vicinity of the Lago di Cignana unit, modified after Kirst and Leiss (2017) and references therein. The red square in the main map indicates the location of Lago di Cignana and Figure 2a. 

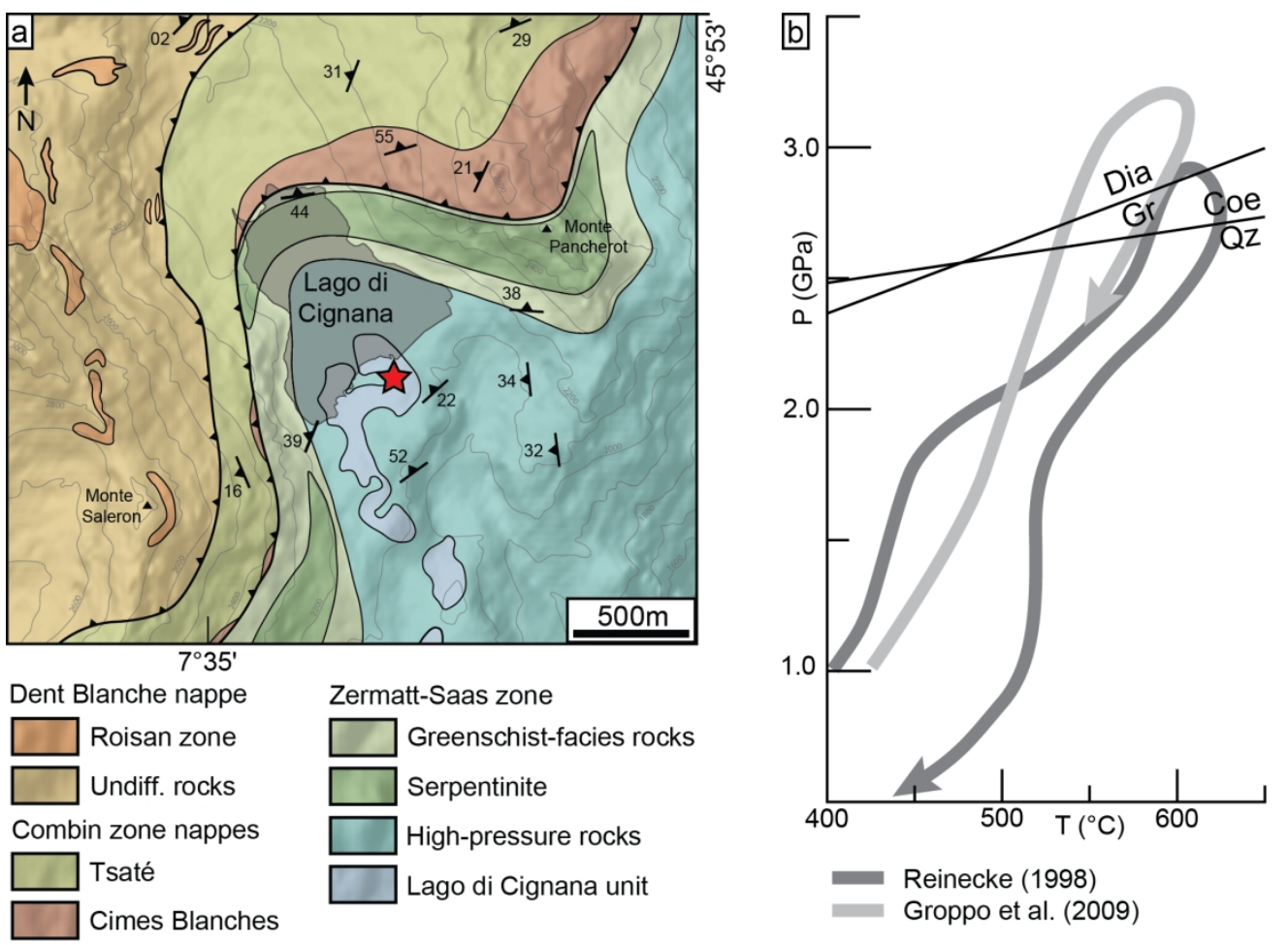

Figure 2: (a) Geological map of the Lago di Cignana area with sample location, modified after Kirst and Leiss (2017) and references therein. (b) P-T paths determined for Lago di Cignana based on metasediments (Reinecke, 1998) and eclogite (Groppo et al., 2009). Mineral abbreviations are from Whitney and Evans (2010). 

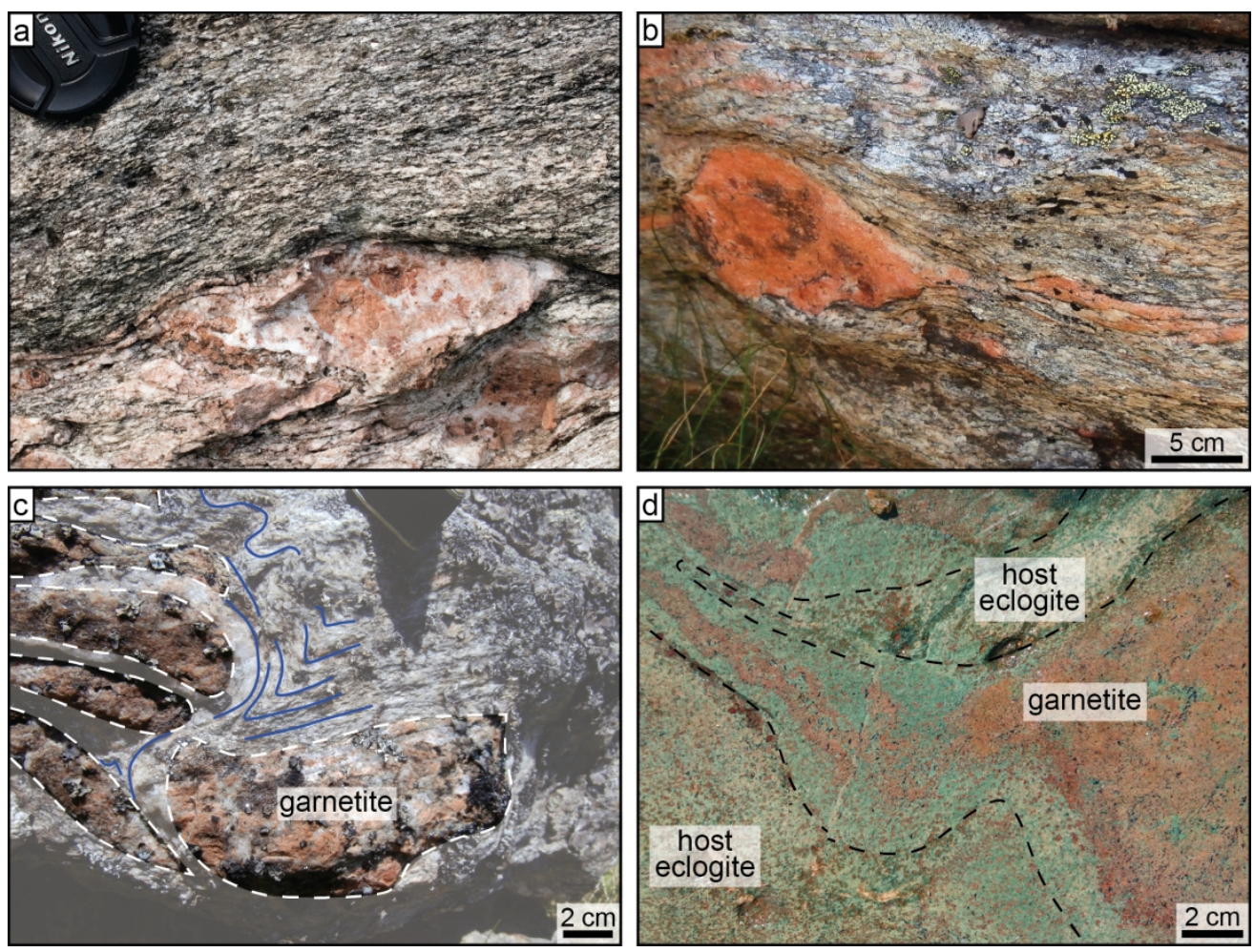

Figure 3: Outcrop photographs of the garnetite pods in quartzite. (a) Fresh cross section through quartzite with garnetite lens, displaying the complex interior of the garnetite. (b) Deformed garnetite lens exhibiting the sheared nature of these rocks. Garnetite continues as a layer of thin boudins through the exposure. (c) Stack of several garnetite bodies, indicated by white dashed lines. Solid blue lines indicate the highly folded foliation in the host rock. (d) Garnetite as occurring in eclogite from LCU. A garnet-poor, omphacite-rich rim surrounds the garnetite layers and lenses. Dashed black line indicates the inferred boundary between host rock and garnetite with rim. 

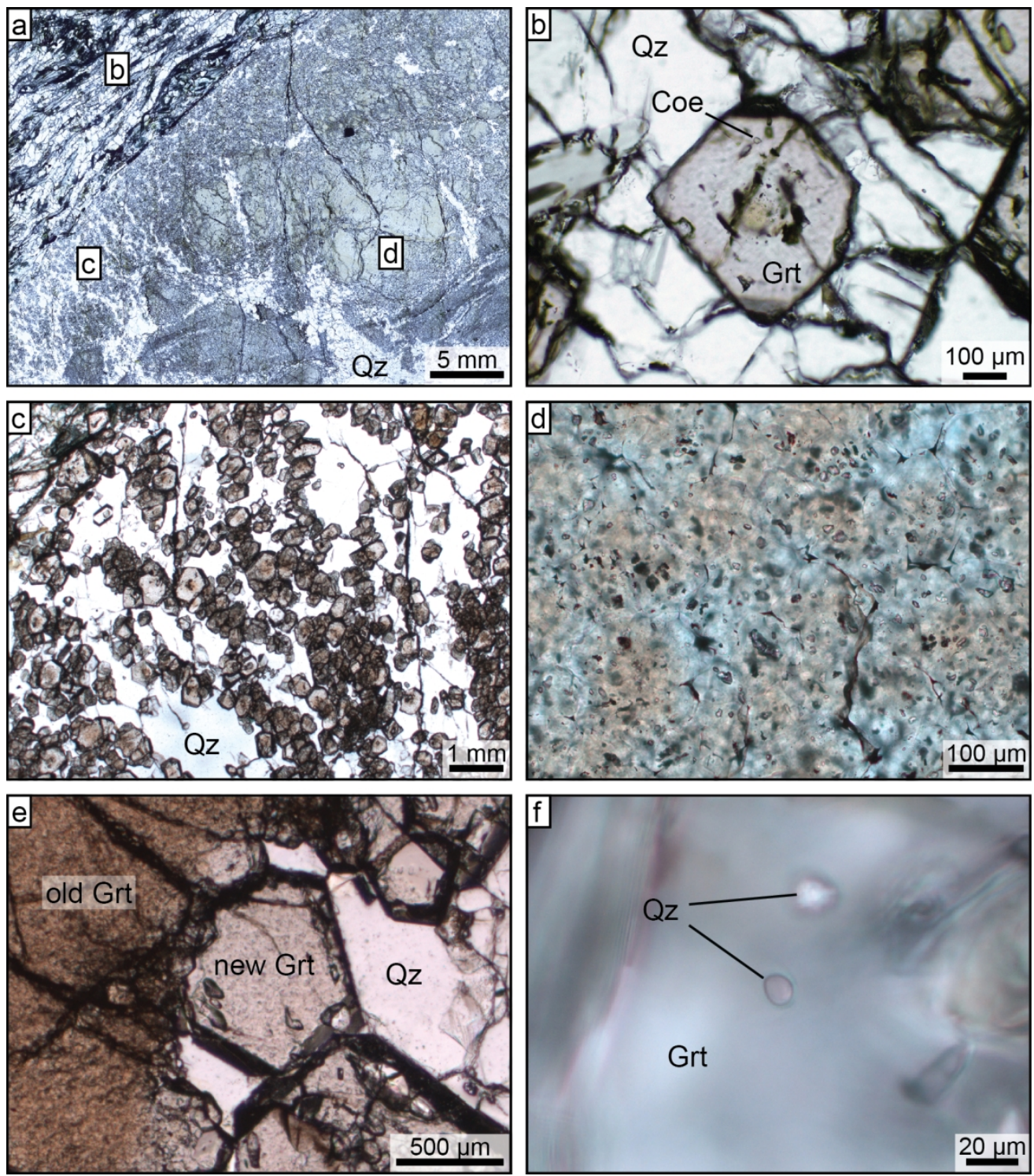

Figure 4: Micrographs of $100 \mu \mathrm{m}$-thick sections of host rock and garnetite, taken with plane-polarized transmitted light. (a) Overview of the section, including host rock in the top left corner. Locations for (b-d) are marked. (b) A garnet typical of those in the host rock. (c) Outer garnetite, occasionally consisting of chains of garnet separated by quartz, (d) Inner garnetite, consisting of "welded" garnet with numerous inclusions. (e) Euhedral garnet crystals grown over inner garnetite. (f) Quartz inclusions located inside euhedral garnet overgrowth in (e). 

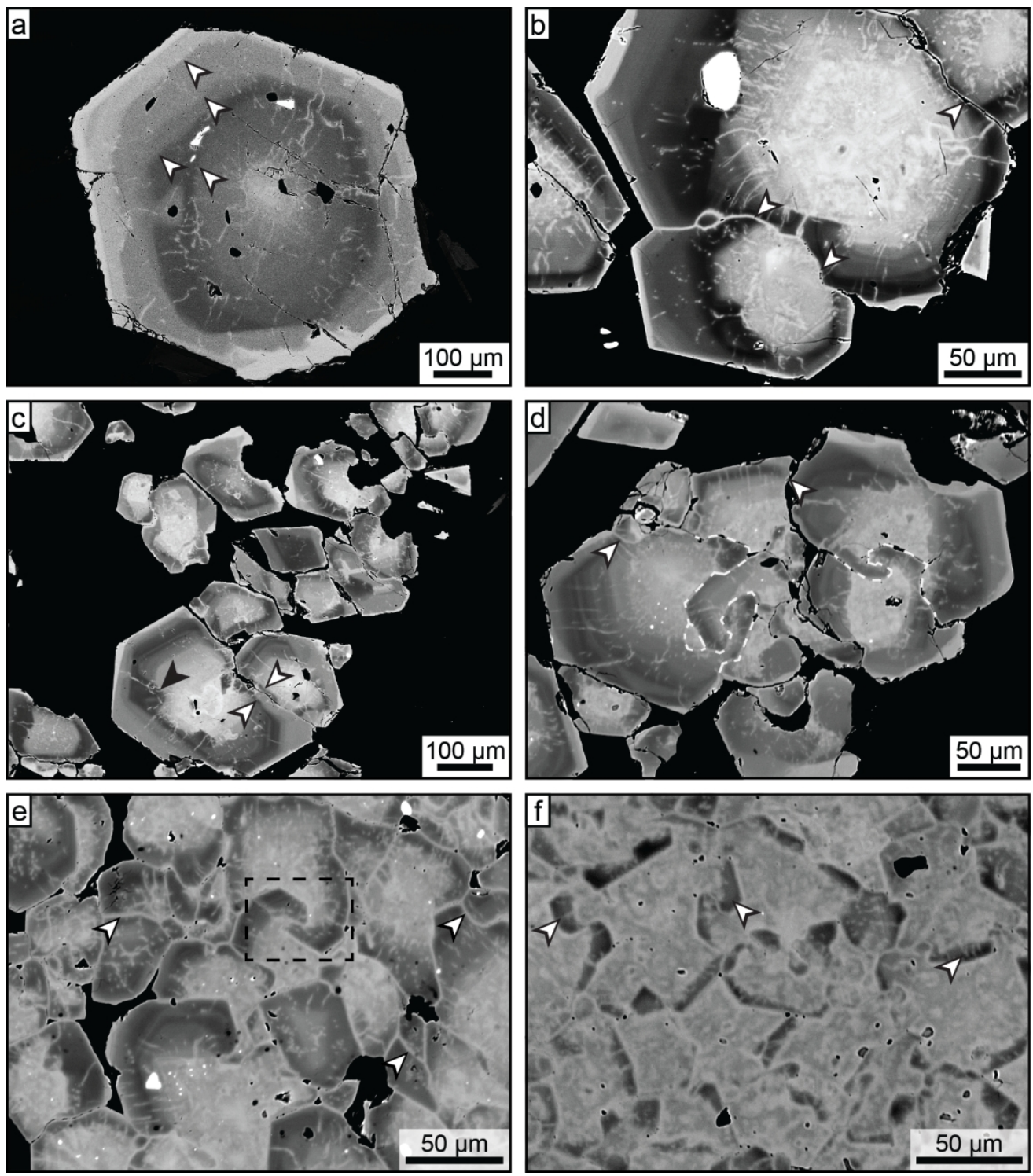

Figure 5: Backscattered electron (BSE) images with contrast adjusted so all minerals besides garnet are black or white and zones within garnet are highlighted. (a) Host-rock garnet exhibiting irregular boundaries between compositional zones, four of which are marked with white arrows. Brighter thin features often perpendicular to the zoning are radial veinlets. (b) Garnets in the outer garnetite garnets exhibit truncated of zones at the grain contacts, as indicated by white arrows. Garnet-garnet contacts are sealed with latestage garnet. Note the similar BSE contrast for the outermost garnet rim, the garnet inside garnet-garnet contacts and within the radial veinlets. The large, white inclusion is rutile. (c) Garnets in the outer garnetite in part of a garnet chain, with white markers indicating truncated zones with late stage zones grown over

the truncation. Black marker indicates an irregular boundary between garnet zones of different compositions. (d) Small aggregate of garnets in the outer garnetite exhibiting truncated zones, indicated by markers, alongside interlocking garnet structures. Selected grain boundaries have been marked by dashed

white lines to emphasise the interlocking structure. (e) Outer garnetite with a low amount of interstitial quartz. Markers indicate a late growth of garnet along grain boundaries with a bright shade in BSE, similar in composition to radial veinlets throughout the garnets and related alteration focused in the cores. Black dashed box highlights an interlocking structure between two neighbouring garnets. (f) Mass of garnets in the inner garnetite. Several recrystallized zones by grain-boundary migration have been marked. 
Page 44 of 75 

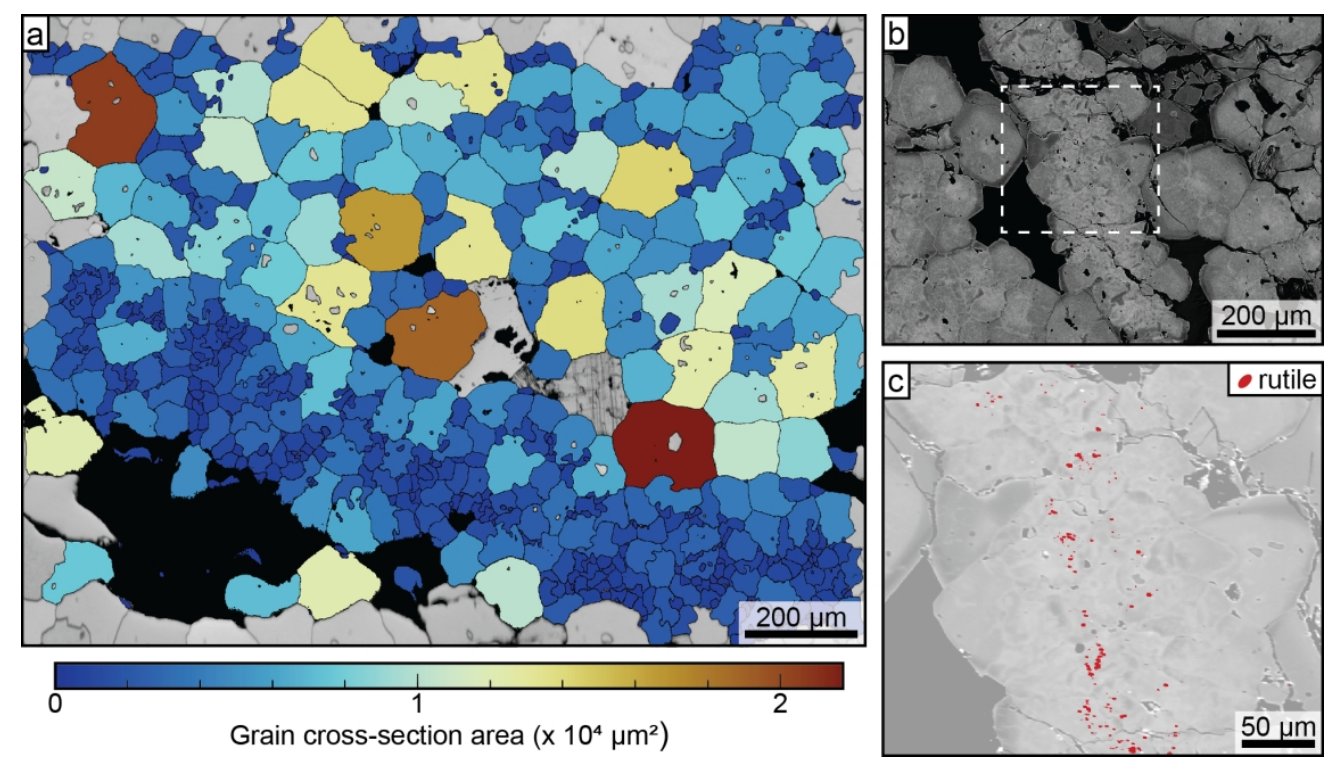

Figure 6: Zones of reduced grain size within the garnetite. (a) EBSD grain-boundary map with grains coloured based on surface area, overlain on the band-contrast image. Grains on the edge of the map were removed. (b) BSE image of a similar zone of reduced grain size. (c) Zoom-in of area marked in (b), in which areas of high Ti content as measured with EPMA element mapping are highlighted in red. 

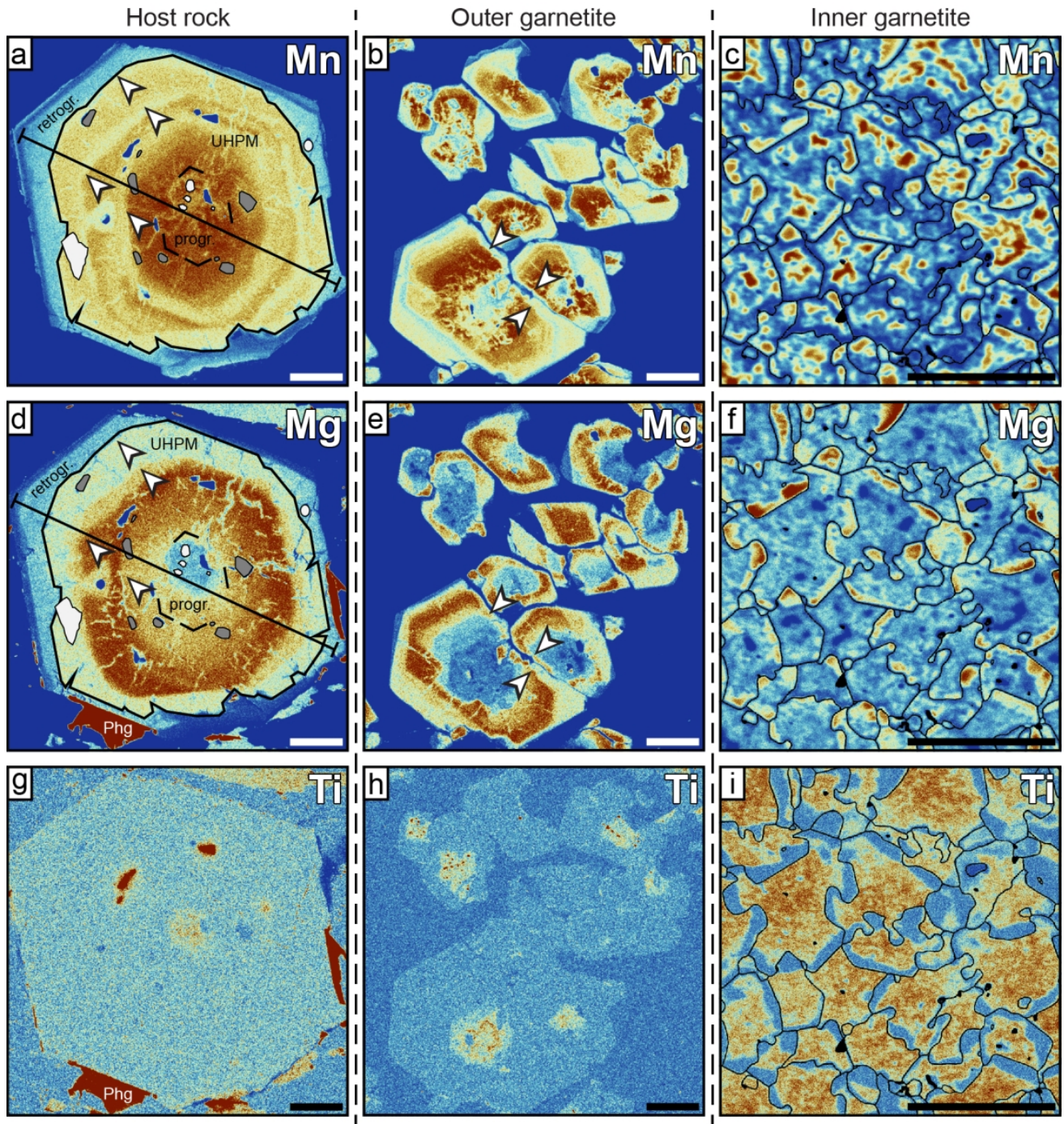

Element signal in garnet:

Min

$\operatorname{Max}$

Figure 7: EPMA element distribution maps for $M n(a-c), M g(d-f)$ and $\mathrm{Ti}(g-i)$ of garnet from three different zones. The host-rock garnet maps $(\mathrm{a}, \mathrm{d}, \mathrm{g})$ correspond to Figure 5a. Quartz and coesite inclusions as identified by Raman spectroscopy, and the transect along which garnet composition was measured (Figure $8 a)$, are marked in (a) and (d). Based on the inclusions, the garnet has been subdivided into prograde, UHPM (peak) and retrograde zones. Irregular boundaries marking a contrast in composition are indicated with arrows. The outer garnetite zone displayed here (b, e, h) corresponds to Figure 5c. In (b) and (e),

markers indicate truncated zones with late stage zones grown over the truncation. The area of inner garnetite $(c, f, i)$ corresponds to Figure $5 f$. Grain boundaries as obtained by EBSD, alongside areas that were not indexed, are indicated in black. Ti map (i) appears more enriched than $(\mathrm{g})$ and $(\mathrm{h})$, as a result of a beam current of $100 \mathrm{nA}$ instead of the $15 \mathrm{nA}$ used for the other maps. Scale bars represent $100 \mu \mathrm{m}$. 


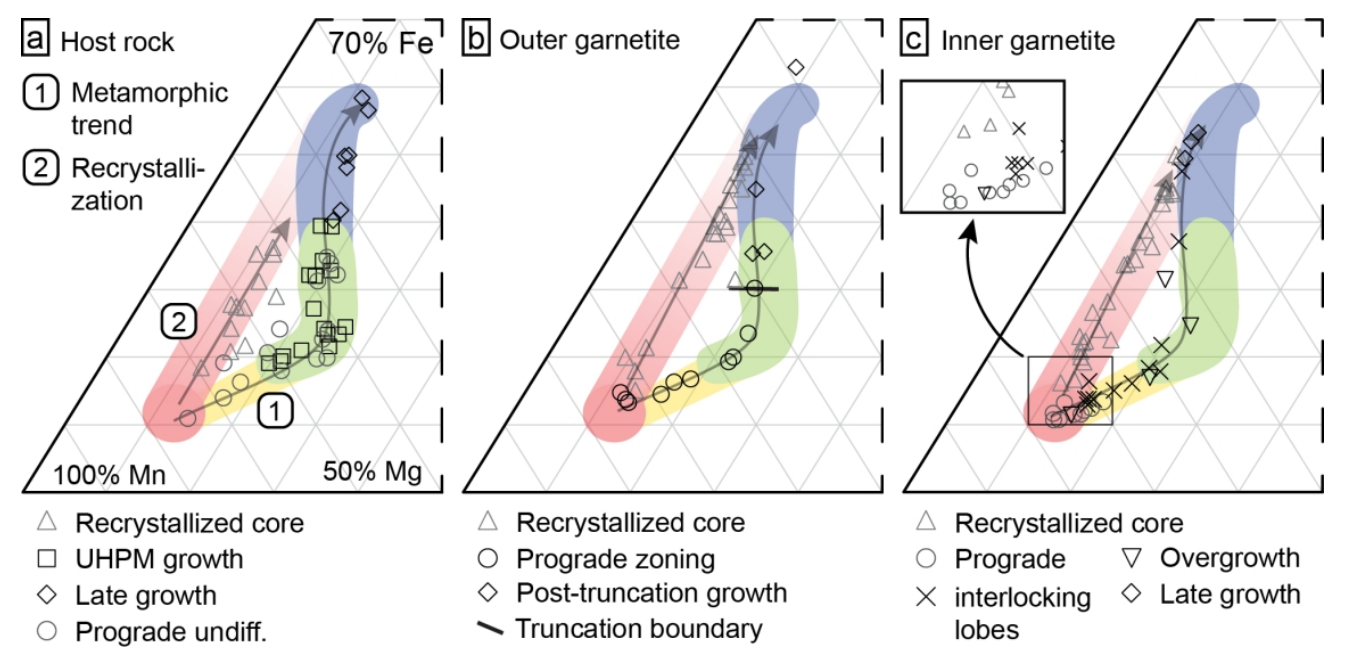

Figure 8: Overview of garnet compositions from the host rock, outer garnetite, and inner garnetite. All EPMA measurements are given with locations in supplementary Tables S1-S7 and Figure S1. (a-c) Ternary diagrams of major-element compositional zonation by garnet type. Density of measurements is no indicator for relative volume of the corresponding composition. Zoning trends are indicated with grey arrows and are labelled in (a). The approximate composition of new growth over the truncated zones at garnet-garnet contacts in the outer garnetite is marked in (b). The area of compositions that contain coesite inclusions in the host-rock garnet has been indicated in diagrams $(b-c)$ for comparison. As calcium concentrations vary only slightly, Ca was not included in these diagrams. 


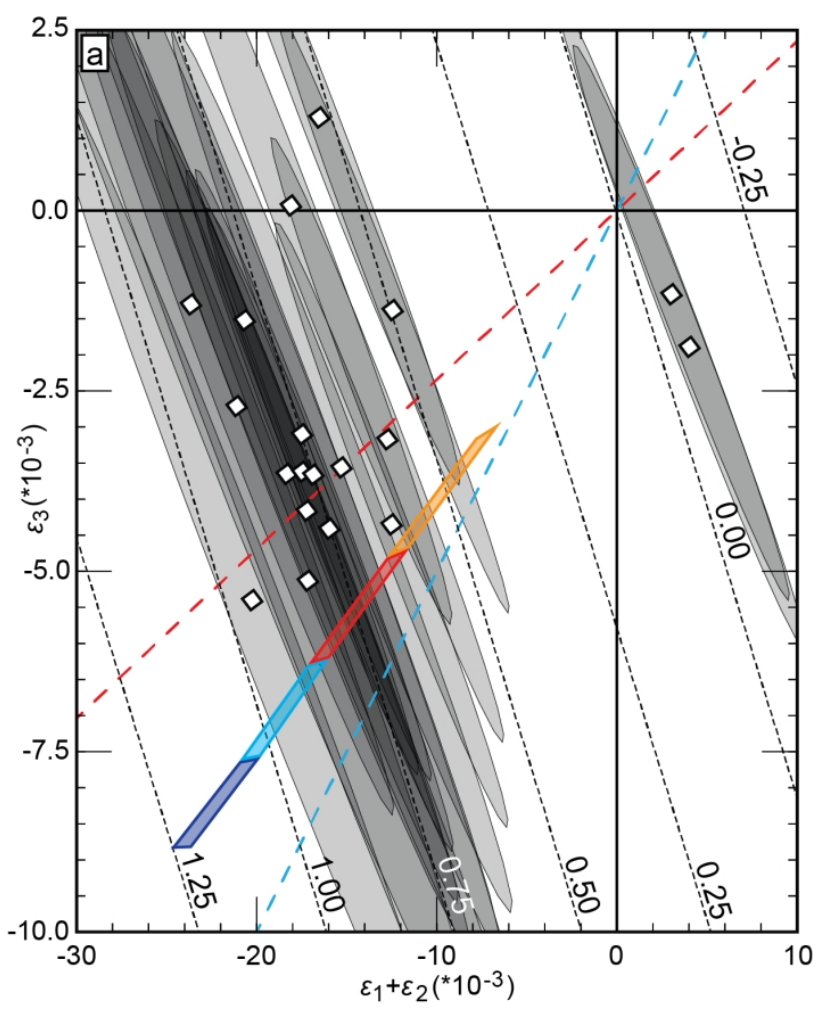

Prograde P-T range:
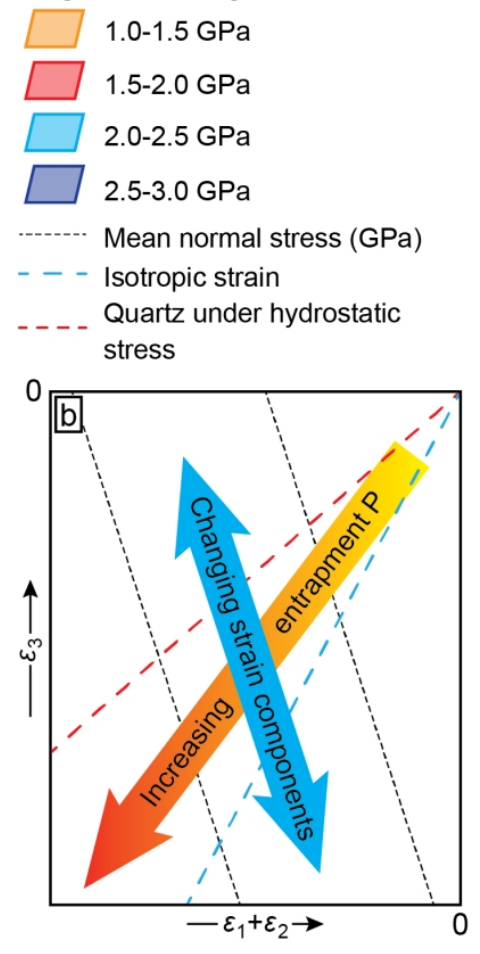

Figure 9: (a) Strain diagram of quartz inclusions in garnet, comparing $\varepsilon 1+\varepsilon 2$ with $\varepsilon 3$. Strain states are plotted per inclusion including the $2 \sigma$ variance-covariance ellipsoid. Strain states predicted based on four segments of the LCU prograde P-T path have been plotted for comparison. The dashed red line indicates the strain ratio for quartz under hydrostatic stress and the green line represents isotropic strain. Black dashed lines indicate states of strain corresponding to the same inclusion pressure. Calculated and predicted strain values are available in the supporting information Tables S10-S11. (b) Simplified $\varepsilon 1+\varepsilon 2$ vs. $\varepsilon 3$ diagram indicating how the strain measured in exhumed quartz inclusions in garnet is affected by entrapment conditions. 

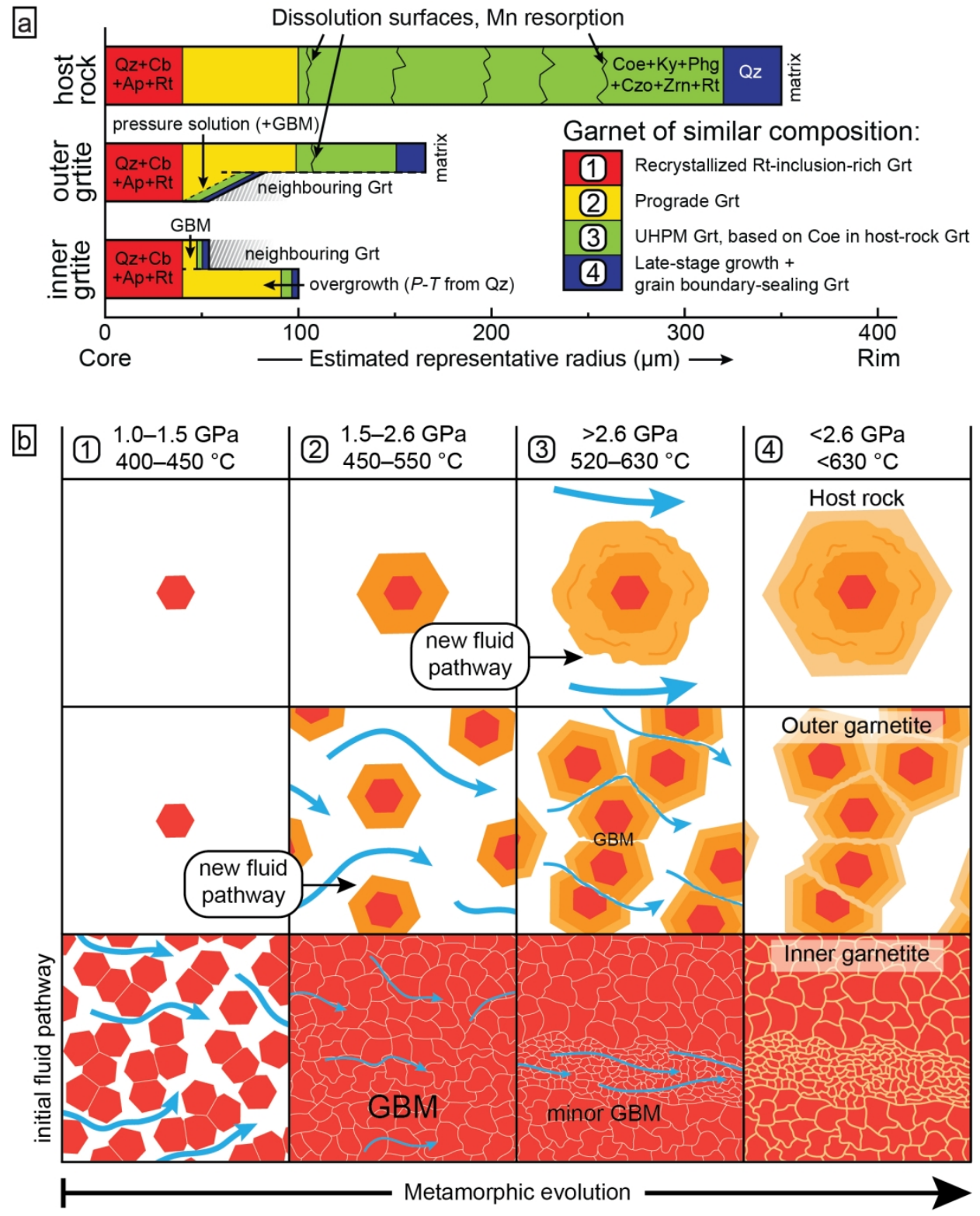

Figure 10: (a) Schematic diagram providing a representative overview of garnet zones for the host rock, outer garnetite and inner garnetite. Garnet has been colour-coded to match the colours used in Figure 8a-c, numbers correspond to (b). The recrystallization trend has been grouped with the rt-inclusion-rich core as

they generally coincide. Two situations are displayed for garnets in the outer garnetite. The top case is representative for free growth whereas the lower indicates garnet zonation at garnet-garnet contacts. Garnets in the inner garnetite are also represented by two scenarios. The top case is for garnets that are in contact and were recrystallized by GBM at grain contacts, the bottom is for garnet at the outer margin of the inner garnetite with an overgrowth of prograde garnet composition. (b) Schematic diagram of garnet growth and microstructural evolution and their relation to fluid flow. Garnet growth, microstructures, and fluid flow are indicated per developing zone of the host rock-garnetite system. Blue arrows indicate fluid flow. White can be assumed to be primarily quartz, but could have included other matrix minerals that have since dissolved. An estimated range of P-T conditions is given per phase. 
Table S1: EPMA measurements in wt\% of transect 1L1, and corresponding calculated garnet compositio $1 \mathrm{~L} 1$

$$
1
$$

$$
2
$$

$$
3
$$

5

$$
6
$$

\begin{tabular}{|c|c|c|c|c|c|c|c|c|}
\hline $\mathrm{SiO} 2$ & 38.96 & 38.9 & 38.71 & 39.26 & 39.53 & 39.53 & 39 & 39.14 \\
\hline TiO2 & 0.0242 & 0 & 0 & 0.0189 & 0.0175 & 0.0271 & 0.0256 & 0.0215 \\
\hline $\mathrm{Al} 2 \mathrm{O} 3$ & 21.63 & 22.07 & 21.81 & 21.52 & 21.8 & 21.83 & 21.83 & 22.08 \\
\hline $\mathrm{Cr} 2 \mathrm{O} 3$ & 0 & 0 & 0.0474 & 0 & 0.055 & 0 & 0 & 0.0167 \\
\hline $\mathrm{FeOx}$ & 18.99 & 15.38 & 15.69 & 13.1 & 13.94 & 10.15 & 10.07 & 8.66 \\
\hline $\mathrm{MgO}$ & 3.28 & 3.85 & 3.51 & 4.43 & 4.14 & 5.85 & 5.33 & 5.15 \\
\hline $\mathrm{MnO}$ & 14.69 & 17.1 & 17.43 & 17.86 & 18.35 & 19.25 & 20.38 & 22.34 \\
\hline $\mathrm{CaO}$ & 4.87 & 5.09 & 5.25 & 6.16 & 5.83 & 5.83 & 5.39 & 5.15 \\
\hline $\mathrm{Na} 2 \mathrm{O}$ & 0.0154 & 0 & 0.0035 & 0.0171 & 0 & 0.0229 & 0 & 0.016 \\
\hline K2O & 0.0006 & 0 & 0.005 & 0.0138 & 0 & 0 & 0.0068 & \\
\hline Total: & 102.46 & 102.39 & 102.46 & 102.38 & 103.66 & 102.49 & 102.03 & 102.57 \\
\hline $\mathrm{O}$ & 12 & 12 & 12 & 12 & 12 & 12 & 12 & \\
\hline $\mathrm{SiO} 2$ & 3.023 & 3.004 & 3.000 & 3.021 & 3.014 & 3.009 & 2.995 & 2.994 \\
\hline TiO2 & 0.001 & 0 & 0 & 0.001 & 0.001 & 0.002 & 0.001 & 0.001 \\
\hline $\mathrm{Al} 2 \mathrm{O} 3$ & 1.979 & 2.010 & 1.993 & 1.952 & 1.960 & 1.959 & 1.976 & 1.991 \\
\hline $\mathrm{Cr} 2 \mathrm{O} 3$ & 0 & 0 & 0.003 & 0 & 0.003 & 0 & 0 & 0.001 \\
\hline $\mathrm{Fe} 2 \mathrm{O} 3$ & 0 & 0 & 0.005 & 0.008 & 0.006 & 0.022 & 0.032 & 0.019 \\
\hline $\mathrm{FeO}$ & 1.232 & 0.993 & 1.013 & 0.835 & 0.883 & 0.624 & 0.615 & 0.535 \\
\hline $\mathrm{MnO}$ & 0.966 & 1.119 & 1.144 & 1.164 & 1.185 & 1.241 & 1.326 & 1.447 \\
\hline $\mathrm{MgO}$ & 0.379 & 0.443 & 0.405 & 0.508 & 0.471 & 0.664 & 0.610 & 0.587 \\
\hline $\mathrm{CaO}$ & 0.405 & 0.421 & 0.436 & 0.508 & 0.476 & 0.476 & 0.444 & 0.422 \\
\hline $\mathrm{Na} 2 \mathrm{O}$ & 0.002 & 0 & 0.001 & 0.003 & 0 & 0.003 & 0 & 0.002 \\
\hline K2O & 0.000 & 0 & 0.000 & 0.001 & 0 & 0 & 0.001 & \\
\hline Totals & 7.987 & 7.991 & 8.000 & 8.000 & 8.000 & 8.000 & 8.000 & 8.00 \\
\hline FeO rec. & 1.250 & 1.017 & 1.014 & 0.820 & 0.868 & 0.619 & 0.621 & 0.54 \\
\hline $\mathrm{Fe}$ & $48.18 \%$ & $39.43 \%$ & $39.56 \%$ & $32.91 \%$ & $34.39 \%$ & $24.54 \%$ & $24.28 \%$ & $21.08 \%$ \\
\hline $\mathrm{Mg}$ & $14.62 \%$ & $17.19 \%$ & $15.81 \%$ & $20.38 \%$ & $18.64 \%$ & $26.29 \%$ & $23.86 \%$ & $22.77 \%$ \\
\hline Mn & $37.20 \%$ & $43.38 \%$ & $44.63 \%$ & $46.70 \%$ & $46.97 \%$ & $49.17 \%$ & $51.86 \%$ & $56.15^{\circ}$ \\
\hline
\end{tabular}$$
7
$$ 
In in atoms per formula unit. Relative molar percentages of Fe vs $\mathrm{Mg}$ vs $\mathrm{Mn}$ as plotted in Figure 8 are alsı

9

10

11

12

13

14

15

16

17

\begin{tabular}{|c|c|c|c|c|c|c|c|c|}
\hline 39.26 & 38.92 & 38.82 & 38.77 & 38.62 & 38.57 & 38.94 & 39.11 & 39.21 \\
\hline 0 & 0.0214 & 0.0414 & 0.1432 & 0.119 & 0 & 0.0456 & 0.094 & 0 \\
\hline 21.83 & 21.6 & 21.65 & 20.93 & 21.5 & 21.75 & 21.73 & 21.9 & 22.04 \\
\hline 0.028 & 0.037 & 0.0039 & 0 & 0 & 0.0328 & 0 & 0.0124 & 0 \\
\hline 8.32 & 10.18 & 9.22 & 8.71 & 11.79 & 8.88 & 8.02 & 8.34 & 10.75 \\
\hline 4.81 & 4.36 & 3.64 & 3.15 & 3.57 & 4.35 & 4.5 & 4.75 & 4.74 \\
\hline 23.8 & 23.61 & 25.29 & 24.63 & 21.83 & 24.47 & 24.33 & 23.35 & 20.35 \\
\hline 4.99 & 3.52 & 4.41 & 6 & 4.9 & 4.15 & 4.82 & 5.15 & 5.33 \\
\hline 0.0335 & 0.0147 & 0.0081 & 0 & 0.0229 & 0.0158 & 0.0574 & 0.0454 & 0.0328 \\
\hline 0.0049 & 0 & 0 & 0 & 0 & 0 & 0 & 0.0018 & 0.0021 \\
\hline 103.08 & 102.26 & 103.08 & 102.33 & 102.35 & 102.22 & 102.44 & 102.75 & 102.45 \\
\hline 12 & 12 & 12 & 12 & 12 & 12 & 12 & 12 & 12 \\
\hline 2.999 & 3.015 & 2.996 & 3.017 & 2.999 & 2.985 & 2.999 & 2.996 & 3.008 \\
\hline 0 & 0.001 & 0.002 & 0.008 & 0.007 & 0 & 0.003 & 0.005 & 0 \\
\hline 1.966 & 1.973 & 1.970 & 1.920 & 1.968 & 1.985 & 1.973 & 1.978 & 1.993 \\
\hline 0.002 & 0.002 & 0.000 & 0 & 0 & 0.002 & 0 & 0.001 & 0 \\
\hline 0.038 & 0 & 0.035 & 0.029 & 0.023 & 0.045 & 0.032 & 0.026 & 0 \\
\hline 0.493 & 0.660 & 0.560 & 0.537 & 0.743 & 0.530 & 0.484 & 0.509 & 0.690 \\
\hline 1.540 & 1.549 & 1.653 & 1.623 & 1.436 & 1.604 & 1.587 & 1.515 & 1.322 \\
\hline 0.548 & 0.503 & 0.419 & 0.365 & 0.413 & 0.502 & 0.516 & 0.542 & 0.542 \\
\hline 0.408 & 0.292 & 0.365 & 0.500 & 0.408 & 0.344 & 0.398 & 0.423 & 0.438 \\
\hline 0.005 & 0.002 & 0.001 & 0 & 0.003 & 0.002 & 0.009 & 0.007 & 0.005 \\
\hline 0.000 & 0 & 0 & 0 & 0 & 0 & 0 & 0.000 & 0.000 \\
\hline 8.000 & 7.997 & 8.000 & 8.000 & 8.000 & 8.000 & 8.000 & 8.000 & 7.998 \\
\hline 0.504 & 0.655 & 0.564 & 0.511 & 0.743 & 0.550 & 0.499 & 0.520 & 0.698 \\
\hline $19.44 \%$ & $24.20 \%$ & $21.39 \%$ & $20.45 \%$ & $28.67 \%$ & $20.70 \%$ & $19.17 \%$ & $20.18 \%$ & $27.23 \%$ \\
\hline $21.13 \%$ & $18.59 \%$ & $15.88 \%$ & $14.61 \%$ & $15.94 \%$ & $18.89 \%$ & $19.85 \%$ & $21.04 \%$ & $21.15 \%$ \\
\hline $59.43 \%$ & $57.21 \%$ & $62.72 \%$ & $64.94 \%$ & $55.39 \%$ & $60.41 \%$ & $60.99 \%$ & $58.78 \%$ & $51.61 \%$ \\
\hline
\end{tabular}


o given. These values are plotted in Figure 8a. See Figure S1a for the location of the measurements.

18

19

20

21

22

23

24

25

\begin{tabular}{|c|c|c|c|c|c|c|c|}
\hline 39.48 & 39.2 & 39.49 & 38.77 & 38.87 & 38.57 & 38.52 & 38.2 \\
\hline 0 & 0.0433 & 0.0149 & 0.0175 & 0.0175 & 0 & 0.063 & 0.0188 \\
\hline 21.93 & 21.99 & 22.09 & 21.83 & 22.02 & 21.71 & 21.72 & 21.81 \\
\hline 0 & 0.0074 & 0 & 0.0581 & 0.0138 & 0.0508 & 0 & \\
\hline 9.39 & 9.18 & 9.44 & 12.68 & 12.52 & 19.83 & 19.9 & 22.69 \\
\hline 5.73 & 5.68 & 5.49 & 4.11 & 3.96 & 3.02 & 3.12 & 2.46 \\
\hline 19.59 & 20.38 & 20.26 & 18.73 & 19.11 & 14.38 & 14.19 & 11.6 \\
\hline 6.05 & 6.2 & 5.96 & 6.08 & 5.92 & 4.89 & 4.8 & 5.4 \\
\hline 0.0128 & 0.0371 & 0.0525 & 0.0013 & 0.0391 & 0.0412 & 0.0343 & 0.0442 \\
\hline 0 & 0 & 0 & 0.0102 & 0 & 0 & 0 & \\
\hline 102.18 & 102.72 & 102.80 & 102.29 & 102.47 & 102.49 & 102.35 & 102.22 \\
\hline 12 & 12 & 12 & 12 & 12 & 12 & 12 & 12 \\
\hline 3.013 & 2.979 & 3.001 & 2.991 & 2.995 & 3.002 & 3.001 & 2.988 \\
\hline 0 & 0.002 & 0.001 & 0.001 & 0.001 & 0 & 0.004 & 0.001 \\
\hline 1.973 & 1.970 & 1.979 & 1.985 & 2.000 & 1.992 & 1.995 & 2.011 \\
\hline 0 & 0.000 & 0 & 0.004 & 0.001 & 0.003 & 0 & \\
\hline 0.003 & 0.073 & 0.025 & 0.029 & 0.013 & 0.007 & 0.002 & 0.016 \\
\hline 0.596 & 0.510 & 0.575 & 0.789 & 0.794 & 1.284 & 1.295 & 1.468 \\
\hline 1.266 & 1.312 & 1.304 & 1.224 & 1.247 & 0.948 & 0.936 & 0.769 \\
\hline 0.652 & 0.643 & 0.622 & 0.473 & 0.455 & 0.350 & 0.362 & 0.287 \\
\hline 0.495 & 0.505 & 0.485 & 0.503 & 0.489 & 0.408 & 0.401 & 0.453 \\
\hline 0.002 & 0.005 & 0.008 & 0.000 & 0.006 & 0.006 & 0.005 & 0.007 \\
\hline 0 & 0 & 0 & 0.001 & 0 & 0 & 0 & \\
\hline 8.000 & 8.000 & 8.000 & 8.000 & 8.000 & 8.000 & 8.000 & 8.000 \\
\hline 0.587 & 0.540 & 0.589 & 0.801 & 0.809 & 1.294 & 1.301 & 1.492 \\
\hline $3.44 \%$ & $21.65 \%$ & $23.41 \%$ & $32.07 \%$ & $32.23 \%$ & $49.91 \%$ & $50.04 \%$ & $58.57 \%$ \\
\hline $26.01 \%$ & $25.78 \%$ & $24.73 \%$ & $18.92 \%$ & $18.11 \%$ & $13.51 \%$ & $13.93 \%$ & $11.26 \%$ \\
\hline $50.55 \%$ & $52.57 \%$ & $51.86 \%$ & $49.01 \%$ & $49.66 \%$ & $36.57 \%$ & $36.02 \%$ & $30.17 \%$ \\
\hline
\end{tabular}


Table S2: EPMA measurements in wt\% of transect 2L1, and corresponding calculated garnet compositio $2 \mathrm{~L} 1$

$$
1
$$

$$
2
$$

$$
3
$$

$$
4
$$

5

\begin{tabular}{|c|c|c|c|c|c|c|c|c|}
\hline $\mathrm{SiO} 2$ & 38.27 & 38.51 & 39.02 & 39.19 & 39.33 & 39.57 & 39.32 & 39.41 \\
\hline TiO2 & 0 & 0.0148 & 0.0364 & 0 & 0.0135 & 0 & 0.0553 & 0.0216 \\
\hline $\mathrm{Al} 2 \mathrm{O} 3$ & 21.35 & 21.82 & 21.85 & 21.95 & 21.97 & 22.04 & 21.91 & 21.56 \\
\hline $\mathrm{Cr} 2 \mathrm{O} 3$ & 0 & 0.0358 & 0 & 0.0227 & 0 & 0 & 0 & \\
\hline $\mathrm{FeOx}$ & 22.91 & 16.23 & 13.23 & 9.96 & 8.25 & 8.25 & 9.09 & 7.4 \\
\hline $\mathrm{MgO}$ & 1.84 & 3.74 & 4.73 & 5.4 & 5.84 & 5.65 & 5.41 & 4.82 \\
\hline $\mathrm{MnO}$ & 12.49 & 16.67 & 18.02 & 20.01 & 20.92 & 21.7 & 20.55 & 23.29 \\
\hline $\mathrm{CaO}$ & 5.23 & 5.4 & 5.87 & 6.1 & 5.93 & 5.73 & 5.89 & 5.88 \\
\hline $\mathrm{Na} 2 \mathrm{O}$ & 0 & 0.0617 & 0.0612 & 0.0655 & 0.0059 & 0.0136 & 0.0273 & \\
\hline K2O & 0 & 0 & 0 & 0.0032 & 0 & 0 & 0 & \\
\hline Total: & 102.09 & 102.48 & 102.82 & 102.70 & 102.26 & 102.95 & 102.25 & 102.47 \\
\hline O & 12 & 12 & 12 & 12 & 12 & 12 & 12 & 12 \\
\hline $\mathrm{SiO} 2$ & 3.014 & 2.978 & 2.985 & 2.984 & 2.998 & 3.003 & 3.006 & 3.022 \\
\hline TiO2 & 0 & 0.001 & 0.002 & 0 & 0.001 & 0 & 0.003 & 0.001 \\
\hline $\mathrm{Al} 2 \mathrm{O} 3$ & 1.982 & 1.990 & 1.970 & 1.970 & 1.975 & 1.972 & 1.975 & 1.949 \\
\hline $\mathrm{Cr} 2 \mathrm{O} 3$ & 0 & 0.002 & 0 & 0.001 & 0 & 0 & 0 & \\
\hline $\mathrm{Fe} 2 \mathrm{O} 3$ & 0 & 0.058 & 0.066 & 0.070 & 0.029 & 0.025 & 0.010 & 0.003 \\
\hline $\mathrm{FeO}$ & 1.509 & 0.992 & 0.780 & 0.564 & 0.497 & 0.498 & 0.572 & 0.477 \\
\hline $\mathrm{MnO}$ & 0.833 & 1.092 & 1.167 & 1.290 & 1.351 & 1.395 & 1.331 & 1.513 \\
\hline $\mathrm{MgO}$ & 0.216 & 0.431 & 0.539 & 0.613 & 0.664 & 0.639 & 0.616 & 0.551 \\
\hline $\mathrm{CaO}$ & 0.441 & 0.447 & 0.481 & 0.498 & 0.484 & 0.466 & 0.483 & 0.483 \\
\hline $\mathrm{Na} 2 \mathrm{O}$ & 0 & 0.009 & 0.009 & 0.010 & 0.001 & 0.002 & 0.004 & \\
\hline $\mathrm{K} 2 \mathrm{O}$ & 0 & 0 & 0 & 0.000 & 0 & 0 & 0 & \\
\hline Totals & 7.995 & 8.000 & 8.000 & 8.000 & 8.000 & 8.000 & 8.000 & 8.000 \\
\hline FeO rec. & 1.510 & 1.029 & 0.812 & 0.599 & 0.501 & 0.500 & 0.570 & 0.45 \\
\hline $\mathrm{Fe}$ & $59.00 \%$ & $40.33 \%$ & $32.25 \%$ & $23.94 \%$ & $19.92 \%$ & $19.74 \%$ & $22.64 \%$ & $18.00 \%$ \\
\hline $\mathrm{Mg}$ & $8.44 \%$ & $16.89 \%$ & $21.40 \%$ & $24.49 \%$ & $26.38 \%$ & $25.21 \%$ & $24.49 \%$ & $21.89 \%$ \\
\hline $\mathrm{Mn}$ & $32.56 \%$ & $42.78 \%$ & $46.35 \%$ & $51.57 \%$ & $53.70 \%$ & $55.04 \%$ & $52.87 \%$ & $60.11 \%$ \\
\hline
\end{tabular}

$$
6
$$

$$
7
$$


In in atoms per formula unit. Relative molar percentages of Fe vs $\mathrm{Mg}$ vs $\mathrm{Mn}$ as plotted in Figure 8 are alsi

9

10

11

12

13

14

15

16

17

$\begin{array}{rrrrrrrrr}38.57 & 39.08 & 38.85 & 38.84 & 38.39 & 38.21 & 38.16 & 38.15 & 38.47 \\ 0.0227 & 0.0373 & 0.0254 & 0.0518 & 0.0611 & 0.1144 & 0.0775 & 0.0961 & 0.1066 \\ 21.6 & 21.53 & 21.7 & 21.55 & 21.65 & 21.42 & 20.98 & 20.86 & 20.78 \\ 0 & 0 & 0.0597 & 0.0146 & 0.0261 & 0 & 0.0136 & 0 & 0 \\ 6.11 & 4.67 & 12.33 & 9.96 & 7.48 & 11.37 & 11.03 & 14.56 & 11.82 \\ 3.75 & 3.18 & 2.84 & 2.97 & 2.76 & 2.94 & 2.57 & 2.26 & 2.41 \\ 26.84 & 29.36 & 22.04 & 25.54 & 27.54 & 23.82 & 23.03 & 20.74 & 23.33 \\ 5.48 & 5.26 & 5.31 & 4.2 & 4.76 & 4.46 & 5.77 & 5.75 & 5.89 \\ 0.035 & 0.0095 & 0.0497 & 0.0709 & 0.0311 & 0 & 0.0408 & 0.0291 & 0.0209 \\ 0.0021 & 0 & 0.0054 & 0 & 0 & 0 & 0.0033 & 0 & 0 \\ 102.41 & 103.13 & 103.21 & 103.20 & 102.70 & 102.33 & 101.68 & 102.45 & 102.83 \\ & & & & & & & & \\ 12 & 12 & 12 & 12 & 12 & 12 & 12 & 12 & 12 \\ 2.983 & 3.016 & 3.003 & 3.007 & 2.986 & 2.985 & 2.999 & 2.988 & 2.998 \\ 0.001 & 0.002 & 0.001 & 0.003 & 0.004 & 0.007 & 0.005 & 0.006 & 0.006 \\ 1.970 & 1.959 & 1.977 & 1.967 & 1.986 & 1.973 & 1.944 & 1.926 & 1.909 \\ 0 & 0 & 0.004 & 0.001 & 0.002 & 0 & 0.001 & 0 & 0 \\ 0.067 & 0.006 & 0.019 & 0.023 & 0.037 & 0.042 & 0.056 & 0.092 & 0.085 \\ 0.329 & 0.295 & 0.778 & 0.622 & 0.449 & 0.700 & 0.669 & 0.862 & 0.686 \\ 1.759 & 1.919 & 1.443 & 1.675 & 1.815 & 1.576 & 1.533 & 1.376 & 1.540 \\ 0.432 & 0.366 & 0.327 & 0.343 & 0.320 & 0.342 & 0.301 & 0.264 & 0.280 \\ 0.454 & 0.435 & 0.440 & 0.348 & 0.397 & 0.373 & 0.486 & 0.483 & 0.492 \\ 0.005 & 0.001 & 0.007 & 0.011 & 0.005 & 0 & 0.006 & 0.004 & 0.003 \\ 0.000 & 0 & 0.001 & 0 & 0 & 0 & 0.000 & 0 & 0 \\ 8.000 & 8.000 & 8.000 & 8.000 & 8.000 & 8.000 & 8.000 & 8.000 & 8.000 \\ 0.355 & 0.280 & 0.790 & 0.634 & 0.468 & 0.708 & 0.680 & 0.878 & 0.688 \\ 13.95 \% & 10.92 \% & 30.87 \% & 23.91 \% & 18.00 \% & 26.95 \% & 27.05 \% & 34.87 \% & 27.43 \% \\ 16.98 \% & 14.26 \% & 12.78 \% & 12.92 \% & 12.29 \% & 13.03 \% & 11.97 \% & 10.48 \% & 11.16 \% \\ 69.07 \% & 74.83 \% & 56.36 \% & 63.17 \% & 69.71 \% & 60.02 \% & 60.98 \% & 54.65 \% & 61.41 \% \\ & & & & & & & \end{array}$


o given. These values are plotted in Figure $8 \mathrm{a}$. See Figure S1b for location of the measurements.

18 19 20 21

22

23

24

25

\begin{tabular}{|c|c|c|c|c|c|c|c|}
\hline 38.62 & 38.81 & 38.77 & 38.59 & 38.97 & 39.31 & 39.06 & 38.87 \\
\hline 0.0534 & 0.0093 & 0.0414 & 0.0576 & 0.0418 & 0.0471 & 0.0014 & 0.0067 \\
\hline 21.15 & 21.5 & 21.72 & 21.64 & 21.86 & 21.87 & 22.31 & 22.28 \\
\hline 0.0414 & 0 & 0.0389 & 0 & 0 & 0.0024 & 0.0039 & 0.0173 \\
\hline 14.78 & 14.24 & 7.7 & 7.03 & 12.8 & 13.57 & 14.05 & 16.64 \\
\hline 2.63 & 2.76 & 3.23 & 3.93 & 4.28 & 4.39 & 4.26 & 3.85 \\
\hline 20.27 & 20.44 & 26.16 & 25.48 & 18.94 & 18.08 & 18.33 & 16.33 \\
\hline 5.26 & 5.4 & 5.03 & 5.64 & 6.06 & 5.73 & 5.33 & 5.04 \\
\hline 0.0261 & 0 & 0.0442 & 0.0191 & 0 & 0.0367 & 0 & 0.0322 \\
\hline 0 & 0 & 0.0113 & 0.0054 & 0.0052 & 0 & 0.0198 & 0.0009 \\
\hline 102.83 & 103.16 & 102.75 & 102.39 & 102.96 & 103.04 & 103.37 & 103.07 \\
\hline 12 & 12 & 12 & 12 & 12 & 12 & 12 & 12 \\
\hline 3.006 & 3.006 & 3.001 & 2.981 & 2.986 & 3.008 & 2.984 & 2.987 \\
\hline 0.003 & 0.001 & 0.002 & 0.003 & 0.002 & 0.003 & 0.000 & 0.000 \\
\hline 1.941 & 1.963 & 1.982 & 1.971 & 1.975 & 1.973 & 2.009 & 2.019 \\
\hline 0.003 & 0 & 0.002 & 0 & 0 & 0.000 & 0.000 & 0.001 \\
\hline 0.042 & 0.023 & 0.016 & 0.065 & 0.048 & 0.011 & 0.026 & 0.010 \\
\hline 0.920 & 0.900 & 0.482 & 0.390 & 0.772 & 0.858 & 0.872 & 1.060 \\
\hline 1.337 & 1.341 & 1.715 & 1.667 & 1.229 & 1.172 & 1.186 & 1.063 \\
\hline 0.305 & 0.319 & 0.373 & 0.452 & 0.489 & 0.501 & 0.485 & 0.441 \\
\hline 0.439 & 0.448 & 0.417 & 0.467 & 0.498 & 0.470 & 0.436 & 0.415 \\
\hline 0.004 & 0 & 0.007 & 0.003 & 0 & 0.005 & 0 & 0.005 \\
\hline 0 & 0 & 0.001 & 0.001 & 0.001 & 0 & 0.002 & 0.000 \\
\hline 8.000 & 8.000 & 8.000 & 8.000 & 8.000 & 8.000 & 8.000 & 8.000 \\
\hline 0.920 & 0.892 & 0.495 & 0.413 & 0.784 & 0.858 & 0.893 & 1.081 \\
\hline $35.90 \%$ & $34.96 \%$ & $19.16 \%$ & $16.32 \%$ & $31.34 \%$ & $33.90 \%$ & $34.82 \%$ & $41.82 \%$ \\
\hline $11.91 \%$ & $12.49 \%$ & $14.43 \%$ & $17.86 \%$ & $19.53 \%$ & $19.79 \%$ & $18.92 \%$ & $17.06 \%$ \\
\hline $52.18 \%$ & $52.55 \%$ & $66.42 \%$ & $65.82 \%$ & $49.13 \%$ & $46.32 \%$ & $46.26 \%$ & $41.12 \%$ \\
\hline
\end{tabular}


Table S3: EPMA measurements in wt\% of transect 3L1, and corresponding calculated garnet compositio $3 \mathrm{~L} 1$

$$
1
$$

$$
2
$$

$$
3
$$

$$
4
$$

$$
5
$$

\begin{tabular}{|c|c|c|c|c|c|c|c|c|}
\hline $\mathrm{SiO} 2$ & 38.42 & 37.93 & 37.6 & 37.68 & 37.46 & 37.22 & 37.68 & 37.68 \\
\hline TiO2 & 0.021 & 0.0726 & 0.2159 & 0.1127 & 0.3282 & 0.1776 & 0.3127 & 0.1682 \\
\hline $\mathrm{Al} 2 \mathrm{O} 3$ & 21.81 & 21.51 & 20.63 & 21.41 & 20.57 & 20.48 & 20.47 & 21.14 \\
\hline $\mathrm{Cr} 2 \mathrm{O} 3$ & 0.0549 & 0 & 0 & 0 & 0 & 0 & 0 & 0.0509 \\
\hline $\mathrm{FeOx}$ & 12.47 & 15.28 & 8.59 & 13.62 & 21.23 & 18.96 & 20.49 & 19.81 \\
\hline $\mathrm{MgO}$ & 3.7 & 2.58 & 2.07 & 2.51 & 1.82 & 2.05 & 1.95 & 1.97 \\
\hline $\mathrm{MnO}$ & 19.94 & 18.45 & 26.89 & 20.71 & 15.02 & 17.41 & 15.87 & 16.43 \\
\hline $\mathrm{CaO}$ & 5.75 & 5.97 & 5.23 & 5.32 & 5.61 & 4.89 & 5.27 & 4.96 \\
\hline \multicolumn{9}{|l|}{$\mathrm{Na} 2 \mathrm{O}$} \\
\hline K2O & 0 & 0.0005 & 0 & 0.0049 & 0 & 0 & 0.0058 & 0.0022 \\
\hline Total: & 102.17 & 101.79 & 101.23 & 101.37 & 102.04 & 101.19 & 102.05 & 102.21 \\
\hline O & 12 & 12 & 12 & 12 & 12 & 12 & 12 & \\
\hline $\mathrm{SiO} 2$ & 2.979 & 2.975 & 2.986 & 2.973 & 2.963 & 2.966 & 2.979 & 2.970 \\
\hline TiO2 & 0.001 & 0.004 & 0.013 & 0.007 & 0.020 & 0.011 & 0.019 & 0.010 \\
\hline $\mathrm{Al} 2 \mathrm{O} 3$ & 1.993 & 1.989 & 1.932 & 1.992 & 1.918 & 1.924 & 1.908 & 1.964 \\
\hline $\mathrm{Cr} 2 \mathrm{O} 3$ & 0.003 & 0 & 0 & 0 & 0 & 0 & 0 & 0.003 \\
\hline $\mathrm{Fe} 2 \mathrm{O} 3$ & 0.043 & 0.052 & 0.070 & 0.049 & 0.118 & 0.123 & 0.097 & 0.074 \\
\hline $\mathrm{FeO}$ & 0.765 & 0.950 & 0.500 & 0.850 & 1.286 & 1.140 & 1.258 & 1.23 \\
\hline $\mathrm{MnO}$ & 1.309 & 1.226 & 1.809 & 1.384 & 1.006 & 1.175 & 1.063 & 1.097 \\
\hline $\mathrm{MgO}$ & 0.428 & 0.302 & 0.245 & 0.295 & 0.215 & 0.243 & 0.230 & 0.231 \\
\hline $\mathrm{CaO}$ & 0.478 & 0.502 & 0.445 & 0.450 & 0.475 & 0.418 & 0.446 & 0.419 \\
\hline $\mathrm{Na} 2 \mathrm{O}$ & 0 & 0 & 0 & 0 & 0 & 0 & 0 & \\
\hline K2O & 0 & 0.000 & 0 & 0.000 & 0 & 0 & 0.001 & 0.000 \\
\hline Totals & 8.000 & 8.000 & 8.000 & 8.000 & 8.000 & 8.000 & 8.000 & 8.000 \\
\hline FeO rec. & 0.785 & 0.971 & 0.501 & 0.871 & 1.304 & 1.164 & 1.261 & 1.25 \\
\hline $\mathrm{Fe}$ & $31.13 \%$ & $38.86 \%$ & $19.61 \%$ & $34.15 \%$ & $51.65 \%$ & $45.07 \%$ & $49.38 \%$ & $48.54 \%$ \\
\hline $\mathrm{Mg}$ & $16.95 \%$ & $12.07 \%$ & $9.59 \%$ & $11.57 \%$ & $8.50 \%$ & $9.43 \%$ & $9.00 \%$ & $8.96 \%$ \\
\hline $\mathrm{Mn}$ & $51.92 \%$ & $49.07 \%$ & $70.80 \%$ & $54.28 \%$ & $39.85 \%$ & $45.50 \%$ & $41.62 \%$ & $42.49^{\circ}$ \\
\hline
\end{tabular}

$$
6
$$

$$
7
$$


In in atoms per formula unit. Relative molar percentages of Fe vs $\mathrm{Mg}$ vs $\mathrm{Mn}$ as plotted in Figure 8 are alsı

\begin{tabular}{|c|c|c|c|c|c|c|c|c|}
\hline 9 & 10 & 11 & 12 & 13 & 14 & 15 & 16 & 17 \\
\hline 37.5 & 37.67 & 37.59 & 37.6 & 38.24 & 37.96 & 38.12 & 38.32 & 38.37 \\
\hline 0.2362 & 0.2789 & 0.3183 & 0.2981 & 0.1252 & 0.0459 & 0.0139 & 0.0376 & 0.0599 \\
\hline 20.64 & 20.81 & 20.49 & 20.26 & 21 & 21.35 & 21.46 & 21.42 & 21.62 \\
\hline 0 & 0 & 0 & 0 & 0 & 0 & 0 & 0 & 0 \\
\hline 16.04 & 16.81 & 17.82 & 17.26 & 12.41 & 16.1 & 18.2 & 19.44 & 15.22 \\
\hline 2.39 & 2.29 & 2.24 & 2.24 & 2.23 & 2.53 & 2.49 & 2.18 & 2.54 \\
\hline 19.46 & 19.5 & 17.8 & 18.97 & 22.25 & 18.86 & 17.63 & 16.66 & 19.88 \\
\hline 5.26 & 5.2 & 5.26 & 4.6 & 5.57 & 5.04 & 4.27 & 4.84 & 4.88 \\
\hline 0 & 0 & 0.0167 & 0.0038 & 0 & 0 & 0 & 0.007 & 0 \\
\hline 101.53 & 102.56 & 101.54 & 101.23 & 101.83 & 101.89 & 102.18 & 102.90 & 102.57 \\
\hline 12 & 12 & 12 & 12 & 12 & 12 & 12 & 12 & 12 \\
\hline 2.967 & 2.955 & 2.979 & 2.994 & 3.011 & 2.984 & 2.994 & 2.993 & 2.995 \\
\hline 0.014 & 0.016 & 0.019 & 0.018 & 0.007 & 0.003 & 0.001 & 0.002 & 0.004 \\
\hline 1.925 & 1.925 & 1.914 & 1.902 & 1.949 & 1.978 & 1.987 & 1.973 & 1.990 \\
\hline 0 & 0 & 0 & 0 & 0 & 0 & 0 & 0 & 0 \\
\hline 0.112 & 0.132 & 0.092 & 0.076 & 0.014 & 0.048 & 0.024 & 0.037 & 0.013 \\
\hline 0.949 & 0.971 & 1.088 & 1.073 & 0.803 & 1.010 & 1.171 & 1.233 & 0.981 \\
\hline 1.304 & 1.296 & 1.195 & 1.279 & 1.484 & 1.256 & 1.173 & 1.102 & 1.314 \\
\hline 0.282 & 0.268 & 0.265 & 0.266 & 0.262 & 0.296 & 0.291 & 0.254 & 0.295 \\
\hline 0.446 & 0.437 & 0.447 & 0.392 & 0.470 & 0.424 & 0.359 & 0.405 & 0.408 \\
\hline 0 & 0 & 0 & 0 & 0 & 0 & 0 & 0 & 0 \\
\hline 0 & 0 & 0.002 & 0.000 & 0 & 0 & 0 & 0.001 & 0 \\
\hline 8.000 & 8.000 & 8.000 & 8.000 & 8.000 & 8.000 & 8.000 & 8.000 & 8.000 \\
\hline 0.968 & 0.999 & 1.094 & 1.063 & 0.785 & 1.023 & 1.177 & 1.239 & 0.982 \\
\hline $37.90 \%$ & $38.99 \%$ & $42.85 \%$ & $40.75 \%$ & $31.01 \%$ & $39.74 \%$ & $44.55 \%$ & $47.74 \%$ & $37.88 \%$ \\
\hline $11.03 \%$ & $10.45 \%$ & $10.36 \%$ & $10.19 \%$ & $10.34 \%$ & $11.51 \%$ & $11.04 \%$ & $9.78 \%$ & $11.40 \%$ \\
\hline $51.07 \%$ & $50.56 \%$ & $46.79 \%$ & $49.06 \%$ & $58.65 \%$ & $48.76 \%$ & $44.41 \%$ & $42.48 \%$ & $50.72 \%$ \\
\hline
\end{tabular}


o given. These values are plotted in Figure $8 \mathrm{~b}$. See Figure S1c for location of the measurements.

18

19

20

$38.07 \quad 38.29 \quad 38.59$

$0 \quad 0.0293 \quad 0.0517$

$21.31 \quad 21.33 \quad 21.54$

$0.003 \quad 0.0183 \quad 0.0048$

$20.66 \quad 18.38 \quad 5.84$

$\begin{array}{lll}1.78 & 2.02 & 2.92\end{array}$

$15.38 \quad 16.68 \quad 28.02$

$\begin{array}{lll}4.89 & 5.53 & 5.19\end{array}$

$\begin{array}{lll}0.0044 & 0 & 0.0091\end{array}$

$102.10 \quad 102.28 \quad 102.17$

$\begin{array}{rrr}12 & 12 & 12 \\ 3.004 & 3.006 & 3.009 \\ 0 & 0.002 & 0.003 \\ 1.982 & 1.974 & 1.980 \\ 0.000 & 0.001 & 0.000 \\ 0.011 & 0.010 & 0 \\ 1.352 & 1.197 & 0.381 \\ 1.028 & 1.109 & 1.851 \\ 0.209 & 0.236 & 0.339 \\ 0.413 & 0.465 & 0.434 \\ 0 & 0 & 0 \\ 0.000 & 0 & 0.001 \\ 8.000 & 8.000 & 7.998 \\ & & \\ 1.349 & 1.189 & 0.376\end{array}$

$52.17 \% \quad 46.92 \% \quad 14.66 \%$

$8.09 \% \quad 9.32 \% \quad 13.22 \%$

$39.74 \% \quad 43.76 \% \quad 72.12 \%$ 
Table S5: EPMA measurements in wt\% of transect 4L1, and corresponding calculated garnet compositio $4 \mathrm{~L} 1$

$$
2
$$

$$
3
$$

$$
4
$$

5

$$
6
$$

\begin{tabular}{|c|c|c|c|c|c|c|c|c|}
\hline $\mathrm{SiO} 2$ & 37.89 & 37.97 & 37.88 & 37.94 & 38.21 & 37.74 & 37.94 & 37.82 \\
\hline TiO2 & 0.2303 & 0.0241 & 0 & 0.0107 & 0 & 0.0319 & 0.0532 & 0.0146 \\
\hline $\mathrm{Al} 2 \mathrm{O} 3$ & 20.52 & 21.36 & 21.67 & 21.43 & 21.6 & 21.79 & 21.55 & 21.42 \\
\hline $\mathrm{Cr} 2 \mathrm{O} 3$ & 0.0055 & 0 & 0 & 0 & 0 & 0.0064 & 0.0064 & 0.0011 \\
\hline $\mathrm{FeOx}$ & 20.28 & 19.88 & 17.38 & 18.15 & 18.58 & 16.31 & 14.6 & 15.14 \\
\hline $\mathrm{MgO}$ & 1.67 & 1.86 & 2.19 & 2.01 & 2.06 & 2.31 & 2.49 & 2.23 \\
\hline $\mathrm{MnO}$ & 16.07 & 16.39 & 18.77 & 18 & 19.05 & 21.43 & 22.55 & 21.22 \\
\hline $\mathrm{CaO}$ & 5.69 & 5.02 & 4.76 & 4.93 & 3.83 & 2.92 & 3.46 & 4. \\
\hline \multicolumn{9}{|l|}{$\mathrm{Na} 2 \mathrm{O}$} \\
\hline K2O & 0.0286 & 0.0412 & 0.0071 & 0.0059 & 0.0183 & 0.0067 & 0 & 0.0077 \\
\hline Total: & 102.38 & 102.55 & 102.66 & 102.48 & 103.35 & 102.55 & 102.65 & 102.05 \\
\hline $\mathrm{O}$ & 12 & 12 & 12 & 12 & 12 & 12 & 12 & 12 \\
\hline $\mathrm{SiO} 2$ & 2.988 & 2.981 & 2.964 & 2.978 & 2.981 & 2.965 & 2.972 & 2.979 \\
\hline TiO2 & 0.014 & 0.001 & 0 & 0.001 & 0 & 0.002 & 0.003 & 0.001 \\
\hline $\mathrm{Al} 2 \mathrm{O} 3$ & 1.908 & 1.977 & 1.999 & 1.983 & 1.987 & 2.018 & 1.990 & 1.989 \\
\hline $\mathrm{Cr} 2 \mathrm{O} 3$ & 0.000 & 0 & 0 & 0 & 0 & 0.000 & 0.000 & 0.000 \\
\hline $\mathrm{Fe} 2 \mathrm{O} 3$ & 0.092 & 0.061 & 0.073 & 0.060 & 0.053 & 0.049 & 0.059 & 0.051 \\
\hline $\mathrm{FeO}$ & 1.245 & 1.244 & 1.064 & 1.131 & 1.159 & 1.023 & 0.898 & 0.946 \\
\hline $\mathrm{MnO}$ & 1.073 & 1.090 & 1.244 & 1.197 & 1.259 & 1.426 & 1.496 & 1.416 \\
\hline $\mathrm{MgO}$ & 0.196 & 0.218 & 0.255 & 0.235 & 0.240 & 0.270 & 0.291 & 0.262 \\
\hline $\mathrm{CaO}$ & 0.481 & 0.422 & 0.399 & 0.415 & 0.320 & 0.246 & 0.290 & 0.355 \\
\hline $\mathrm{Na} 2 \mathrm{O}$ & 0 & 0 & 0 & 0 & 0 & 0 & 0 & \\
\hline K2O & 0.003 & 0.004 & 0.001 & 0.001 & 0.002 & 0.001 & 0 & 0.001 \\
\hline Totals & 8.000 & 8.000 & 8.000 & 8.000 & 8.000 & 8.000 & 8.000 & 8.000 \\
\hline FeO rec. & 1.250 & 1.270 & 1.101 & 1.154 & 1.181 & 1.058 & 0.922 & 0.96 \\
\hline $\mathrm{Fe}$ & $49.60 \%$ & $49.26 \%$ & $42.34 \%$ & $44.62 \%$ & $44.09 \%$ & $38.40 \%$ & $34.05 \%$ & $36.58 \%$ \\
\hline Mg & $7.79 \%$ & $8.44 \%$ & $9.82 \%$ & $9.09 \%$ & $8.94 \%$ & $9.82 \%$ & $10.73 \%$ & $9.90 \%$ \\
\hline $\mathrm{Mn}$ & $42.61 \%$ & $42.29 \%$ & $47.84 \%$ & $46.29 \%$ & $46.97 \%$ & $51.78 \%$ & $55.23 \%$ & $53.52^{\prime}$ \\
\hline
\end{tabular}

$$
7
$$

8 
In in atoms per formula unit. Relative molar percentages of Fe vs $\mathrm{Mg}$ vs $\mathrm{Mn}$ as plotted in Figure 8 are alsi

10

11

12

13

14

15

16

17

\begin{tabular}{|c|c|c|c|c|c|c|c|c|}
\hline 38.28 & 37.98 & 37.91 & 37.48 & 37.51 & 37.73 & 37.99 & 37.83 & 37.76 \\
\hline 0.1388 & 0.1734 & 0.0613 & 0.0902 & 0.065 & 0.0225 & 0.0173 & 0.0292 & 0 \\
\hline 21.29 & 21.32 & 21.41 & 21.43 & 21.29 & 21.51 & 21.52 & 21.89 & 21.75 \\
\hline 0.0312 & 0 & 0.0402 & 0.0133 & 0.0478 & 0.0243 & 0.0078 & 0.0284 & 0.0458 \\
\hline 13.98 & 13.69 & 11.91 & 9.81 & 9.2 & 9.4 & 10.74 & 9.66 & 6.64 \\
\hline 2.26 & 2.17 & 2.37 & 2.49 & 2.52 & 2.44 & 2.14 & 2.23 & 2.44 \\
\hline 22.19 & 22.16 & 24.44 & 27.18 & 27.69 & 27.41 & 25.34 & 27.14 & 28.86 \\
\hline 4.81 & 4.95 & 4.45 & 3.63 & 3.56 & 3.58 & 4.46 & 4.15 & 4.56 \\
\hline 0 & 0 & 0 & 0 & 0 & 0.0002 & 0 & 0 & 0.0092 \\
\hline 102.98 & 102.44 & 102.59 & 102.12 & 101.88 & 102.12 & 102.22 & 102.96 & 102.06 \\
\hline 12 & 12 & 12 & 12 & 12 & 12 & 12 & 12 & 12 \\
\hline 2.987 & 2.979 & 2.968 & 2.950 & 2.959 & 2.969 & 2.986 & 2.952 & 2.962 \\
\hline 0.008 & 0.010 & 0.004 & 0.005 & 0.004 & 0.001 & 0.001 & 0.002 & \\
\hline 1.959 & 1.971 & 1.976 & 1.988 & 1.980 & 1.995 & 1.994 & 2.014 & 2.012 \\
\hline 0.002 & 0 & 0.002 & 0.001 & 0.003 & 0.002 & 0.000 & 0.002 & 0.003 \\
\hline 0.049 & 0.051 & 0.079 & 0.101 & 0.091 & 0.063 & 0.032 & 0.077 & 0.062 \\
\hline 0.863 & 0.847 & 0.701 & 0.545 & 0.515 & 0.555 & 0.674 & 0.553 & 0.374 \\
\hline 1.467 & 1.472 & 1.621 & 1.812 & 1.850 & 1.827 & 1.687 & 1.794 & 1.918 \\
\hline 0.263 & 0.254 & 0.277 & 0.292 & 0.296 & 0.286 & 0.251 & 0.259 & 0.285 \\
\hline 0.402 & 0.416 & 0.373 & 0.306 & 0.301 & 0.302 & 0.376 & 0.347 & 0.383 \\
\hline 0 & 0 & 0 & 0 & 0 & 0 & 0 & 0 & 0 \\
\hline 0 & 0 & 0 & 0 & 0 & 0.000 & 0 & 0 & 0.001 \\
\hline 8.000 & 8.000 & 8.000 & 8.000 & 8.000 & 8.000 & 8.000 & 8.000 & 8.000 \\
\hline 0.868 & 0.858 & 0.730 & 0.590 & 0.553 & 0.585 & 0.687 & 0.600 & 0.413 \\
\hline $33.42 \%$ & $33.21 \%$ & $27.77 \%$ & $21.90 \%$ & $20.47 \%$ & $21.69 \%$ & $26.17 \%$ & $22.60 \%$ & $15.80 \%$ \\
\hline $10.12 \%$ & $9.82 \%$ & $10.53 \%$ & $10.84 \%$ & $10.98 \%$ & $10.60 \%$ & $9.55 \%$ & $9.78 \%$ & $10.90 \%$ \\
\hline $56.46 \%$ & $56.97 \%$ & $61.70 \%$ & $67.26 \%$ & $68.55 \%$ & $67.70 \%$ & $64.28 \%$ & $67.62 \%$ & $73.29 \%$ \\
\hline
\end{tabular}


o given. These values are plotted in Figure $8 \mathrm{c}$. See Figure S1d for location of the measurements.

18

19

20

21

22

23

24

25

26

$\begin{array}{rrrrrrrrr}38.21 & 38.04 & 37.78 & 38.1 & 37.79 & 38.36 & 38.15 & 38.29 & 38.37 \\ 0 & 0.0267 & 0.036 & 0.0881 & 0 & 0.0853 & 0.0066 & 0.0681 & 0.0762 \\ 21.67 & 21.63 & 21.75 & 21.77 & 21.6 & 21.58 & 21.56 & 21.38 & 21.67 \\ 0 & 0 & 0 & 0.0003 & 0 & 0 & 0 & 0 & 0.0346 \\ 8.2 & 9.93 & 7.87 & 6.26 & 5.69 & 4.93 & 4.61 & 4.59 & 4.77 \\ 2.52 & 2.56 & 2.69 & 2.72 & 2.79 & 2.68 & 2.83 & 2.93 & 3.25 \\ 26.78 & 25.19 & 26.86 & 27.8 & 28.72 & 29.7 & 30.28 & 29.59 & 28.87 \\ 5.25 & 5.14 & 4.95 & 4.93 & 5.02 & 5.11 & 4.54 & 4.97 & 5.04 \\ & & & & & & & & \\ 0.004 & 0 & 0 & 0 & 0.0008 & 0 & 0.005 & 0.001 & 0.0055 \\ 102.63 & 102.52 & 101.94 & 101.67 & 101.61 & 102.45 & 101.98 & 101.82 & 102.09 \\ & & & & & & & & \\ 12 & 12 & 12 & 12 & 12 & 12 & 12 & 12 & 12 \\ 2.977 & 2.968 & 2.960 & 2.989 & 2.967 & 2.991 & 2.987 & 2.999 & 2.989 \\ 0 & 0.002 & 0.002 & 0.005 & 0 & 0.005 & 0.000 & 0.004 & 0.004 \\ 1.990 & 1.990 & 2.009 & 2.014 & 2.000 & 1.983 & 1.990 & 1.974 & 1.990 \\ 0 & 0 & 0 & 0.000 & 0 & 0 & 0 & 0 & 0.002 \\ 0.056 & 0.070 & 0.066 & 0 & 0.066 & 0.025 & 0.035 & 0.020 & 0.021 \\ 0.478 & 0.578 & 0.450 & 0.411 & 0.308 & 0.296 & 0.267 & 0.281 & 0.289 \\ 1.767 & 1.665 & 1.783 & 1.848 & 1.910 & 1.961 & 2.008 & 1.963 & 1.905 \\ 0.293 & 0.298 & 0.314 & 0.318 & 0.327 & 0.311 & 0.330 & 0.342 & 0.377 \\ 0.438 & 0.430 & 0.416 & 0.414 & 0.422 & 0.427 & 0.381 & 0.417 & 0.421 \\ 0 & 0 & 0 & 0 & 0 & 0 & 0 & 0 & 0 \\ 0.000 & 0 & 0 & 0 & 0.000 & 0 & 0.000 & 0.000 & 0.001 \\ 8.000 & 8.000 & 8.000 & 7.999 & 8.000 & 8.000 & 8.000 & 8.000 & 8.000 \\ & & & & & & & & \\ 0.502 & 0.608 & 0.487 & 0.420 & 0.341 & 0.300 & 0.280 & 0.278 & 0.297 \\ 19.59 \% & 23.64 \% & 18.86 \% & 16.24 \% & 13.22 \% & 11.68 \% & 10.71 \% & 10.76 \% & 11.52 \% \\ 11.42 \% & 11.58 \% & 12.16 \% & 12.30 \% & 12.67 \% & 12.10 \% & 12.61 \% & 13.24 \% & 14.63 \% \\ 68.99 \% & 64.78 \% & 68.98 \% & 71.46 \% & 74.11 \% & 76.22 \% & 76.68 \% & 76.00 \% & 73.86 \% \\ & & & & & & & & \end{array}$


27

$\begin{array}{rrrr}38.21 & 38.28 & 38.34 & 38.61 \\ 0.0294 & 0.0067 & 0.0174 & 0.0148 \\ 21.85 & 21.87 & 21.66 & 21.65 \\ 0 & 0.039 & 0.0477 & 0 \\ 5.01 & 5.3 & 5.32 & 5.57 \\ 3.44 & 3.48 & 3.6 & 3.82 \\ 28.51 & 28.45 & 27.74 & 27.1 \\ 5.14 & 5.01 & 5.25 & 5.19\end{array}$

$\begin{array}{rrrr}0.0018 & 0.0044 & 0 & 0 \\ 102.19 & 102.44 & 101.98 & 101.95\end{array}$

$\begin{array}{rrrr}12 & 12 & 12 & 12 \\ 2.969 & 2.968 & 2.982 & 2.998 \\ 0.002 & 0.000 & 0.001 & 0.001 \\ 2.001 & 1.999 & 1.986 & 1.982 \\ 0 & 0.002 & 0.003 & 0 \\ 0.058 & 0.063 & 0.045 & 0.019 \\ 0.268 & 0.281 & 0.301 & 0.343 \\ 1.876 & 1.868 & 1.827 & 1.783 \\ 0.398 & 0.402 & 0.417 & 0.442 \\ 0.428 & 0.416 & 0.438 & 0.432 \\ 0 & 0 & 0 & 0 \\ 0.000 & 0.000 & 0 & 0 \\ 8.000 & 8.000 & 8.000 & 8.000 \\ & & & \\ 0.297 & 0.313 & 0.318 & 0.343 \\ & & & \\ 11.56 \% & 12.13 \% & 12.40 \% & 13.37 \% \\ 15.49 \% & 15.56 \% & 16.28 \% & 17.22 \% \\ 72.95 \% & 72.31 \% & 71.32 \% & 69.42 \%\end{array}$


Table S4: EPMA measurements in wt\% of transect $3 \mathrm{~L} 2$ and point measurement 3-3, and corresponding , $\mathrm{Mn}$ as plotted in Figure 8 are also given. These values are plotted in Figure $8 \mathrm{~b}$. See Figure S1c for locatio 3L2

2

3

37.93
0.0388
20.95
0
9.27
2.51
26.36
4.78

37.94

0.0498

38.01

0.0458

38.31
0.0444
21.45
0.0115
5.66
2.78
28.8
4.88

4

5

6

38.07
0.0528
21.32
0
5.42
2.87
28.45
4.99

38.1
0.0515

21.77

0

6.05

3.6

26.73

5.35

$\mathrm{Na} 2 \mathrm{O}$

$\mathrm{K} 2 \mathrm{O}$

Total:

$$
0.0102
$$

101.85

0

101.87

$\begin{array}{rr}0 & 0 \\ 101.55 & 101.94\end{array}$

0
101.17

0.0058

101.66

$\mathrm{Al} 2 \mathrm{O} 3$

$\mathrm{Cr} 2 \mathrm{O} 3$

$\mathrm{Fe} 2 \mathrm{O} 3$

$\mathrm{FeO}$

$\mathrm{MnO}$

$\mathrm{MgO}$

$\mathrm{CaO}$

$\mathrm{Na} 2 \mathrm{O}$

$\mathrm{K} 2 \mathrm{O}$

Totals

$\mathrm{FeO}$ rec.

$\mathrm{Fe}$

$\mathrm{Mg}$

$\mathrm{Mn}$
12

12

2.986

0.002

1.945

0.003

1.983

0

0.080

0.531

1.758

0.295

0.403

0.048

0.445

1.859

0.309

0.371

0

0.001

8.000

0

8.000

12

$$
2.992
$$

0.003

1.993

0.002

0.016

0.375

1.902

0.294

0.423

$$
12
$$

3.001

0.003

1.981

0.001

0.012

0.358

1.911

0.324

0.410

101.17

12

3.001

0.003

1.981

0

0.012

0.346

1.899

0.337

0.421

12

2.970

0.003

2.001

0

0.053

0.342

1.765

0.418

0.447

0.447
0

0.001
8.000

8.000

8.000

8.000

0.380

0.355

0.342

0.369

$13.71 \%$

$13.27 \%$

$13.07 \%$

$12.53 \%$

$73.76 \%$

$14.74 \%$

$11.43 \%$

$73.83 \%$

$67.70 \%$

$70.73 \%$

$73.66 \%$

$14.47 \%$

$16.38 \%$

$69.14 \%$

$16.28 \%$

$16.75 \%$

$17.02 \%$

$18.75 \%$

$66.71 \% \quad 64.50 \%$ 
calculated garnet composition in atoms per formula unit. Relative molar percentages of Fe vs Mg vs sn of the measurements.

\begin{tabular}{|c|c|c|c|c|c|c|c|}
\hline 9 & 10 & 11 & 12 & 13 & 14 & 15 & 3-3 \\
\hline 38.72 & 38.79 & 38.67 & 38.5 & 38.67 & 38.55 & 37.68 & 37.58 \\
\hline 0 & 0.1067 & 0 & 0.0337 & 0 & 0.0561 & 0.0098 & 0.0266 \\
\hline 21.81 & 21.65 & 21.95 & 21.94 & 21.86 & 21.83 & 21.95 & 21.96 \\
\hline 0.0135 & 0 & 0 & 0 & 0 & 0 & 0 & 0.0541 \\
\hline 8.22 & 8.06 & 9.68 & 11.97 & 13.77 & 13.88 & 17.6 & 24.62 \\
\hline 4.86 & 4.81 & 4.86 & 4.25 & 3.89 & 3.67 & 2.71 & 1.85 \\
\hline 22.24 & 22.63 & 20.83 & 19.04 & 17.52 & 18.32 & 16.26 & 11.16 \\
\hline 5.88 & 5.84 & 6.04 & 6.21 & 6.26 & 5.83 & 5.62 & 5.42 \\
\hline 0 & 0.0122 & 0 & 0.0137 & 0 & 0 & 0 & 0.0029 \\
\hline 101.74 & 101.90 & 102.03 & 101.96 & 101.97 & 102.14 & 101.83 & 102.67 \\
\hline 12 & 12 & 12 & 12 & 12 & 12 & 12 & 12.000 \\
\hline 2.987 & 2.991 & 2.975 & 2.975 & 2.995 & 2.989 & 2.952 & 2.943 \\
\hline 0 & 0.006 & 0 & 0.002 & 0 & 0.003 & 0.001 & 0.002 \\
\hline 1.984 & 1.968 & 1.991 & 1.999 & 1.996 & 1.996 & 2.027 & 2.028 \\
\hline 0.001 & 0 & 0 & 0 & 0 & 0 & 0 & 0.003 \\
\hline 0.041 & 0.038 & 0.060 & 0.049 & 0.015 & 0.019 & 0.068 & 0.079 \\
\hline 0.489 & 0.481 & 0.562 & 0.724 & 0.877 & 0.881 & 1.085 & 1.533 \\
\hline 1.453 & 1.478 & 1.357 & 1.246 & 1.149 & 1.203 & 1.079 & 0.740 \\
\hline 0.559 & 0.553 & 0.557 & 0.489 & 0.449 & 0.424 & 0.316 & 0.216 \\
\hline 0.486 & 0.483 & 0.498 & 0.514 & 0.519 & 0.484 & 0.472 & 0.455 \\
\hline 0 & 0 & 0 & 0 & 0 & 0 & 0 & 0.000 \\
\hline 0 & 0.001 & 0 & 0.001 & 0 & 0 & 0 & 0.000 \\
\hline 8.000 & 8.000 & 8.000 & 8.000 & 8.000 & 8.000 & 8.000 & 8.000 \\
\hline 0.502 & 0.487 & 0.588 & 0.750 & 0.882 & 0.888 & 1.133 & 1.589 \\
\hline $19.96 \%$ & $19.33 \%$ & $23.49 \%$ & $30.18 \%$ & $35.57 \%$ & $35.31 \%$ & $44.81 \%$ & $62.43 \%$ \\
\hline $22.23 \%$ & $21.96 \%$ & $22.27 \%$ & $19.69 \%$ & $18.10 \%$ & $16.86 \%$ & $12.51 \%$ & $8.48 \%$ \\
\hline $57.81 \%$ & $58.72 \%$ & $54.24 \%$ & $50.13 \%$ & $46.33 \%$ & $47.83 \%$ & $42.68 \%$ & $29.09 \%$ \\
\hline
\end{tabular}


Table S6: EPMA measurements in wt\% of transect 5L1, and corresponding calculated garnet compositio $5 \mathrm{~L} 1$
2$$
3
$$
4

$$
5
$$

$$
6
$$

7

8

$\mathrm{SiO} 2$

$\mathrm{TiO} 2$

37.79
0.3173
20.49
0.0458
18.33
2.07
17.86
5.36

37.93

37.64

38.21

0.3246

0.2294

0.1931

37.97

21.02

20.68

20.91

Cr2O3

$\mathrm{FeOx}$

0.007

0.0199

18.15

17.86

0
20.35

2.19

2.22

1.96

17.6

17.47

16.1

5.19

5.28

37.97
0
21.26
0.0251
18.88
2.07
16.47
5.25

38.62

0.0282

38.45

0.0389

38.8

$\mathrm{CaO}$

5.3

5.25

21.38

21.51

21.47

$\mathrm{Na} 2 \mathrm{O}$

$\mathrm{K} 2 \mathrm{O}$

Total:

0
102.26

O

$\mathrm{SiO} 2$

$\mathrm{TiO} 2$

Al2O3

$\mathrm{Cr} 2 \mathrm{O} 3$

$\mathrm{Fe} 2 \mathrm{O} 3$

$\mathrm{FeO}$

$\mathrm{MnO}$

$\mathrm{MgO}$

$\mathrm{CaO}$

$$
\begin{array}{r}
12 \\
2978
\end{array}
$$

2.978
0.019

1.904

$$
0.0057
$$

0

0

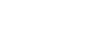
102.5

\section{$\mathrm{Na} 2 \mathrm{O}$}

$\mathrm{K} 2 \mathrm{O}$

Totals

0.003

0.099

1.109

1.192

$$
\begin{array}{r}
12 \\
2975
\end{array}
$$

$$
12
$$

102.91

FeO rec

$\mathrm{Fe}$

$\mathrm{Mg}$

$\mathrm{Mn}$

0.243

0.453

0.019

1.944

0.000

0.067

1.123

1.169

0.256

0.445

$\begin{array}{rrr}12 & 12 & 12 \\ 2.984 & 2.993 & 2.993 \\ 0.014 & 0.011 & 0 \\ 1.933 & 1.931 & 1.975 \\ 0.001 & 0 & 0.002 \\ 0.072 & 0.061 & 0.038 \\ 1.112 & 1.272 & 1.207 \\ 1.173 & 1.068 & 1.100 \\ 0.262 & 0.229 & 0.243 \\ 0.448 & 0.436 & 0.443\end{array}$

14.34

2.61

20.45

4.95

0

8.72

0

3.03

24.97

3.11

27.19

5.09

FeO rec.

1.112

0

0

6E-04

$6 \mathrm{E}-04$

8.000

8.000

0
8.000

0

0
8.000

0.0025

102.38

0

12

$\begin{array}{rrr}12 & 12 & 12 \\ 3.017 & 3.009 & 3.020 \\ 0.002 & 0.002 & 0 \\ 1.969 & 1.985 & 1.970 \\ 0 & 0 & 0 \\ 0 & 0 & 0 \\ 0.937 & 0.571 & 0.427 \\ 1.353 & 1.655 & 1.793 \\ 0.304 & 0.353 & 0.361 \\ 0.414 & 0.420 & 0.425 \\ 0 & 0 & 0 \\ 2 \mathrm{E}-04 & 0 & 0 \\ 7.997 & 7.996 & 7.995\end{array}$

1.129

1.116

1.268

1.214

0.928

0.571

0.422

$\begin{array}{llllll}43.74 \% & 49.43 \% & 47.48 \% & 35.91 \% & 22.13 \% & 16.39 \%\end{array}$

$10.28 \% \quad 8.92 \% \quad 9.51 \% \quad 11.75 \%$

$13.70 \%$

$14.01 \%$

$45.98 \% \quad 41.65 \% \quad 43.01 \% \quad 52.34 \%$

$64.17 \%$

$69.60 \%$ 
In in atoms per formula unit. Relative molar percentages of Fe vs $\mathrm{Mg}$ vs $\mathrm{Mn}$ as plotted in Figure 8 are alsi

10

11

12

13

$\begin{array}{lll}38.7 & 38.62 & 38.46\end{array}$

$0.0281 \quad 0.0429 \quad 0.0214$

21.54

0.0475

5.89

3.31

27.99

5.13

21.8

0.0568

5.52

3.38

27.7

5.25

0.0192

102.37

$12 \quad 12$

$2.999 \quad 2.996$

$0.002 \quad 0.003$

$1.968 \quad 1.993$

$0.003 \quad 0.003$

$0.030 \quad 0.007$

$0.351 \quad 0.351$

$1.837 \quad 1.820$

$0.382 \quad 0.391$

$0.426 \quad 0.436$

$\begin{array}{rrrrrrrrr}0.0192 & 0 & 0 & 0.0032 & 0 & 0.0083 & 0.0064 & 0 & 0 \\ 102.65 & 102.37 & 102.07 & 102.02 & 102.53 & 102.42 & 101.96 & 102.66 & 102.26 \\ 12 & 12 & 12 & 12 & 12 & 12 & 12 & 12 & 12 \\ 2.999 & 2.996 & 2.993 & 3.012 & 3.011 & 2.993 & 3.025 & 2.994 & 3.006 \\ 0.002 & 0.003 & 0.001 & 0.002 & 0 & 0.001 & 0 & 0.006 & 0.003 \\ 1.968 & 1.993 & 1.978 & 1.971 & 1.969 & 1.981 & 1.971 & 1.968 & 1.990 \\ 0.003 & 0.003 & 0 & 0 & 0.001 & 0.000 & 0.003 & 0 & 0 \\ 0.030 & 0.007 & 0.033 & 0.001 & 0.008 & 0.032 & 0 & 0.033 & 0 \\ 0.351 & 0.351 & 0.326 & 0.366 & 0.396 & 0.405 & 0.453 & 0.456 & 0.557 \\ 1.837 & 1.820 & 1.842 & 1.812 & 1.730 & 1.657 & 1.558 & 1.542 & 1.494 \\ 0.382 & 0.391 & 0.400 & 0.408 & 0.453 & 0.494 & 0.511 & 0.555 & 0.511 \\ 0.426 & 0.436 & 0.425 & 0.427 & 0.432 & 0.436 & 0.466 & 0.447 & 0.437 \\ 0 & 0 & 0 & 0 & 0 & 0 & 0 & 0 & 0 \\ 2 \mathrm{E}-03 & 0 & 0 & 3 \mathrm{E}-04 & 0 & 8 \mathrm{E}-04 & 6 \mathrm{E}-04 & 0 & 0 \\ 8.000 & 8.000 & 8.000 & 8.000 & 8.000 & 8.000 & 7.988 & 8.000 & 7.997 \\ & & & & & & & & \\ 0.355 & 0.353 & 0.332 & 0.352 & 0.385 & 0.413 & 0.465 & 0.456 & 0.558 \\ & & & & & & & & \\ 13.78 \% & 13.77 \% & 12.90 \% & 13.70 \% & 15.01 \% & 16.10 \% & 18.34 \% & 17.86 \% & 21.78 \% \\ 14.85 \% & 15.24 \% & 15.54 \% & 15.86 \% & 17.65 \% & 19.26 \% & 20.18 \% & 21.74 \% & 19.93 \% \\ 71.37 \% & 70.99 \% & 71.56 \% & 70.44 \% & 67.34 \% & 64.64 \% & 61.48 \% & 60.40 \% & 58.29 \%\end{array}$

2E-03 0

$8.000 \quad 8.000$

21.56

0

5.53

3.45

27.95

5.1

38.71
0.0322
21.49

39
0
21.64
0.0184
6.26
3.94
26.45
5.22

14

15

16

17

0

5.64

3.52

27.5

5.12

5.22

0.0032

$$
0
$$

102.53

38.84
0.0094
21.81
0.002
6.78
4.3
25.39
5.28

39.24

39.08
0.0984

39.02

21.69

0.0457

21.79

21.91

7.03

4.45

23.86

5.64

7.62

0

8.64 
o given. These values are plotted in Figure 8c. See Figure S1e for location of the measurements.

18

19 20

$\begin{array}{rrr}38.93 & 38.19 & 37.69 \\ 0.0499 & 0.0927 & 0.3635 \\ 21.57 & 21.35 & 20.72 \\ 0 & 0 & 0.0135 \\ 14.55 & 21.33 & 21.67 \\ 3.14 & 1.87 & 1.87 \\ 18.66 & 14.58 & 15.52 \\ 5.76 & 5.64 & 4.51 \\ & & \\ 0 & 0 & 0.0007 \\ 102.66 & 103.05 & 102.36 \\ & & \\ 12 & 12 & 12 \\ 3.016 & 2.982 & 2.977 \\ 0.003 & 0.005 & 0.022 \\ 1.970 & 1.965 & 1.929 \\ 0 & 0 & 0.001 \\ 0 & 0.059 & 0.073 \\ 0.943 & 1.334 & 1.358 \\ 1.224 & 0.964 & 1.038 \\ 0.363 & 0.218 & 0.220 \\ 0.478 & 0.472 & 0.382 \\ 0 & 0 & 0 \\ 0 & 0 & 7 \mathrm{E}-05 \\ 7.996 & 8.000 & 8.000 \\ & & \\ 0.935 & 1.346 & 1.360 \\ & & \\ 37.07 \% & 53.24 \% & 51.94 \% \\ 14.37 \% & 8.61 \% & 8.41 \% \\ 48.55 \% & 38.15 \% & 39.66 \% \\ & & \\ & & \end{array}$


Table S7: EPMA measurements in wt\% of transect $6 \mathrm{~L} 1$, and corresponding calculated garnet composition in atoms per formula unit. Relative molar percentages of Fe vs $\mathrm{Mg}$ vs $\mathrm{Mn}$ as plotted in Figure 8 are also given. These values are plotted in Figure 8c. See Figure S1f for location of the measurements.

$\mathrm{SiO} 2$

$\mathrm{TiO} 2$

$\mathrm{Al} 2 \mathrm{O} 3$

$\mathrm{Cr} 2 \mathrm{O} 3$

$\mathrm{FeOx}$

$\mathrm{MgO}$

$\mathrm{MnO}$

$\mathrm{CaO}$

$\mathrm{Na} 2 \mathrm{O}$

$\mathrm{K} 2 \mathrm{O}$

Total:

38.59
0.0125
21.92

38.92
0

2

3

4

O

$\mathrm{SiO} 2$

$\mathrm{TiO} 2$

$\mathrm{Al} 2 \mathrm{O} 3$

$\mathrm{Cr} 2 \mathrm{O} 3$

$\mathrm{Fe} 2 \mathrm{O} 3$

$\mathrm{FeO}$

0

22.25

0.0604

$\begin{array}{rr}38.82 & 38.69 \\ 0.043 & 0.0248 \\ 22.07 & 21.77 \\ 0 & 0.03 \\ 7.33 & 4.73 \\ 4.63 & 3.19 \\ 24.25 & 29.33 \\ 5.66 & 4.82 \\ 0.0167 & 0.0111 \\ 0.0038 & 0 \\ 102.82 & 102.60\end{array}$

$\mathrm{MnO}$

12.83

10.15

4.84

3.37

20.73

5.67

5.94

0.0198

0.0396

0

102.86

102.93

12
2.979

12

0.001

2.968

12

2.971

12

$\mathrm{MgO}$

1.995

0

0.002

3.001

2.000

1.991

0.001

$\begin{array}{ll}0 & 0.004\end{array}$

0.048

0.066

$0-0.002$

\section{$\mathrm{CaO}$}

0.780

0.582

0.066

0.002

$\mathrm{Na} 2 \mathrm{O}$

1.337

1.339

0.404

0.004

$$
0.388
$$

0.550

1.572

0.303

0.469

0.485

0.528

1.927

$\mathrm{K} 2 \mathrm{O}$

0.003

0.006

0.464

0.369

Totals

8.000

0

0.002

0.401

0.002

Totals

8.000

8.000

8.000

FeO rec.

0.806

0.625

0.436

0.304

$\mathrm{Fe}$

$31.85 \%$

$24.87 \%$

$17.19 \%$

$11.68 \%$

$\mathrm{Mn}$

$15.32 \%$

$21.88 \%$

$20.82 \%$

$14.19 \%$

$52.84 \%$

$53.25 \%$

$61.98 \%$

$74.13 \%$ 
Table S8: Fitted peak positions and uncertainties for Raman spectra of inclusions and standards, given in in cm-1. Measurement

$$
\begin{array}{ccllll}
\text { Acq. time (s) } & \text { rep. } & \begin{array}{l}
\text { mode_128 } \\
\text { value }
\end{array} & 2 \sigma \text { mean } & \text { mode_206 } & \text { mode_265 } \\
& & & \text { value } & 2 \sigma \text { mean } & \text { value }
\end{array}
$$

\begin{tabular}{|c|c|c|c|c|c|c|c|}
\hline i001 & 10 & 2 & 132.6 & 0.03 & 224.82 & 0.08 & \\
\hline i002 & 10 & 2 & 130.46 & 0.03 & 217.91 & 0.06 & 266.6 \\
\hline i003 & 10 & 2 & 132.48 & 0.05 & 223.97 & 0.1 & 268.47 \\
\hline i004 & 10 & 2 & 132.49 & 0.03 & 225.88 & 0.07 & 269.17 \\
\hline i005 & 10 & 2 & 131.01 & 0.05 & 220.37 & 0.08 & 267.31 \\
\hline i006 & 10 & 2 & 132.66 & 0.03 & 225.73 & 0.06 & 268.11 \\
\hline i007 & 15 & 2 & 133.61 & 0.03 & 228.22 & 0.07 & 269.64 \\
\hline i008 & 15 & 2 & 133.35 & 0.04 & 225.51 & 0.06 & 269.63 \\
\hline i009 & 15 & 2 & 132.3 & 0.03 & 223.63 & 0.05 & 268.7 \\
\hline i010 & 15 & 2 & 130.7 & 0.05 & 218.11 & 0.11 & 266.93 \\
\hline i011 & 15 & 2 & 132.56 & 0.04 & 224.1 & 0.06 & 267.97 \\
\hline i012 & 15 & 2 & 131.86 & 0.1 & 221.5 & 0.1 & 267.09 \\
\hline i013 & 15 & 2 & 131.19 & 0.05 & 220.42 & 0.11 & 266.6 \\
\hline i014 & 15 & 2 & 127.73 & 0.09 & 206.27 & 0.24 & 264.1 \\
\hline i015 & 15 & 2 & 132.26 & 0.09 & 224.37 & 0.08 & 267.98 \\
\hline i018 & 15 & 2 & 132 & 0.03 & 222.9 & 0.06 & 266.61 \\
\hline i019 & 15 & 2 & 132.25 & 0.05 & 223.99 & 0.1 & \\
\hline i020 & 15 & 2 & 127.62 & 0.05 & 206.2 & 0.26 & \\
\hline i021 & 15 & 2 & 132.6 & 0.03 & 224.82 & 0.08 & \\
\hline Qz_std_23_11_1433 & 5 & 3 & 127.9 & 0.02 & 206.96 & 0.05 & 263.71 \\
\hline Qz_std_19_12_1007 & 30 & 2 & 128.12 & 0.08 & 207.63 & 0.05 & 264.3 \\
\hline Qz_std_19_12_1237 & 30 & 2 & 127.88 & 0.03 & 206.88 & 0.05 & 264.54 \\
\hline average_Qtz_std_19_12 & & & 128 & 0.06 & 207.26 & 0.05 & 264.42 \\
\hline
\end{tabular}




\begin{tabular}{|c|c|c|c|c|c|c|c|c|}
\hline \multirow{3}{*}{$2 \sigma$ mean } & \multicolumn{2}{|l|}{ mode_393 } & \multicolumn{2}{|l|}{ mode_403 } & \multicolumn{2}{|l|}{ mode_464 } & \multicolumn{2}{|l|}{ mode_1080 } \\
\hline & value & $2 \sigma$ mean & value & $2 \sigma$ mean & value & $2 \sigma$ mean & value & $2 \sigma$ mean \\
\hline & & & & & 471.32 & 0.02 & 1083.25 & 1.26 \\
\hline 0.18 & 393.35 & 0.2 & 402.9 & 0.14 & 468.27 & 0.02 & & \\
\hline 0.39 & 393.66 & 0.32 & 403.53 & 0.27 & 470.71 & 0.03 & 1083.14 & 0.9 \\
\hline 0.19 & 393.52 & 0.34 & 403.05 & 0.13 & 471.75 & 0.02 & & \\
\hline 0.19 & & & & & 469.5 & 0.02 & & \\
\hline 0.31 & 393.1 & 0.19 & 401.27 & 0.26 & 471.67 & 0.05 & & \\
\hline 0.29 & 393.3 & 0.24 & 403.49 & 0.18 & 472.86 & 0.03 & & \\
\hline 0.22 & & & 404.15 & 0.16 & 471.65 & 0.02 & & \\
\hline 0.17 & & & 403.2 & 0.11 & 470.88 & 0.02 & & \\
\hline 0.56 & & & & & 468.64 & 0.03 & & \\
\hline 0.19 & 393.51 & 0.13 & & & 471.08 & 0.03 & 1073.87 & 1.09 \\
\hline 0.27 & & & & & 470.17 & 0.04 & & \\
\hline 0.36 & & & & & 469.79 & 0.02 & & \\
\hline 0.29 & & & & & 464.77 & 0.03 & 1082.19 & 0.13 \\
\hline 0.26 & & & 401.91 & 0.44 & 471.27 & 0.01 & 1082.6 & 0.15 \\
\hline 0.33 & & & & & 470.45 & 0.04 & 1083.12 & 0.82 \\
\hline & & & & & 471.04 & 0.03 & 1083.1 & 1.08 \\
\hline & & & & & 464.66 & 0.03 & & \\
\hline & & & & & 471.32 & 0.02 & 1083.25 & 1.26 \\
\hline 0.11 & 393.58 & 0.11 & 400.64 & 0.14 & 464.67 & 0.01 & & \\
\hline 0.14 & & & & & 464.68 & 0.02 & 1081.61 & 0.17 \\
\hline 0.11 & 393.53 & 0.09 & 402.49 & 0.24 & 464.55 & 0.02 & & \\
\hline 0.13 & 393.53 & 0.09 & 402.49 & 0.24 & 464.62 & 0.02 & 1081.61 & 0.17 \\
\hline
\end{tabular}


Page 71 of 75

\begin{tabular}{|c|c|}
\hline \multicolumn{2}{|c|}{ mode_1160 } \\
\hline value & $2 \sigma$ mean \\
\hline 1158.25 & 0.18 \\
\hline 1157.83 & 0.16 \\
\hline 1156.92 & 0.46 \\
\hline 1156 & 0.3 \\
\hline 1157.24 & 0.34 \\
\hline 1157.27 & 0.22 \\
\hline 1156.13 & 0.28 \\
\hline 1156.09 & 0.35 \\
\hline 1156.21 & 0.25 \\
\hline 1158.57 & 0.37 \\
\hline 1158.28 & 0.2 \\
\hline 1158.37 & 0.12 \\
\hline 1158.74 & 0.62 \\
\hline 1156.25 & 0.5 \\
\hline 1158.48 & 0.09 \\
\hline 1158.45 & 0.15 \\
\hline 1161.04 & 0.16 \\
\hline 1158.25 & 0.18 \\
\hline 1160.38 & 0.19 \\
\hline 1160.32 & 0.24 \\
\hline 1160.32 & 0.24 \\
\hline
\end{tabular}


Table S9: Shifts in peak positions in Raman spectra of quartz inclusions in comparison to an unstrained standard crystal. The shift of inclusions i001 to 006 where obtained by subtracting the value of the standard

"Qz_std_23_11_1433", while shifts for inclusions i007 to i021 were obtained by subtracting the average of standards "Qz_std_19_12_1007" and "Qz_std_19_12_1237". The shifts are reported together with the instrumental uncertainty $(0.5 \mathrm{~cm}-1)$, or the fitting uncertainties if $>0 . \overline{\mathrm{cm}}-1$.

\begin{tabular}{|c|c|c|c|c|c|c|c|c|}
\hline Measurement & mode_128 & & mode_206 & & mode_265 & & mode_464 & \\
\hline & value & $2 \sigma$ mean & value & $2 \sigma$ mean & value & $2 \sigma$ mean & value & $2 \sigma$ mean \\
\hline i001 & 4.7 & 0.5 & 17.86 & 0.5 & & & 6.65 & 0.5 \\
\hline i002 & 2.56 & 0.5 & 10.95 & 0.5 & 2.89 & 0.5 & 3.6 & 0.5 \\
\hline i003 & 4.58 & 0.5 & 17.01 & 0.5 & 4.76 & 0.5 & 6.04 & 0.5 \\
\hline i004 & 4.59 & 0.5 & 18.92 & 0.5 & 5.46 & 0.5 & 7.08 & 0.5 \\
\hline i005 & 3.11 & 0.5 & 13.41 & 0.5 & 3.6 & 0.5 & 4.83 & 0.5 \\
\hline i006 & 4.76 & 0.5 & 18.77 & 0.5 & 4.4 & 0.5 & 7 & 0.5 \\
\hline i007 & 5.61 & 0.5 & 20.96 & 0.5 & 5.22 & 0.5 & 8.24 & 0.5 \\
\hline i008 & 5.35 & 0.5 & 18.25 & 0.5 & 5.21 & 0.5 & 7.03 & 0.5 \\
\hline i009 & 4.3 & 0.5 & 16.37 & 0.5 & 4.28 & 0.5 & 6.26 & 0.5 \\
\hline i010 & 2.7 & 0.5 & 10.85 & 0.5 & 2.51 & 0.56 & 4.02 & 0.5 \\
\hline i011 & 4.56 & 0.5 & 16.84 & 0.5 & 3.55 & 0.5 & 6.46 & 0.5 \\
\hline i012 & 3.86 & 0.5 & 14.24 & 0.5 & 2.67 & 0.5 & 5.55 & 0.5 \\
\hline i013 & 3.19 & 0.5 & 13.16 & 0.5 & 2.18 & 0.5 & 5.17 & 0.5 \\
\hline i014 & -0.27 & 0.5 & -0.99 & 0.5 & -0.32 & 0.5 & 0.15 & 0.5 \\
\hline i015 & 4.26 & 0.5 & 17.11 & 0.5 & 3.56 & 0.5 & 6.65 & 0.5 \\
\hline i018 & 4 & 0.5 & 15.64 & 0.5 & 2.19 & 0.5 & 5.83 & 0.5 \\
\hline i019 & 4.25 & 0.5 & 16.73 & 0.5 & & & 6.42 & 0.5 \\
\hline i020 & -0.38 & 0.5 & -1.06 & 0.5 & & & 0.04 & 0.5 \\
\hline i021 & 4.6 & 0.5 & 17.56 & 0.5 & & & 6.7 & 0.5 \\
\hline
\end{tabular}


Table S10: Calculated strains, estimated standard deviations (esd) and errors for quartz inclusions.

\begin{tabular}{|c|c|c|c|c|c|c|c|c|}
\hline & $\varepsilon 1+\varepsilon 2$ & esd & $\varepsilon 3$ & esd & $\varepsilon_{-} \mathrm{V}$ & esd & var_x & var_y \\
\hline i001 & -0.01833 & 0.00669 & -0.00365 & 0.00432 & -0.02198 & 0.0024 & 4.476E-05 & 1.866E-05 \\
\hline i002 & -0.01652 & 0.00518 & 0.00129 & 0.00336 & -0.01523 & 0.0019 & 2.683E-05 & $1.129 \mathrm{E}-05$ \\
\hline i003 & -0.02066 & 0.01027 & -0.00152 & 0.00666 & -0.02218 & 0.0037 & 0.0001055 & 4.436E-05 \\
\hline i004 & -0.02365 & 0.01057 & -0.0013 & 0.00685 & -0.02495 & 0.0039 & 0.0001117 & 4.692E-05 \\
\hline i005 & -0.0181 & 0.00591 & 0.00007 & 0.00383 & -0.01804 & 0.0021 & 3.493E-05 & $1.467 \mathrm{E}-05$ \\
\hline i006 & -0.02111 & 0.00577 & -0.00271 & 0.00374 & -0.02382 & 0.0021 & 3.329E-05 & $1.399 \mathrm{E}-05$ \\
\hline i007 & -0.02025 & 0.0079 & -0.0054 & 0.00512 & -0.02565 & 0.0029 & 6.241E-05 & $2.621 \mathrm{E}-05$ \\
\hline i008 & -0.01716 & 0.01174 & -0.00513 & 0.00761 & -0.02229 & 0.0043 & 0.0001378 & $5.791 \mathrm{E}-05$ \\
\hline i009 & -0.01748 & 0.00727 & -0.0031 & 0.00471 & -0.02058 & 0.0026 & $5.285 \mathrm{E}-05$ & $2.218 \mathrm{E}-05$ \\
\hline i010 & -0.01245 & 0.00428 & -0.00138 & 0.00277 & -0.01382 & 0.0015 & 1.832E-05 & 7.673E-06 \\
\hline i011 & -0.01597 & 0.00455 & -0.00441 & 0.00295 & -0.02038 & 0.0016 & 0.0000207 & 8.703E-06 \\
\hline i012 & -0.01251 & 0.00427 & -0.00435 & 0.00277 & -0.01686 & 0.0015 & $1.823 \mathrm{E}-05$ & 7.673E-06 \\
\hline i013 & -0.01274 & 0.00427 & -0.00317 & 0.00277 & -0.01591 & 0.0015 & 1.823E-05 & 7.673E-06 \\
\hline i014 & 0.00403 & 0.00427 & -0.00189 & 0.00277 & 0.00214 & 0.0015 & $1.823 \mathrm{E}-05$ & 7.673E-06 \\
\hline i015 & -0.01747 & 0.00427 & -0.00362 & 0.00277 & -0.0211 & 0.0015 & $1.823 \mathrm{E}-05$ & 7.673E-06 \\
\hline i018 & -0.01529 & 0.00627 & -0.00356 & 0.00407 & -0.01885 & 0.0023 & $3.931 \mathrm{E}-05$ & 1.656E-05 \\
\hline i019 & -0.01685 & 0.00433 & -0.00366 & 0.0028 & -0.02051 & 0.0016 & $1.875 \mathrm{E}-05$ & 7.84E-06 \\
\hline i020 & 0.00303 & 0.00433 & -0.00116 & 0.0028 & 0.00188 & 0.0016 & $1.875 \mathrm{E}-05$ & $7.84 \mathrm{E}-06$ \\
\hline i021 & -0.01722 & 0.00556 & -0.00416 & 0.00359 & -0.02137 & 0.0020 & $3.091 \mathrm{E}-05$ & $1.289 \mathrm{E}-05$ \\
\hline
\end{tabular}




\begin{tabular}{lll} 
cov corr\% & \multicolumn{2}{c}{$\mathrm{X}^{2}$} \\
$-2.86 \mathrm{E}-05$ & -99 & 2.38 \\
$-1.72 \mathrm{E}-05$ & -99 & 1.47 \\
$-6.76 \mathrm{E}-05$ & -99 & 5.78 \\
$-7.17 \mathrm{E}-05$ & -99 & 6.13 \\
$-2.24 \mathrm{E}-05$ & -99 & 1.91 \\
$-2.14 \mathrm{E}-05$ & -99 & 1.83 \\
$-4.01 \mathrm{E}-05$ & -99 & 3.42 \\
$-8.85 \mathrm{E}-05$ & -99 & 7.56 \\
$-3.39 \mathrm{E}-05$ & -99 & 2.9 \\
$-1.18 \mathrm{E}-05$ & -99 & 0.47 \\
$-1.33 \mathrm{E}-05$ & -99 & 1.14 \\
$-1.17 \mathrm{E}-05$ & -99 & 0.62 \\
$-1.17 \mathrm{E}-05$ & -99 & 0.38 \\
$-1.17 \mathrm{E}-05$ & -99 & 0.3 \\
$-1.17 \mathrm{E}-05$ & -99 & 0.36 \\
$-2.53 \mathrm{E}-05$ & -99 & 2.16 \\
-0.000012 & -99 & 0.94 \\
-0.000012 & -99 & 0.63 \\
$-1.98 \mathrm{E}-05$ & -99 & 1.65 \\
& &
\end{tabular}


Table S11: P-T conditions representing prograde metamorphism of Lago di Cignana, and corresponding strain estimations for quartz inclusions.

\begin{tabular}{rrrrrrr}
\hline & \multicolumn{3}{c}{ EosFit } \\
\hline & $\mathrm{GPa})$ & \multicolumn{3}{c}{ unrelaxed } \\
1 & 370 & -0.0138 & -0.0049 & -0.0042 & -0.0039 & -0.0032 \\
1 & 470 & -0.0118 & -0.0040 & -0.0039 & -0.0032 & -0.0029 \\
1.5 & 400 & -0.0220 & -0.0079 & -0.0064 & -0.0064 & -0.0048 \\
1.5 & 500 & -0.0203 & -0.0071 & -0.0062 & -0.0058 & -0.0047 \\
2 & 440 & -0.0293 & -0.0106 & -0.0083 & -0.0086 & -0.0063 \\
2 & 540 & -0.0277 & -0.0099 & -0.0082 & -0.0080 & -0.0062 \\
2.5 & 500 & -0.0356 & -0.0130 & -0.0101 & -0.0105 & -0.0076 \\
2.5 & 600 & -0.0341 & -0.0123 & -0.0100 & -0.0099 & -0.0076 \\
3 & 530 & -0.0418 & -0.0154 & -0.0117 & -0.0124 & -0.0088 \\
3 & 630 & -0.0404 & -0.0146 & -0.0117 & -0.0118 & -0.0088
\end{tabular}



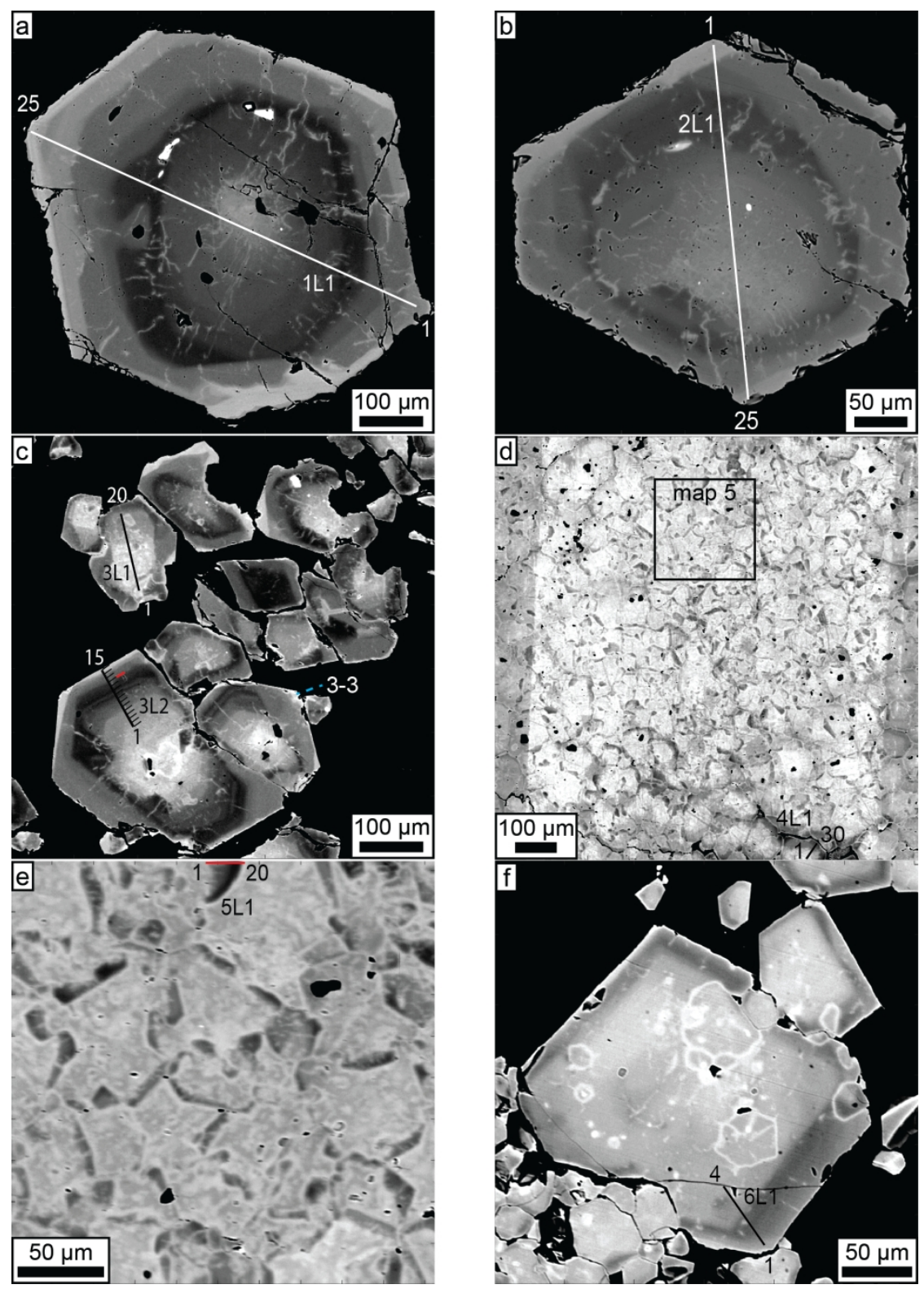

Figure S1: BSE images including the locations of all EPMA measurements, of $(a, b)$ representative host-rock garnets, (c) outer garnetite, $(d, e)$ inner garnetite where (e) is a close-up of the marked area in (d), and (f) euhedral overgrowth on the outer margin of the inner garnetite. 